University of Nebraska - Lincoln

DigitalCommons@University of Nebraska - Lincoln

Theses, Dissertations, and Student Research:

Department of Psychology

Psychology, Department of

$4-2012$

\title{
Motivation \& Loss Aversion in the Health Savings Account Paradigm
}

Michael Holtje

University of Nebraska-Lincoln, michaelholtje@hotmail.com

Follow this and additional works at: https://digitalcommons.unl.edu/psychdiss

Part of the Psychiatry and Psychology Commons, and the Psychology Commons

Holtje, Michael, "Motivation \& Loss Aversion in the Health Savings Account Paradigm" (2012). Theses, Dissertations, and Student Research: Department of Psychology. 40.

https://digitalcommons.unl.edu/psychdiss/40

This Article is brought to you for free and open access by the Psychology, Department of at DigitalCommons@University of Nebraska - Lincoln. It has been accepted for inclusion in Theses, Dissertations, and Student Research: Department of Psychology by an authorized administrator of DigitalCommons@University of Nebraska - Lincoln. 
MOTIVATION \& LOSS AVERSION IN THE HEALTH SAVINGS ACCOUNT PARADIGM

by

Michael J. Holtje

A DISSERTATION

Presented to the Faculty of

The Graduate College at the University of Nebraska

In Partial Fulfillment of Requirements

For the Degree of Doctor of Philosophy

Major: Psychology

Under the Supervision of Professor Richard Wiener

Lincoln, Nebraska

April, 2012 


\title{
MOTIVATION \& LOSS AVERSION IN THE HEALTH \\ SAVINGS ACCOUNT PARADIGM
}

\author{
Michael J. Holtje, Ph.D. \\ University of Nebraska, 2012
}

Adviser: Richard Wiener

This investigation examined the role of "loss aversion" and consumers' motivational orientations in the context of healthcare purchasing under the individual account paradigm and the defined benefit (insurance) paradigm. Specifically, this dissertation investigated (1) whether Health Savings Accounts (HSAs) encourage more prudent health care spending compared to traditional health insurance plans and (2) the impact of individuals' motivational preferences (either towards "gains" or towards "losses") between decision tasks under each type of health plan.

Three experiments varied the type of healthcare plan that consumers had and the manner in which they received information (either as a "gain" or "loss"). The experiments examined (a) intentions to obtain skin cancer screening and willingness to pay for cancer screening, (b) intentions to obtain an immunization injection and willingness to pay for it, and (c) preferred treatment option in the face of an imagined lung cancer and willingness to pay for each of the two possible treatments.

The results reveal several interesting findings. Individuals' knowledge about their healthcare plans was consistently a significant factor. Individuals with a high degree of knowledge would spend less money on healthcare services than would individuals with less knowledge. 
Individuals' motivational orientations were also consistently influential. A persistent motivational tendency towards "promotion" concerns increased the likelihood that individuals would obtain certain healthcare services and enhanced the amount of money participants would spend on other services. Conversely, a persistent motivational tendency towards "prevention" concerns decreased the likelihood that individuals would obtain certain healthcare services and decreased the amount of money individuals would spend on other services.

Moreover, the experiments yielded some evidence of loss aversion, albeit inconsistently. The findings support the conclusion that the framing of healthcare information can impact the choice-behaviors of healthcare consumers.

As a whole, this investigation helps advance our understanding of how the individual account paradigm interfaces with decision making errors and how "loss aversion" may impact healthcare choices. The results have implications for both psychological theories of decision making and healthcare policy. 
CC Copyright 2012, Michael J. Holtje

All Rights Reserved. 


\section{Acknowledgements}

I would like thank the National Science Foundation's Law \& Social Sciences Program (LSS) and Decision, Risk, \& Management Sciences Program (DRMS) for funding this project.

I would also like to thank my advisor and doctoral committee chair, Dr. Richard Wiener, as well as the members of my committee, Professor of Law Craig Lawson, Warren R. Wise Professor of Law Colleen Medill, Dr. Brian Wilcox, and Dr. Cynthia Willis-Esqueda, for their contributions. 


\section{Table of Contents}

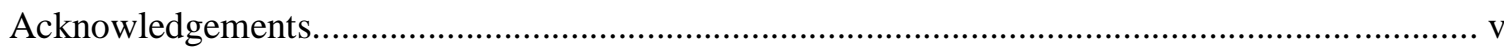

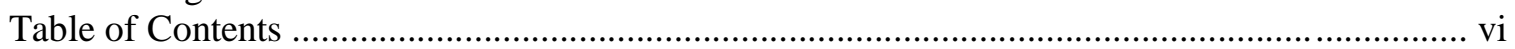

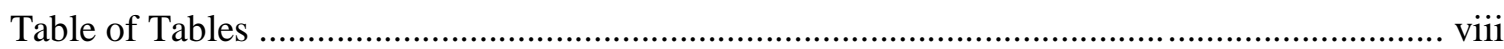

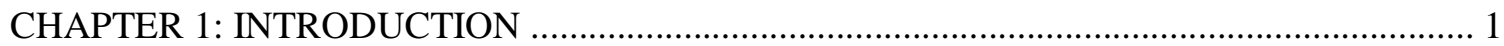

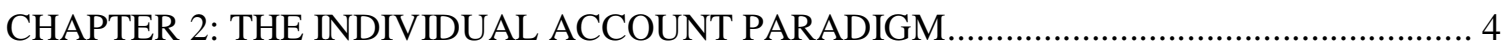

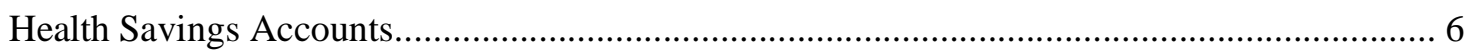

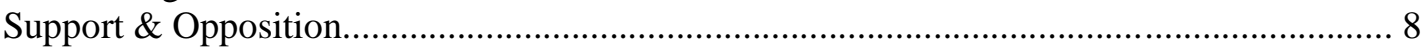

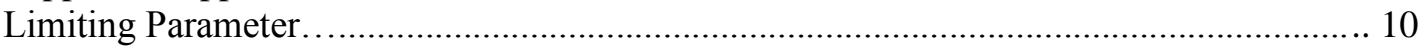

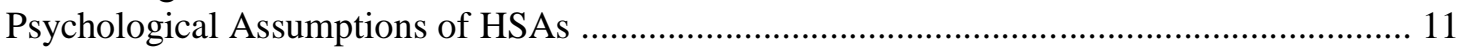

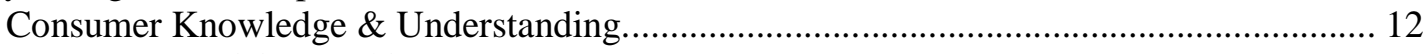

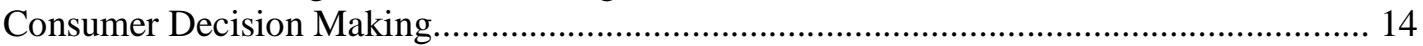

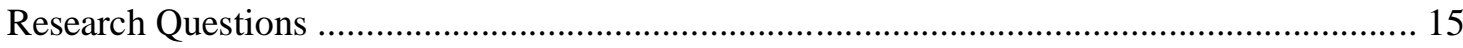

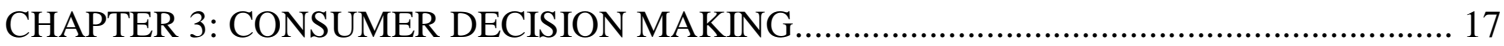

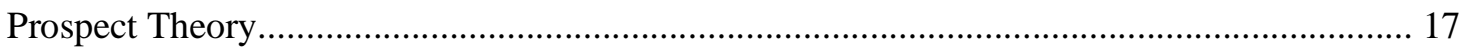

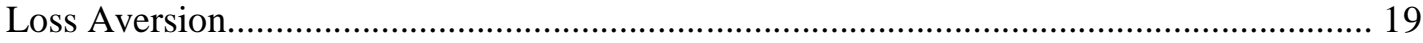

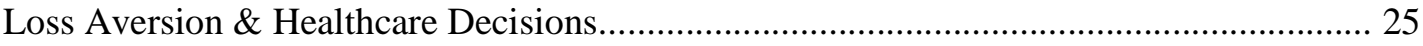

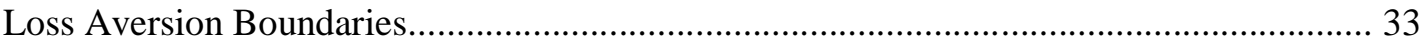

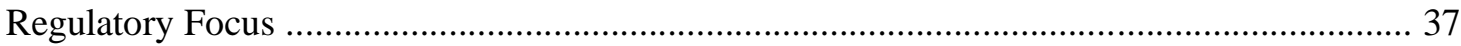

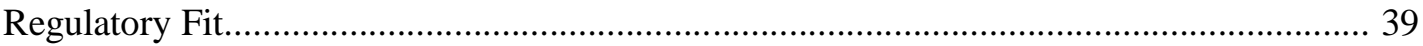

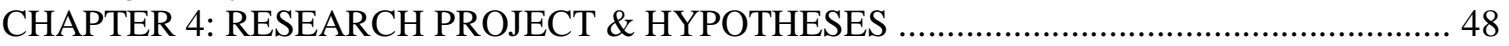

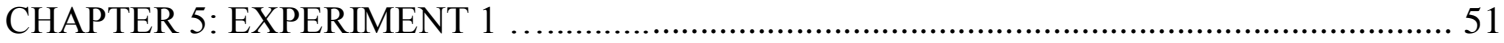

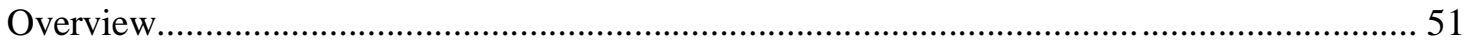

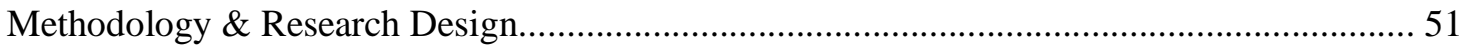

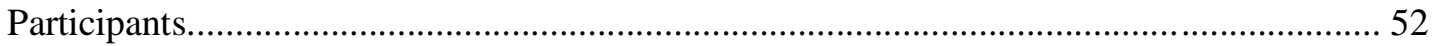

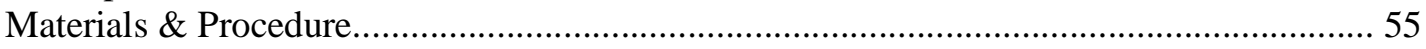

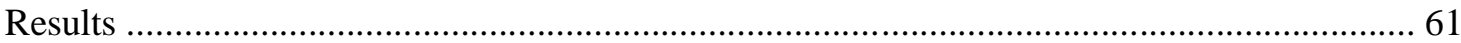

RFQ

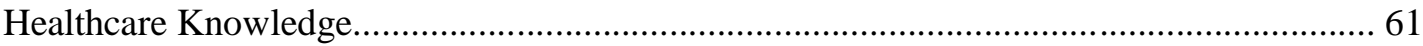

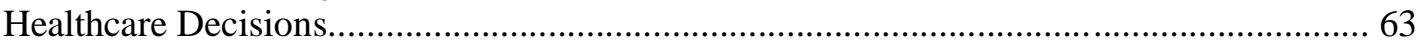

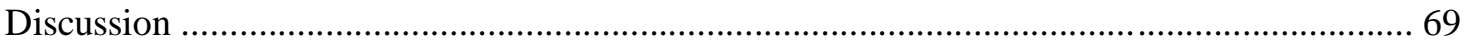

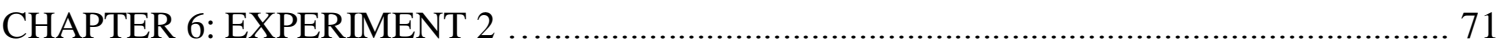

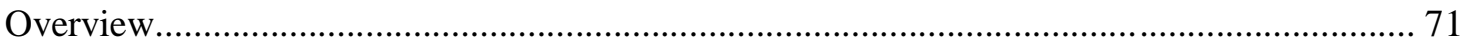

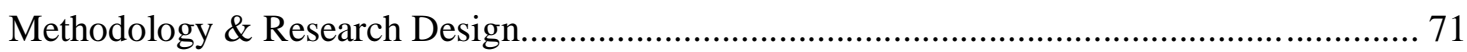

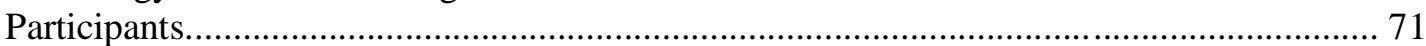

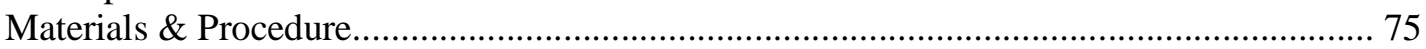

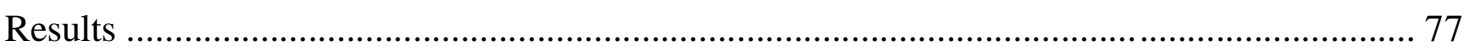

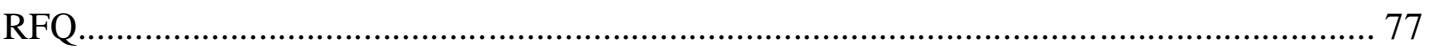

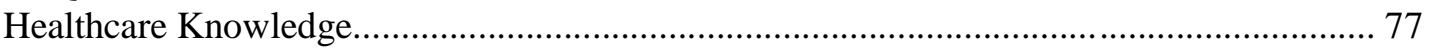

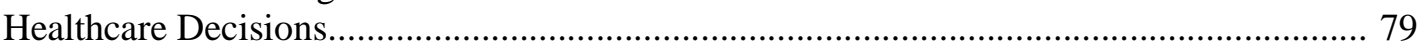

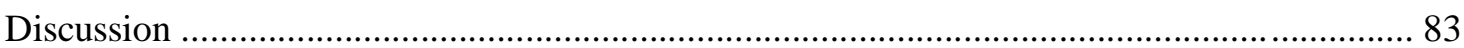

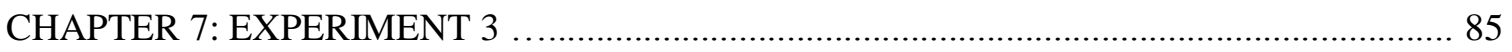

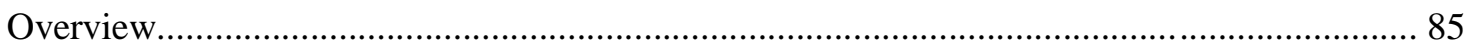

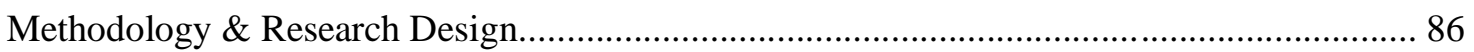

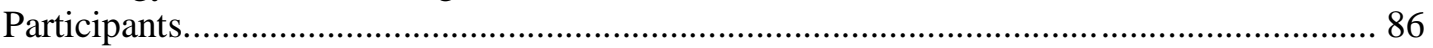

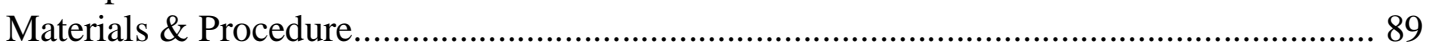

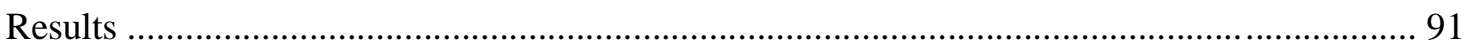


RFQ

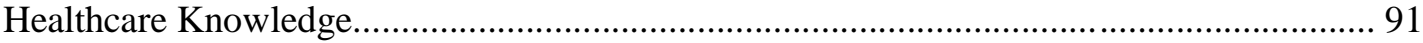

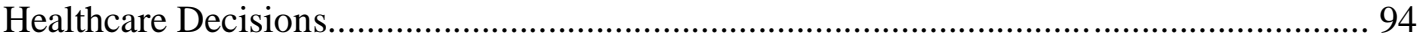

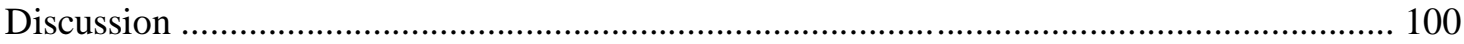

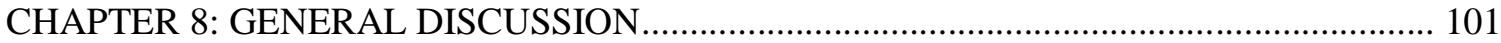

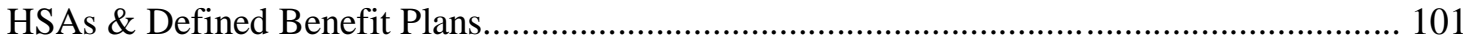

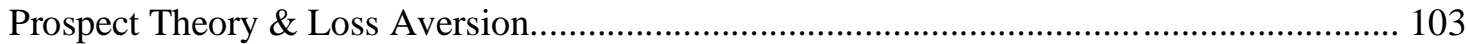

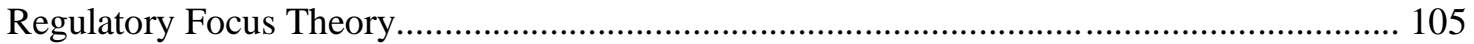

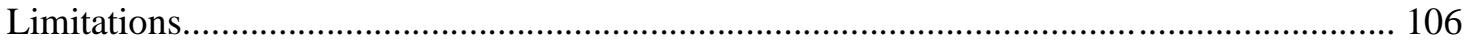

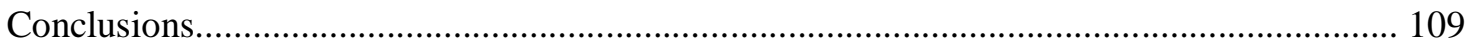

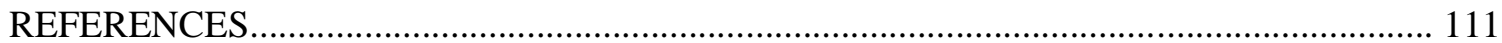

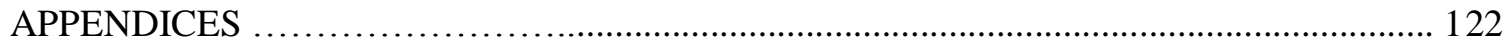




\section{Table of Tables}

Table 1. Experiment 1 participants' demographic characteristics............................................... 53

Table 2. Experiment 1 participants' healthcare plan knowledge scores........................................ 62

Table 3. Results of regression analyses on likelihood to obtain a cancer screening..................... 65

Table 4. Means and standard error for significant effects on likelihood to obtain a skin cancer

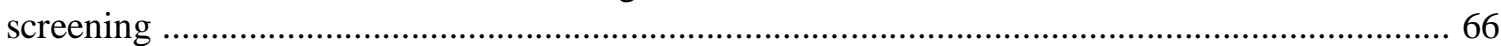

Table 5. Results of regression analysis on amount of money willing to spend.......................... 68

Table 6. Means and standard error for significant effects on amount of money willing to spend

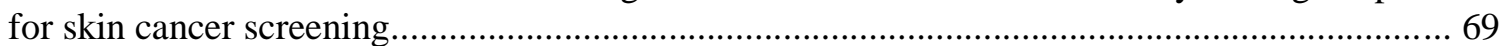

Table 7. Experiment 2 participants' demographic characteristics........................................... 73

Table 8. Experiment 2 participants' healthcare plan knowledge scores....................................... 78

Table 9. Results of regression analysis on likelihood to obtain immunization injection............... 80

Table 10. Results of regression analysis on amount of money willing to spend on immunization

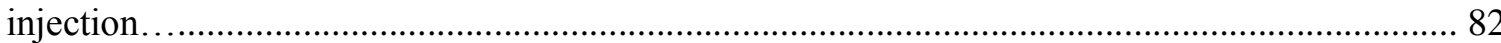

Table 11. Experiment 3 participants' demographic characteristics............................................. 87

Table 12. Experiment 3 participants' healthcare plan knowledge scores.................................... 92

Table 13. Results of logistic regression analysis on choice of lung cancer treatment.................. 95

Table 14. Results of regression analysis on amount of money willing to spend on selected lung

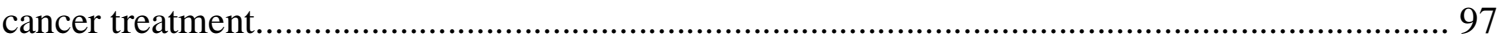

Table 15. Results of regression analysis on amount of money willing to spend on unselected

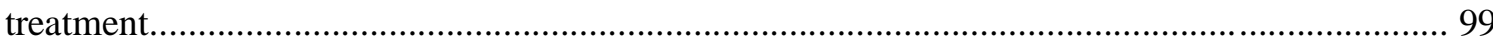




\section{Chapter 1: Introduction}

Social Analytic Jurisprudence entails generating empirical descriptions of the cognitive and behavioral assumptions implicit in legal doctrines and assessing the accuracy of those assumptions in light of socio-psychological theories and empirical research (Wiener, 1993; Wiener, Block-Lieb, Gross, \& Donovan, 2005). According to Wiener and colleagues (2005), Social Analytic Jurisprudence is a four-step process: describing a selected legal doctrine or policy rule, identifying the cognitive and behavioral assumptions implicit in the legal doctrine or rule, assessing the accuracy of those assumptions based on existing socio-psychological theories and empirical studies, and conducting research directed at testing the identified psychological models with regard to the legal rule in question.

This project identifies some assumptions underlying Health Savings Accounts (HSAs), describes psychological theories that illuminate possible failure points of the HSA paradigm, and reports on three experiments that test whether HSAs facilitate rational expenditure decisions or whether they facilitate systematic errors predicted by psychological theories of decision making. The investigation enhances our understanding of (1) how HSA owners expend funds to acquire healthcare services and (2) whether decision makers' motivational orientations can help explain the inconsistent presence of loss aversion effects.

The HSA paradigm is premised on the notion that individual account holders can make rational decisions concerning healthcare expenditures. The expectation of utilitybased expenditure decisions by HSA owners is a critical assumption underlying the HSA paradigm, and as such, constitutes a possible failure point of the paradigm. Not 
surprisingly, a notable amount of decision making research, suggests that individuals may not be able to make rational purchasing decisions.

Compared to traditional defined benefit plans, do HSAs facilitate more rational decision outcomes by healthcare consumers making purchasing decisions, or alternatively, do HSAs facilitate systematic decision making errors? Both Kahneman and Tversky’s (1979) prospect theory and E. Tory Higgins' (1997) regulatory focus theory suggest the potential for systematic errors in HSA expenditure decisions. This dissertation tests whether owners of HSAs exhibit loss aversion (i.e., a risk-seeking preference when considering loss-framed decisions and a risk-avoiding preference when considering gain-framed decisions), as predicted by prospect theory, or alternatively, whether HSAs inhibit loss aversion, as predicted by contemporary research concerning intentions of decision makers and pre-budgeted funds (see Novemsky \& Kahneman, 2005; Koszegi \& Rabin, 2004).

Additionally, can the matching or "fit" of decision framing and decision makers' motivational orientations either limit or mediate loss aversion effects? Prospect theory predicts that all decision makers will value losses more than equivalent gains. In contrast, regulatory focus theory offers a possible explanation for why losses "loom larger" than gains in some circumstances, while in other circumstances losses do not "loom larger" than gains.

Regulatory focus theory predicts that individuals in a promotion-oriented motivational focus who experience a promotion-oriented task will value gains more than equivalent losses (i.e., promotion-oriented "fit" inhibits loss aversion). This is because the matching or "fit" of task framing and motivational orientations will produce a 
psychological benefit, which will transfer to the promotion-oriented outcome (i.e., presence/absence of a gain). As a result, that outcome will have increased value. For example, healthcare consumers who maintain a chronic promotion focus should assign a significantly higher price to a medical procedure when they receive promotion-framed descriptions of the procedure (e.g., think about what you could gain by undergoing the procedure).

Correspondingly, regulatory focus theory predicts that individuals in a preventionoriented motivational focus who experience prevention-oriented task will value losses more than equivalent gains (i.e., prevention-oriented "fit" mediates loss aversion). This is because the matching or "fit" of task framing and motivational orientations will produce a psychological benefit, which will transfer to the prevention-oriented outcome (i.e., presence/absence of a loss). As a result, that outcome will have increased value. For example, healthcare consumers who maintain a chronic prevention focus should assign a significantly higher price to a medical procedure when they receive prevention-framed descriptions of the procedure (e.g., think about what you could lose by not undergoing the procedure).

In this dissertation, I describe HSAs and highlight a critical assumption underlying the HSA paradigm. The paper goes on to describe a psychological theory of decision making, prospect theory (Kahneman \& Tversky, 1979), which illuminates frequent deviations from rational decision outcomes, and it explains how prospect theory's loss aversion principle applies to medical decision making. Next, I discuss how decision makers' intentions and motivational orientations might preclude loss aversion. In the end, the dissertation reports three experiments that test a number of hypotheses 
concerning how loss aversion impacts HSA expenditure decisions and whether individuals' motivational orientations can help explain the presence and absence of loss aversion effects.

\section{Chapter 2: The Individual Account Paradigm}

The last half-century witnessed employee benefit plans shifting away from employer-driven, defined benefit plans and towards individualized, defined contribution plans (Zelinsky, 2004). Health Savings Accounts (HSAs) are one of the most recent manifestations of these individualized plans. Prior embodiments of individual account plans include education plans, healthcare plans, and retirement plans.

In a 2004 Yale Law Journal article, Edward Zelinsky described the individualaccount movement as a "paradigm shift," which is manifested in a variety of individualaccount plans. By meticulously articulating the numerous tax-incentivized individual accounts currently available under the Internal Revenue Code (IRC), including Individual Retirement Accounts (IRAs), 401(k) retirement plans, Roth IRAs, educational savings accounts, Flexible Spending Accounts, Medical Savings Accounts, Health Reimbursement Arrangements, and HSAs, Zelinsky (2004) argues that a revolution has occurred. The revolution moved employee benefit plans away from employer-driven, defined benefit plans and towards individual-driven, defined contribution plans.

This shift, Zelinsky argues, transferred the risks and rewards associated with investment planning from employers to individuals. Under the defined-benefit paradigm, employers bore the responsibility for funding employee benefit plans and for distributing benefits to employees. Under the defined contribution paradigm, employees bear the 
responsibility for funding their own individualized benefit plans and for distributing their own individualized benefits.

A number of factors contributed to the shift of employee benefit plans from defined benefit plans to defined contribution plans, including employers' administrative burdens under the defined-benefit paradigm, the increasing availability of individual accounts, and the regulatory and fiduciary burdens imposed on employers by the Employee Retirement Income and Security Act (ERISA) of 1974 (Medill, 2006; Zelinsky, 2004).

In a 2006 Cornell Law Review article, Colleen Medill reaches a conclusion similar to that of Zelinsky. Medill (2006) goes further than Zelinsky, though, and notes a distinction between employer-based individual accounts and non-employer-based individual accounts. Employer-based individual accounts are individualized employee accounts that exist within the framework of an employer's benefit plan. These accounts maintain a role for the employer in the regulation and/or administration of employee benefits. Examples of employer-based individual accounts include 401(k) retirement plans and health reimbursement accounts (HRAs).

In contrast, non-employer-based individual accounts exist without regard to an employer (Medill, 2006). Employers do not play a central role in either the funding or administration of the benefit plan. Because these accounts are independent of employment, workers who change jobs do not have to be concerned with portability of their benefits (or lack thereof), and the accounts are available to individuals who are unemployed, self-employed, or who are employed by an employer that does not offer a benefit plan. Additionally, non-employer-based individual accounts circumvent the 
intricate and technical legal impediments presented by ERISA (U.S. Department of Labor, 2004).

Medill (2006) classifies non-employer-based individual-accounts into three overarching categories: retirement, education, and health. Retirement accounts include the traditional IRA and the Roth IRA (IRC $\S \S 408 ; 408 A)$. Education accounts include the Coverdell educations savings account and the 529 plan savings account (IRC $\S \S 530$; 529). HSAs comprise the last category, individual health accounts (IRC§ 223).

\section{Health Savings Accounts}

The Medicare Prescription Drug Improvement and Modernization Act (2003) authorized the creation of HSAs, which first became available in 2004. Essentially, an HSA is a tax-exempt trust or custodial account administered by a bank, insurance company, or other trustee approved by the Internal Revenue Service (IRS). Any individual can establish an HSA to pay for qualified medical expenses of account beneficiaries. Any person can be an eligible HSA beneficiary, unless she is claimed as a dependent on another person's tax forms or enrolled in another, non-qualified health plan (IRC $§ 223$; Fronstin, 2004; Medill, 2004). Individuals and/or their employers may contribute to an HSA (Fronstin, 2004). Furthermore, HSAs voluntarily established by employees do not constitute employee benefit plans subject to regulation under Title 1 of ERISA. This is true even if the employer contributes to the HSA (U.S. Department of Labor, 2004).

During the months that individuals or their employers contribute to the HSA, the account beneficiary must be covered under qualified health plans, known as highdeductible health plans (HDHP). The Internal Revenue Code defines an HDHP as a 
healthcare plan having a minimum deductible of $\$ 1,150$ for individual coverage or $\$ 2,300$ for family coverage, though amounts vary by year (IRC $\S 223$ ). If an employer sponsors an HDHP, the HDHP itself is a benefit plan subject to ERISA regulation, and the employer is subject to the same benefits and responsibilities laid out in Title 1 of ERISA. Individual employees, however, are not required to join an employer's HDHP but may obtain private HDHPs.

Similar to other individualized defined-contribution plans, HSAs offer economic incentives to individuals who adopt the plans (IRC $\S 223$; Fronstin, 2004; Medill, 2004). First, HSAs allow individuals to make tax-free contributions and expenditures, up to statutorily established annual limits, so long as the beneficiary uses the funds for approved healthcare expenses. In 2012, the maximum contribution limit was $\$ 3100$ for individuals and $\$ 6250$ for families; the maximum expenditure limit is $\$ 6050$ for individuals and \$12,100 for families (Internal Revenue Service, 2011). Individuals cannot use HSA funds to pay the premiums for an HDHP, but individuals with HSAs do use pretax dollars to pay for medical expenses that an HDHP does not cover. For federal income purposes, an individual's gross income does not include funds that the holder withdraws from an HSA to pay qualified medical expenses. Second, HSAs provide for yearly rollovers of the account balance. If HSA funds are unused and remain in the account at year's end, the account holder can carry forward the remaining funds into the next year. Third, and finally, the interest earned on HSA funds is treated the same as the principal contribution. The interest is not subject to federal income tax, and the account holder can carry forward the earned interest from one year to the next. 
As described above, HSAs reflect a consumer accountability approach to health care spending (Fronstin, 2004; Government Accountability Office, 2006; Medill, 2004). In accordance with one of the central functions of the individual account paradigm, HSAs shift the benefits (tax exclusions and tax-free investment earnings) and the responsibilities (account funding and expenditure decisions) away from employers and towards individuals. The expectation is that the personalized nature of the expenditure of personalized and discretionary medical expenses encourages consumers to make prudent expenditure decisions. ${ }^{1}$

Support \& Opposition. Healthcare expenditures equal approximately $17.6 \%$ of the United States' annual gross domestic product (U.S. Department of Health and Human Services, 2009). Proponents of HSAs assert that the individual-account paradigm provides an avenue for decreasing healthcare costs because they will encourage individuals to become more astute healthcare consumers. These proponents argue that the combination of HDHPs and HSAs can reduce overall health spending or at least reduce growth in overall spending (Fronstin, 2004; Mango \& Riefberg, 2005).

Unlike defined benefit plans, the individual account paradigm reflects a marketbased approach to healthcare, such that account holders make their own decisions (within certain statutory parameters) about when and how to purchase healthcare services. HSA supporters predict that by allowing individuals more control over funds designated for

\footnotetext{
${ }^{1}$ HSAs are not the first embodiment of individualized healthcare accounts. Rather, HSAs are the most recent version of a broader category of healthcare plans, known as defined-contribution healthcare plans, in which individuals have personal accounts used to pay health benefits (Fronstin, 2004; Medill, 2004; Zelinsky, 2004). Several other defined-contribution healthcare plans are also available, including Flexible Spending Accounts (IRC § 125), Medical Savings Account (IRC § 220), and Health Reimbursements Arrangements (IRC $\S \S 105,106$ ). HSAs, however, are unique in that they are the only defined-contribution healthcare plan that is non-employer-based. Ownership of HSAs is not tied to employment. Other individual healthcare accounts (i.e., FSAs, MSAs, and HRAs) are part of an employer-based benefit plan.
} 
healthcare services, individuals will utilize those funds more responsibly than they would under traditional defined-benefit plans (Fronstin, 2004; Mango \& Riefberg, 2005). This outcome assumes that HSA holders will acquire education about the cost and quality of health services. Others argue that HSAs can be tax-advantaged vehicles to save for future healthcare needs. They envision the savings from HSA yearly rollovers and tax-free interest defraying a portion of healthcare costs incurred during retirement (Medill, 2006).

On the other hand, critics of HSAs point out the notable obstacles which arise under the HSA paradigm, which more traditional benefit plans avoid (Davis, Doty, \& Ho, 2005). First, because employers are not the central funders and administrators of the benefit plans, account holder must possess sufficient ability and accept responsibility to administer and fund the healthcare plans (Zelinsky, 2004; Fronstin, 2004). Moreover, unlike individualized retirement plans, which only require account holders to possess financial aptitude and be knowledgeable about available health care services, HSAs require account holders to be strategic regarding both their finances and their health.

HSA critics argue that the individual account paradigm shifts the financial risks (i.e., investment risk, funding risk, and longevity risk) away from employers and places those risks on individual citizens who may not be prepared or capable of dealing with them (Zelinsky, 2004). A number of concerns arise as a result of this transfer. First, poor consumer knowledge about saving mechanisms and healthcare expenditures may inhibit individuals from taking advantage of the individual-account structure. Some argue that unless consumers become strategic about their health care and costs, HSAs will become nothing more than a tax-favored vehicle for personal saving among wealthier individuals (Davis, Doty, \& Ho, 2005; Fronstin, 2004). 
A second concern, and one that is central to the purpose of the research conducted in this dissertation, is that the expectations of HSA proponents may not correspond with a sophisticated understanding of human decision-making. It is questionable whether an average, untrained individual will make the necessary choices to fund an HSA, to select the best HDHP, or to obtain appropriate healthcare services. In other words, the anticipated positive outcomes of HSA's will only result if account holders make rational healthcare choices free of cognitive, motivational, and emotional heuristics and biases. The HSA model assumes that economic actors are informed, rational decision-makers. Many researchers, though, criticize such rational-actor models that incorrectly assume people make choices based only on the expected utility of potential outcomes (Hastie \& Dawes, 2001; Kahneman \& Tversky, 1979; Loewenstein et al., 2001; Thaler, 1983; Wiener et al., 2006; 2007). These criticisms are the focus of this investigation.

Limiting Parameter. Some factors that limit the effectiveness of the HSA approach are beyond serious question. Foremost, consumers without sufficient financial resources will be unable to take advantage of HSAs. It is an economic reality that, even if all other assumptions hold true, some portion of the population will be unable to utilize HSAs because they do not have the requisite discretionary funds for healthcare investment. Those for whom personal saving is impossible will not have the funds necessary to take advantage of the economic incentives of HSAs. Thus, the tax-favored healthcare accounts will produce no advantages to this portion of the population. This inevitability has led some HSA critics to conclude that HSAs provide disproportionate tax subsidies to the financially better off (Davis, Doty, \& Ho, 2005). 
HSA opponents speak of the adverse selection problem (Fronstin, 2004) and predict that the wealthiest individuals (who, as a group, tend to be the healthiest population) will enter into one type of plan (i.e., HSAs), while other poorer (and likely less healthy) individuals will not have that type of plan as an option. As a result, the alternative (non-HSA) health insurance programs will become more expensive for the less healthy, poorer individuals who, though not legally excluded, are excluded as a practical matter from the HSA system. Current studies show higher income employees are more attracted to health reimbursement accounts (HRAs) than are low income employees (Fronstin, 2004; Lo Sasso et al., 2004; Parente, 2004), and there is emerging evidence of this type of adverse selection occurring with existing HSAs (Government Accountability Office, 2006).

Undeniably, some lower-income consumers lack the available financial resources to benefit from HSA plans. Therefore, the HSA paradigm is not a panacea for the healthcare needs of all segments of the U.S. population (i.e., HSAs are not "the solution" to "the healthcare problem"). Healthcare is a multi-faceted public policy issue that requires a variety of responses. An effective HSA paradigm is only one aspect of a larger national healthcare scheme. Other measures are needed to reach low-income portions of the population, and policy makers should view lack of financial resources as a limiting parameter of the HSA paradigm.

\section{Psychological Assumptions underlying HSAs}

The HSA paradigm assumes that economic actors are informed, rational decisionmakers. The consumer-driven model expects and requires that individual actors will be able to accurately identify their needs, identify their resources, and demonstrate rational 
connections between their needs, their resources, and their purchasing decisions. In the HSA paradigm, individuals are responsible for two sets of decisions: (1) financial funding decisions (allocating money to the HSA) and (2) healthcare purchasing decisions (using HSA funds to purchase healthcare services). The financial decisions concern personal saving and investing, including determinations of how to establish an account, where to establish it, and how to fund the account (Medill, 2006). These decisions require individuals to be able to strategically assess financial risks and rewards. The healthcare decisions concern determining one's own health status and health needs. These decisions require individuals to be able to wisely determine whether they need medical care, what type they need, when they need it, and the costs and benefits of available services.

Problems in each set of decisions can arise from high transaction costs and/or from less-than-rational decision making (Medill, 2006). Medill includes consumer efforts to acquire and understand the information necessary for making a rational decision as part of high transaction costs. Account holders must be aware of HSAs, be able to obtain the relevant information necessary to utilize HSAs, and be able to understand that information. Moreover, they must be able to use that information to make rational choices concerning HSA funding and expenditures. The problem of less-than-rational decision making refers to the possible inappropriate use or non-use of information and/or improper reliance on other, non-rational factors.

The efficacy of the HSA paradigm depends upon the individual choices and behaviors of account holders. This research project examines the extent to which potential account holders' will make rational decisions concerning expenditures from 
HSAs to obtain healthcare services. First, I consider some of the research concerning consumers' knowledge of healthcare.

Consumer Knowledge \& Understanding. Disparities in acquiring and understanding healthcare information among consumers may present a significant impediment to the success of the HSA paradigm. Inadequate financial literacy impedes individuals' decision-making capabilities for the first set of HSA-related decisions, saving and investments. Unfortunately, the American public is largely financially illiterate. There is a general lack of knowledge and understanding about fundamental economic concepts (Lusardi \& Mitchell, 2005; National Council on Economic Education, 2005). In general, women, minorities, the elderly, and less-education persons are at greater risk for low financial knowledge (Lusardi \& Mitchell, 2005; 2006).

Inadequate health literacy also impedes individuals' decision-making capabilities for the second set of HSA-related decisions, healthcare expenditures. Not surprisingly, research on health literacy indicates shortcomings similar to those concerning financial literacy. Many hospital patients are not able to read and comprehend basic health-related materials (Williams et al., 1995). This is especially true of patients 65 and older (Parker, 2000). Moreover, many Americans do not understand how traditional or market driven healthcare plans operate (Edgman-Levitan \& Cleary, 1996; Hibbard \& Jewett, 1997; Hibbard et al., 1998; Isaacs, 1996; Lubalin \& Harris-Kojetin, 1999). Persons low in health literacy tend to have less knowledge about medical conditions and treatments (Williams et al., 1998), receive fewer preventative services (Scott et al., 2002), report worse health status (Baker et al., 1997), and are more likely to be hospitalized (Baker et al., 2002). 
In efforts to address healthcare illiteracy, researchers have discovered a number of methods to improve the communication of technical information (for an overview of this literature, see Kools, Ruiter, Weil, \& Kok, 2004; Wogalter, Howe, Sifuentes, \& Luginbuhl, 1999). Others have shown that substantive education about financial and health plans can positively influence individual account holders' knowledge and behavior (Clark et al., 2003; Lusardi, 2004; McCormack, Garfinkel, Hibbard, Norton, \& Bayen, 2001). Additionally, Schwartz, Bertrand, Mullainathan, and Shafir (as cited in Loewenstein \& Haisley, 2008) found that contribution rates into employer-sponsored flexible spending accounts were higher when the researchers framed the decision as a loss ("Stop losing money now") compared to when they framed the decision as a gain ("Start saving money now"). This pattern supports the basic finding that decision makers are risk averse to loss, a result that the research literature consistently supports.

Consumer Decision Making. Despite the potential for improving consumers' knowledge and dispositions about healthcare, the HSA paradigm remains dependent upon increasing the likelihood that account holders will use relevant information in a rational manner when using HSA funds to purchase healthcare services. After all, the primary function of HSAs is to encourage consumers to make prudent cost-benefit spending decisions and act responsibly (Fronstin, 2004; Medill, 2004). By providing economic incentives and allowing HSA owners to reap the benefits of prudent purchasing decisions, HSAs adopt a "rational actor" model of decision making.

The standard "rational actor" model proposes that people assess the severity and likelihood of possible outcomes, integrate those assessments in an expectancycalculation, and choose the best alternative (Hastie \& Dawes, 2001). Accordingly, people 
evaluate the outcomes of each possible choice, assign a value to each choice's outcome, judge the probability of each outcome, and sum the probability of each outcome multiplied by the value of its consequence. Many social scientists criticize the model because it incorrectly assumes that people make choices based on nothing more than the expected utility of potential outcomes. In other words, the model fails to account for other influential factors, such as emotions, motivations, and cognitive biases (Hastie \& Dawes, 2001; Kahneman \& Tversky, 1979; Loewenstein et al., 2001; Thaler, 1983).

\section{Research Questions}

This research examined two specific questions relating to HSA expenditure decisions. First, when deciding to pursue a particular healthcare service, do prospective HSA holders exhibit loss aversion in which they attach more value to losses than to equivalent gains (i.e., risk-seeking preferences when considering loss-framed decisions and risk-avoiding preferences when considering gain-framed decisions), as predicted by prospect theory? Alternately, owners of HSAs might engage in rational behavior free from loss aversion, as predicted by contemporary research concerning intentions of decision makers and pre-budgeted funds. Second, does the matching or "fit" of decision framing (i.e., gain frame or loss frame) and decision makers' motivational orientations (i.e., predisposition to focus on gains or predisposition to focus on losses) either impede or mediate loss aversion?

As noted above, the HSA paradigm assumes that owners of HSAs will make rational decisions concerning healthcare expenditures. Neither the framing of healthcare options as gains or losses nor individuals motivation orientations should influence the likelihood of HSA owners to pursue a healthcare option or the amount of money HSA 
owners are willing to expend to obtain a service. For example, emphasizing the benefits that result from obtaining a cancer screening or immunization injection should produce identical decision preferences as emphasizing the detriments resulting from not obtaining a cancer screening or immunization injection. Similarly, discussing the risks of lung cancer treatments in terms of survival rates ought not to produce different decision preferences than discussing those same risks of lung cancer treatments in terms of mortality rates.

In contrast, psychological theories suggest possible failure points inherent in the HSA assumption. Kahneman and Tversky’s (1979) prospect theory and E. Tory Higgins' (1997) regulatory focus theory each suggest the potential for systematic deviations from rationality in expenditure decisions. Prospect theory predicts that all decision makers should value losses more than equivalent gains. Thus, individuals should be inclined to pay more money for loss-framed healthcare options than for those same options presented in gain-frames.

However, contemporary research suggests that decision makers' intentions to exchange pre-budgeted funds may inhibit or reduce loss aversion (Novemsky \& Kahneman, 2005; Koszegi \& Rabin, 2004). That is, when consumers decide to spend funds from HSAs, they are exchanging pre-budgeted funds for services. Therefore, HSAs may diminish or eliminate any differences in decision maker preferences produced by gain-loss framing. For example, while decision makers operating under other healthcare paradigms (e.g., defined benefit plans) may value loss-framed healthcare options more highly than equivalent gain-framed healthcare options, decision makers possessing HSAs 
may value the gain- and loss-framed healthcare options equally because they are using pre-budgeted funds.

In addition, regulatory focus theory predicts that decision makers should value losses more than equivalent gains only under certain specified circumstances. Individuals in a promotion-oriented motivational focus who experience a gain-framed healthcare decision should be willing to pay more money for the healthcare options (e.g., cancer screening, immunization, cancer treatments) than individuals in a prevention-oriented motivational focus who experience the same gain-framed decision. Correspondingly, individuals in a prevention-oriented motivational focus who experience a loss-framed healthcare decision should be willing to pay more money for the healthcare options than individuals in a promotion-oriented motivational focus who experience the same lossframed decision.

To address these issues, I next explore research concerning Kahneman and Tversky's (1979) prospect theory and E. Tory Higgins' (1997) regulatory focus theory.

\section{Chapter 3: Consumer Decision Making}

\section{Prospect Theory}

Centuries ago, Daniel Bernoulli (1738/1954) proposed that people do not assess wealth per se, but rather they assess the psychological satisfaction of wealth, a construct termed "utility." Bernoulli further asserted that utility increases rapidly at first and then gradually slows as wealth increases, such that the pleasure associated with a change in wealth is inversely related to an individual's total wealth. Bernoulli also predicted that decision makers would select the option that maximized their expected utilities (Hastie \& Dawes, 2001; Mellers, 2000). 
In the mid-twentieth century, Von Neumann and Morgenstern (1947) extended Bernoulli's ideas to the development of expected utility theory, which also predicted that people select options that maximize their expected utilities. In this theory, utilities are measurable choice propensities premised on defensible axioms. Option A has greater measurable utility than option B simply because people prefer option A over option B (Hastie \& Dawes, 2001; Mellers, 2000). This leads to the intuitive conclusion that people weight each utility by the probability it will occur.

Savage (1954) also proposed that people select the option which maximizes their expected utilities, but in contrast to expected utility theory, his subjective expected utility theory postulated that people do not weight each utility by the probability it will occur. Instead, people weight each utility by their subjective belief that it will occur. Unfortunately, neither subjective nor objective expected utility theory could account for common decision making errors that researchers repeatedly reported in the empirical literature (Hastie \& Dawes, 2001; Kahneman \& Tversky, 1979; Mellers, 2000).

To account for these common deviations from rationality in risky choices, Kahneman and Tversky (1979) proposed prospect theory. Using a variety of choice problems, they illustrated how actual choices deviate from expected utility theory and subjective expected utility theory. Prospect theory is the most renowned alternative to the rational actor model of human decision making (Hastie \& Dawes, 2001).

In one contemporary description of prospect theory, Hastie and Dawes (2001) explain the theory's two phases of decision making. First, decision makers edit the prospects. This entails constructing a cognitive representation of alternatives, contingencies, and outcomes. When making a decision, the first editing act is to set a 
reference point on an objective valuation scale. This reference point defines zero on a gain-loss scale. Status quo is the most common reference point for decision-makers, but in some circumstances, other references (such as aspiration level) can serve as the reference point. The second editing act is combining or segregating outcomes, such that people group gains and losses to increase their overall satisfaction. After editing the prospects, decision makers move on to the second phase of decision making, evaluating the prospects. This entails valuation, decision weighting, and integration of weighted values across the outcomes associated with each prospect. Prospect theory proffers three major characteristics of the valuation process: reference level dependence, gain and loss satiation (i.e., diminishing returns), and most important for this review, loss aversion. According to prospect theory, decision makers view the consequences from choices in terms of changes from the pre-determined reference level. Because of the attachment to a reference point, the valuation process entails high sensitivity to initial changes in position. Both positive and negative consequences (i.e., "wins" and "losses") have decreasing marginal value. Put more simply, the law of diminishing returns applies to good and bad consequences of decisions (Hastie \& Dawes, 2001).

Loss Aversion. Prospect theory further asserts that equal magnitude gains and losses do not have symmetrical impacts on decision making. Instead, preferences reverse around the reference level. Losses (outcomes below the reference level) hurt more than gains (outcomes above the reference level) satisfy. In other words, people assign more value to losses than to gains, especially the closer they are to the reference point. The pain of a loss increases more rapidly than the pleasure of an equivalent gain, such that the resulting value function predicted by prospect theory is steeper for losses than for gains. 
This implies that decision makers will be loss averse. In other words, people will have risk-averse preferences in the gain domain but risk-seeking preferences in the loss domain (Hastie \& Dawes, 2001; Kahneman \& Tversky, 1979). When choosing between gains, decision makers will avoid risks (i.e., they will prefer the outcome associated with less risk), but when choosing between losses, decision makers will be risk seeking (i.e., they will prefer the outcome associated with more risk). In other words, when it comes to losses, decision makers are likely to take chances in order to avoid the pain of a loss but this is less true for the opportunity to obtain the pleasure associated with a gain.

For example, when people have the choice between a guaranteed win (100\% certainty) of $\$ 3,000$ and a gamble involving an $80 \%$ chance to win $\$ 4,000$ or a $20 \%$ chance to wind up with no money, people generally prefer the guaranteed amount. However, when faced with a choice between a guaranteed loss (100\% certainty) of $\$ 3,000$ and a gamble involving an $80 \%$ chance to lose $\$ 4,000$ or a $20 \%$ chance to lose no money at all, people generally prefer the gamble. The mere $20 \%$ possibility of losing nothing is enticing because people are so averse to loss that they are willing to take the risk of losing an additional $\$ 1000$ for an opportunity to avoid losing any money. These same individuals, however, are not willing to accept the $20 \%$ probability of losing everything (i.e., a guaranteed \$3000) to gain the same $\$ 1000$ (Hastie \& Dawes, 2001; Kahneman \& Tversky, 1979; Mellers, 2000). ${ }^{2}$

Perhaps the clearest manifestation of loss aversion is the "endowment effect." Thaler (1980) defined the endowment effect as a discrepancy between buying and selling

\footnotetext{
${ }^{2}$ Notably, prospect theory does not offer any reason justifying why loss aversion should occur. The theory does not attempt to explain why people should value losses more than gains. Instead, loss aversion is merely a post-hoc description of choice behavior.
} 
prices, such that selling prices are notably higher than buying prices. After people possess an object, they behave as if "losing it matters more than gaining it would have mattered if they didn't have it" (Hastie \& Dawes, 2001, p. 308). Giving up an object produces negative utility and acquiring an object produces positive utility. However, the negative utility resulting from giving up an object is greater than the positive utility resulting from acquiring the same object. Through numerous studies examining valuation decisions, researchers have generated substantial evidence of this irrational inconsistency between acquisition and relinquishment (Kahneman, Knetsch, \& Thaler, 1990; 1991; Kahneman \& Tversky, 1979; Knetsch, 1989; Knetsch \& Sinden, 1984).

According to an implicit assumption of microeconomics, if someone owns item A and is indifferent between keeping it or trading it for item B, then when owning item B, the individual should be indifferent about keeping it or trading it for item A (Kahneman, Knetsch, \& Thaler, 1991). However, the endowment effect (i.e., loss aversion) inhibits this reversibility. A quarter-century ago, Knetsch and Sinden (1984) conducted an early demonstration of the endowment effect in which they provided some participants with a lottery ticket and provided others with $\$ 2.00$. Later, the researchers offered each subject an opportunity to trade the endowed item for the alternative item. If the endowment effect did not exist, approximately half of the participants should have traded their item. Instead, only a very few subjects in each condition chose to exchange items.

Similarly, Knetsch (1989) gave a mug to one half of the participants and a chocolate bar to the other half and then asked all participants whether they preferred to keep their endowed item or to trade it for the other item. Approximately $90 \%$ of participants in each condition chose to retain their endowed item. In another experiment, 
Knetsch (1989) found that students initially endowed with a pair of chocolate bars put forth a selling price for the chocolate bars, which was over double the price that students endowed with money put forth as a buying price for those same chocolate bars.

Nevertheless, not all researchers accepted the principle of loss aversion. One early critique of the endowment effect contended that it would only occur in controlled settings and would disappear after people experienced market environments with frequent learning opportunities (Kahneman, Knetsch, \& Thaler, 1991). Knez, Smith, and Williams (1985), for example, alleged that the empirical findings from which researchers inferred endowment effects might rather be the product of individuals' application of bargaining habits in a novel or uncommon marketplace. Similarly, Coursey, Hovis, and Schultze (1987) opined that the discrepancies between market actors' willingness to purchase and willingness to sell would diminish as actors' experience in the marketplace increases.

In response, Kahneman, Knetsch, and Thaler (1990) conducted a series of experiments designed to address the concern that experience in the marketplace might diminish endowment effects. In one experiment, the researchers compared participants' valuation of coffee mugs. After some preliminary buying and selling tasks designed to ensure that participants understood the task and that the task did not involve high transaction costs, the researchers gave coffee mugs to one-half of the participants. Next, participants possessing mugs had several opportunities to sell their mugs, and participants not possessing mugs had several opportunities to purchase the mugs. The results indicated that those participants endowed with the mugs placed significantly higher selling prices on them than did participants with the opportunity to purchase the mugs. Several replications of the experiment indicated that median selling prices were 
approximately double the median buying prices, and the volume of trade was

approximately half of the expected volume (Kahneman, Knetsch, \& Thaler, 1990; 1991).

To examine whether low volume of trade resulted from reluctance to buy or reluctance to sell, another experiment randomly assigned participants to one of three groups: buyers, sellers, and choosers. The researchers gave the sellers a coffee mug and asked them whether they would sell it for each of a series of prices ranging from $\$ 0.50$ to \$9.25. The researchers also asked the buyers whether they would buy the mug at the same set of prices and asked the choosers whether, for each of the prices, they would prefer the mug or the money. Results indicated that choosers were more similar to buyers than to sellers. Median prices were over $\$ 7$ for sellers, just over $\$ 3$ for choosers, and just under $\$ 3$ for buyers, suggesting that the low volume of trade resulted primarily from owners' reluctance to exchange the endowed item (Kahneman, Knetsch, \& Thaler, 1990; 1991).

However, not all research supports Kahneman, Knetsch, and Thaler's (1990) finding that buyers and choosers set equivalent buying prices. Bateman and colleagues (1997; 2005) report that buyers' and choosers' valuations differ, leading those researchers' to assert that loss aversion applies to any loss from the status quo, including money exchanged during a purchase (Novemsky \& Kahneman, 2005).

In addition to the endowment effect, another manifestation of the loss aversion principle is Samuelson and Zeckhauser's (1988) status quo bias. This bias manifests itself as a preference for retention of the status quo in decision making that predisposes an actor against both buying and selling. Individuals have a strong tendency to remain at the status quo because, when considering departure from the status quo, the disadvantages of 
doing so "loom larger" than the advantages (Kahneman, Knetsch, \& Thaler, 1991). Put another way, the status quo bias is an example of loss aversion because departing the status quo constitutes a loss, the pain of experiencing that loss increases more rapidly than the pleasure of an equivalent gain. As a result, decision makers will seek to avoid the pain of a loss (i.e., avoid the pain that results from choosing to depart from the status quo).

For example, in one experiment Samuelson and Zeckhauser (1988) provided subjects with a hypothetical choice task concerning investing inherited money in a moderate-risk company, a high risk company, treasury bills, or municipal bonds. Some subjects read a version without a description of the status quo, while other subjects received a version with one of the options designated as the status quo (e.g., "a significant portion of this portfolio is invested in ...”). The researchers examined the probability that participants would select an option when it was the status quo or when it is an alternative to the status quo. The results from this and other similarly designed experiments showed that an alternative became significantly more popular when the researchers defined it as the status quo. Furthermore, the advantage of the status quo increased as the number of alternatives increased (Kahneman, Knetsch, \& Thaler, 1991; Samuelson \& Zeckhauser, 1988).

Hartman, Doane, and Woo (1991) found similar evidence of the status quo bias in a field setting involving electric power consumers. The researchers mailed a survey to a stratified random sample of 2,200 residential customers of the Pacific Gas and Electric Company (PG\&E). Based on their current service (i.e., status quo), customers were divided into two groups. One group of customers had more reliable electric service (high 
reliability group: approximately three outages of two-hour duration per year) and another group of consumers had less reliable electric service (low reliability group: fifteen outages of four-hour duration per year).

The survey reminded respondents that the reliability of electric service helps PG\&E determine the cost of that service, and that although PG\&E could not prevent all power outages, it could spend more money to improve the service, which would increase rates, or it could reduce reliability of service, possibly reducing rates. The survey then asked both groups of consumers to state their preference among six different combinations of service reliabilities and rates. For each group of consumers (i.e., high reliability and low reliability), one of the six combinations was designated as the status quo service and rate.

The results indicated a clear status quo bias by both groups of consumers. In the high reliability group, over 60 percent of respondents selected their status quo service and rate as their first choice, and less than 6 percent expressed a preference for the low reliability option (which the other group was experiencing) even though it came with a 30 percent reduction in rates. Correspondingly, among the low reliability group, slightly less than 60 percent selected their status quo service and rate as their first choice, and less than 6 percent selected the high reliability option (again, which the other group was experiencing) at a proposed increased rate of 30 percent.

Loss Aversion \& Healthcare Decisions. Researchers have studied loss aversion in two distinct types of health decisions: public health decisions, which concern health outcomes for populations of people, and personal health decisions, which concern health outcomes for a particular decision maker (Rothman \& Salovey, 1997). Because HSAs 
rely upon individual account holders making healthcare decisions for themselves, I limit this review to loss aversion effects resulting from personal health decisions.

Message framing. Within the context of personal healthcare decisions, the combination of reference level dependence and loss aversion can produce gain-loss framing effects among medical procedures. A framing effect occurs when two different statements describe identical situations using different phrasing and produce different choices by decision makers. Although both statements suggest identical outcomes, the mere phrasing of the statements leads decision makers to choose different courses of action (Hastie \& Dawes, 2001; Rothman \& Salovey, 1997; Rothman et al., 1993). Rothman and Salovey (1997) articulate several ways that researchers can construct gainframed and loss-framed health communications. A health message can emphasize either outcomes associated with health-promoting behaviors (e.g., having a cancer screening) or outcomes associated with health-damaging behaviors (e.g., smoking cigarettes). Health messages can also frame information so that the consequences of a behavior differ in desirability and likelihood.

Two dimensions underlie message-framing, namely "behavior action" (i.e., attain; not attain) and "outcome" (i.e., desirable; undesirable) (Detweiler et al., 1999; Rothman \& Salovey, 1997). Gains are either attaining a desirable outcome (e.g., receive an immunization shot and enhance your immune system) or not attaining an undesirable outcome (e.g., receive an immunization shot and decrease your risk of disease). Losses are either attaining an undesirable outcome (e.g., by not receiving an immunization shot, you increase your risk of disease) or not attaining a desirable outcome (e.g., by not 
receiving an immunization shot, you cannot guarantee the strength of your immune system).

Rothman and colleagues $(1993 ; 1997)$ also differentiated between framing experiments that used a "same consequences" or "different consequences" manipulation. "Different consequences" framing describes a behavioral option (e.g., obtaining a cancer screening) as having either desirable or undesirable consequences, such as discovering that your skin is healthy (gain) or discovering you have a tumor (loss). In contrast, "same consequences" framing concerns whether an individual obtains or does not obtain a single, common outcome. For example, under a "same consequences" manipulation, a gain-framed message describes the desirable outcome associated with performing a health-behavior (e.g., discover your skin healthy), whereas the loss-framed message describes the desirable outcome that one does not obtain by not performing a healthbehavior (e.g., you do not discover that your skin is healthy).

Medical procedures. Interestingly, the empirical research concerning gain-loss framing effects show different results depending upon the type of medical services in question. Among prevention and treatment procedures, gain-framed health messages appear to be more influential than health messages that are loss-framed; however, the opposite result typically occurs for detection-oriented healthcare services (Rothman \& Salovey, 1997).

Among detection-oriented healthcare services, such as skin cancer screening, loss-framed messages promote positive attitudes toward, intentions to perform, and engagement in healthcare procedures (Rothman \& Salovey, 1997). In one study, Block \& Keller (1995) asked graduate and undergraduate students to read a brochure on skin 
cancer. The brochure resembled actual brochures disseminated by the American Cancer Society and other health organizations, which contain facts on skin cancer, provide information on the consequences and warning signs of skin cancer, and recommend health-promoting behaviors. The experimental brochure recommended both detection and prevention behaviors. The researchers manipulated message framing by altering the recommendation section of the pamphlet as either positive or negative. For example: "By [not] using a sunscreen with a Sun Protection Factor (SPF) of 15 or greater, and [not] wearing wide-brimmed hats and protective clothing as much as possible, you will [not] avoid ultraviolet rays." Participants' responses to a subsequent questionnaire indicated that loss-framed brochures about skin cancer led participants to express stronger intentions to perform skin cancer self-examinations. Similar findings have surfaced for other detection-oriented healthcare services, such as breast self-examinations (Meyerowitz \& Chaiken, 1987), obtaining a mammogram (Banks et al., 1995), bloodcholesterol screening (Maheswaran \& Meyers-Levy, 1990), and HIV testing (Kalichman \& Coley, 1995).

The conclusion that loss-framed messages lead to greater preferences, though, does not hold true for other types of healthcare decisions. In fact, for prevention-oriented behaviors (e.g., using condoms, mouth rinse, and sunscreen), gain-framed messages seem to be more effective than loss-framed messages (Detweiler, Bedell, Salovey, Pronin, \& Rothman, 1999; Linville, Fischer, \& Fischhoff, 1993; Rothman, Martino, Bedell, Detweiler, \& Salovey, 1999; Rothman \& Salovey, 1997; Rothman et al., 1993). In one study, Linville, Fischer, and Fischhoff (1993) investigated students' intentions to use condoms. The researchers informed student participants that a particular 
brand of condoms had either a $90 \%$ success rate or a $10 \%$ failure rate and asked (a) should regulators allow the manufacturers of this condom to advertise it as an effective method to reduce the risk of AIDS and (b) whether the students would use this condom themselves. Results indicated that describing the condoms in terms of its success rate led to more support from students on both questions. Similar, though somewhat weaker, results appeared in subsequent investigations, which altered the success/failure percentages (i.e., $95 \%$ and $99 \%$ success rates).

In another study, Rothman and colleagues (1993) examined the influence of framing on intentions to use sunscreen with an appropriate SPF. Undergraduate students read either a loss-framed or gain-framed pamphlet on skin cancer and skin cancer prevention. The positively framed pamphlet emphasized benefits rather than risks and focused on positive aspects of being concerned about skin cancer. The negatively framed pamphlet emphasized losses rather than gains and focused on risks of not performing cancer-related behaviors. After reading the pamphlets and completing several ratings regarding the pamphlets, participants received pre-paid postcards, which they could mail to request sunscreen as well as additional information on skin cancer. Results indicated that women who read the gain-framed pamphlet were more likely to request a sunscreen sample with an SPF of 15 than those who had read a loss-framed pamphlet. No framing effect was apparent among the male participants, only a small percentage of whom requested a free sunscreen sample. Addressing this gender difference, the researchers discussed the possible role of issue-involvement (i.e., whether skin cancer "mattered" more to women than to men), though they admitted that their data was unclear on this subject. 
In a similar study examining use of sunscreen, Detweiler and colleagues (1999) compared beach-goers who received loss-framed educational brochures to beach-goers who received gain-framed educational brochures. They found that beach-goers who received gain-framed brochures were more likely to report their intention to use sunscreen with SPF 15 or higher, to request sunscreen, and to report their intention to reapply sunscreen at the beach.

In addition to the effects observed among prevention procedures, the enhanced efficacy of gain-framed messages, as compared to loss-framed messages, is also apparent in treatment-oriented healthcare decisions, such as whether or not to undergo surgery. For these treatment services, gain-framed information produces greater participant preferences for treatment regardless of whether the decision maker's role is one of patient, doctor, or third party (McNeil et al., 1982; Rothman \& Salovey, 1997). In a classic study, McNeil et al. (1982) investigated how variations in the presentation of risk can influence patients' choices between alternative therapies. The participants included three different populations: graduate students, physicians, and patients with chronic medical conditions. The researchers told participants to assume that they had been diagnosed with lung cancer and asked to choose a type of treatment, either surgery or radiation. The researchers presented participants with the short-term and long-term consequences of both treatments, in either a gain-framed presentation (survival rates) or a loss-framed presentation (mortality rates). Compared to the radiation treatment, the surgery treatment had better long-term survival rates (i.e., $34 \%$ compared to $22 \%$ for radiation) but also had higher risk of death in the short-term (i.e., 10\% chance of perioperative death compared to $0 \%$ for radiation). The results indicated that framing the 
possible outcomes as survival rates or as mortality rates altered the choices made by all three populations of respondents. The choice of surgery was significantly higher when the researcher presented the treatment consequences as survival rates (gain frame).

Explanation. To explain the differential effects of message framing observed between types of medical procedures, Rothman and Salovey (1997) proposed that when people consider a health-related behavior that they perceive involves risk or uncertainty (e.g., the behavior may detect a health problem), loss-framed messages are more persuasive (because, in the loss domain, decision makers prefer risky prospects over certain prospects). Conversely, when people consider a health-related behavior that they perceive involves a safe or certain outcome (e.g., the behavior prevents a health problem), gain-framed appeals are more persuasive (because, in the gain domain, decision makers prefer certain prospects over risky prospects). Investigating the validity of that proposal, Rothman and colleagues (1999) found that participants' willingness to engage in a recommended behavior was a function of information-framing and type of behavior promoted. Specifically, gain-framed pamphlets enhanced participants' interest in a mouth rinse framed as plaque-fighting, and loss-framed pamphlets enhanced participants' interest in a rinse framed as plaque-detecting.

Rothman and colleagues $(1997 ; 1999 ; 2006)$ further proposed that the reason lossframed appeals are more effective in promoting detection behaviors is because contemporary society portrays detection behaviors, such as cancer screenings, as illnessdetecting. It is possible, though, to frame these behaviors as health-affirming (e.g., "get a mammogram to affirm that your breasts are healthy"). If decision makers perceive a detection behavior as a safe, health-affirming practice, gain-framed messages should be 
more persuasive than loss-framed messages. Correspondingly, if decision makers perceive a prevention behavior as a risky practice, loss-framed messages should be more persuasive than gain-framed messages.

In an investigation into the role of risk and certainty in framing effects, Apanovitch, McCarthy, \& Salovey (2003) compared the effectiveness of gain-framed and loss-framed videotapes designed to motivate HIV testing among low-income, ethnic minority women. The researchers found that participants' perceptions of the certainty of the outcome of an HIV test moderated the framing effects of HIV testing behavior. Among participants who reported being certain of the test's outcome, those who viewed the gain-framed materials reported a higher rate of testing than those who viewed the loss-framed materials. In contrast, among women who perceived the outcome of HIV testing as uncertain, gain-framed and loss-framed videos produced similar rates testing, with some preference for loss-framed materials.

Rothman and colleagues (1997; 1999; 2006) acknowledge that observed preferences for gain-framed or loss-framed messages could plausibly result from differential degrees of message processing (e.g., participant involvement or need for cognition). However, the researchers noted that it is difficult for differential processing to explain framing effects obtained with highly involved participants who were likely to have systematically processed information regardless of its frame (e.g., Banks et al., 1995; Detweiler et al., 1999; Rothman et al., 1993).

Rothman and colleagues (2006) also acknowledge the growing body of research that suggests congruency between message frame and people's sensitivity to favorable/unfavorable outcomes can regulate their reactions to framed appeals (Cesario, 
Grant, \& Higgins, 2004; Lee \& Aaker, 2004; Mann, Sherman, \& Updegraff, 2004;

Sherman et al., 2006; Updegraff, Sherman, Luyster, \& Mann, 2007). In other words, gain-framed and loss-framed messages may be more persuasive when they are consistent with a person's predominant motivational orientation (i.e., how the recipient of the message generally thinks and reasons about her environment). Loss-framed appeals may be more effective among risky behaviors because thinking about a behavior such as cancer screening may induce a particular mindset (i.e., prevention motivation), whereas considering health promoting behaviors, such as using sunscreen, may induce an alternative mindset (i.e., promotion motivation). In a later section, I will discuss research on motivation-message congruency in greater detail, as it is one focus of this investigation.

Loss Aversion Boundaries. Some investigators have recently begun to propose and examine conditions that reduce or eliminate loss aversion effects. Examples include increasing the similarity between endowed and un-endowed items (Chapman, 1998), shortening the duration of ownership (Strahilevitz \& Loewenstein 1998), increasing perceived necessity (Wicker et al. 2001), focusing buyers on benefits of the object and sellers on alternative uses of money (Carmon \& Ariely; 2000), exchanging goods of fixed value (Van Dijk \& Van Knippenberg 1996), and inducing decision-makers to experience disgust (Lerner, Small, \& Loewenstein, 2004). Two factors that appear to systematically influence loss aversion are the intentions of the decision maker and the cognitive focus of decision maker (Ariely, Huber, \& Wertenbroch, 2005; Novemsky \& Kahneman, 2005a; Novemsky \& Kahneman, 2005b). 
Intentions. Recently, investigators have proposed that decision makers' intentions can determine whether they designate items as objects of exchange or consumption, which influences whether parting with that item constitutes a loss or a foregone gain (Novemsky \& Kahneman, 2005a; 2005b). For example, shoes are an object of consumption for consumers who intend to wear the shoes, but the same shoes are an object of exchange for a shoe merchant who holds the shoes with the intention of exchanging them for money. Items given up "as intended" do not exhibit loss aversion. Thus, a shoe merchant should happily sell the shoes without demonstrating loss aversion, whereas a consumer will demonstrate loss aversion choosing not to sell the shoes. In a different line of research, Koszegi and Rabin (2006) showed that, after decision makers budget an amount of money for expenses (reflecting intentions to exchange), expenditures that fall within their budgets do not materialize as "losses," whereas extrabudget expenditures produce typical loss aversion effects. This finding suggests that holders of HSA accounts who have budgeted specific dollars for health care expenditures may show lower loss aversion effects than do holders of more traditional insurance policies.

In one line of research, Novemsky and Kahneman (2005a) provided empirical evidence that individuals' intentions to exchange (as compared to intentions to consume) can moderate loss aversion, such that items given up "as intended" do not generate loss aversion. Using Kahneman, Knetsch, and Thaler's (1990) endowment paradigm, plus two additional conditions (i.e., risky selling and risky buying), the researchers conducted a series of experiments concerning low-cost goods (i.e., mugs, pens, and chocolates). 
First, the researchers gave an item to "sellers" and to "risky sellers" and told them that it was theirs to keep. In order to elicit preferences that would be free of biases caused by strategic responding, the researchers informed the researchers informed participants that they would be offered the opportunity to buy or sell an item at several prices, and that one of those prices was preselected as the price that would be used to assess the outcome of their decisions. The researchers then asked sellers to consider an opportunity to sell the good at each of the several listed prices. The researchers offered risky sellers a gamble with equal chances $(50 \%)$ to win an amount of money and keep their good or to lose the good and receive no money. Risky sellers indicated whether they would accept or refuse the gamble for each dollar amount. The researchers then asked "choosers" to make choices between receiving the good or receiving an amount of money specified in the same series of dollar amounts. "Buyers" received an opportunity to buy the good (using their own money) at each of the series of dollar amounts. Finally, the researchers offered "risky buyers" a gamble with equal chances (50\%) to receive the good and pay nothing or to pay the selected amount without receiving the good. Risky buyers indicated whether they accepted or refused the gamble for each cash amount.

If loss aversion affected the money that buyers gave up, buying prices should have been approximately half of the choice-equivalence (minimum amount of money for which choosers prefer receiving money to receiving the good) that the choosers reported. The results did not reflect this outcome. Instead, the results depicted similarity between choosing prices and buying prices, suggesting that there is no loss aversion for money that one spends in a purchase. 
Interestingly, risky buyers stated a price that was approximately half of the choosers' choice-equivalence, indicating that risk can induce loss aversion for money spent in an exchange. Moreover, for the balanced risks presented in these experiments, there did not appear to be any risk aversion beyond loss aversion (i.e., risky sellers setting higher prices than sellers). Sellers and risky sellers exhibited the same degree of loss aversion for the good that they were selling/wagering.

In another line of research, Koszegi and Rabin (2006) propose that people may evaluate outcomes against an expected endowment rather than only against a current endowment. As a result, giving up a good in an exchange would not produce loss aversion if the good were not part of the reference point. This proposition coincides with the original formulation of prospect theory, which incorporates the idea that the reference point can reflect aspirations (Kahneman \& Tversky, 1979; Novemsky \& Kahneman, 2005b). Koszegi and Rabin's proposal merely adds that an actor's own intentions can be a determinant of such a reference point (Novemsky \& Kahneman, 2005b).

Cognitive focus. Differences in cognitive focus between people endowed and people not endowed with an item is another potential moderator of loss aversion (Ariely, Huber, \& Wertenbroch, 2005). Cognitive focus during evaluation may mediate the effects of intentions on loss aversion, such that alternate cognitive foci might explain why people assign more or less weight to items usually construed as losses. When evaluating a possible exchange of money for an item, a person endowed with the item may focus on the good, whereas a person not endowed with the item may instead focus on the money (Carmon \& Ariely 2000). Such shifts in cognitive focus may help explain the inconsistency of loss aversion (Ariely, Huber, \& Wertenbroch, 2005; Lerner, Small, \& 
Loewenstein 2004), such that persons who focus on the endowed item may display loss aversion, whereas persons who focus on something other than the endowed item may not display loss aversion.

Carmon and Ariely (2000) argued that loss aversion could result from decision makers' asymmetrical focus on what they forego in an exchange. The researchers suggest that buyers and sellers focus on different aspects of a potential transaction. Buyers focus on what they forgo in an exchange (money), and as a result, they are sensitive to moneyrelated aspects of the transaction. Conversely, sellers focus on what they forgo in an exchange (the item for sale), and as a result, they are sensitive to features relevant to the item. Carmon and Ariely (2000) investigated this possibility in the context of buying and selling prices for basketball tickets. They found that selling prices were closely correlated with evaluations of the basketball game (e.g., the importance of the game, the subject's level of fandom), while buying prices were closely correlated with evaluations of the expenditure (e.g., the ticket's list price, the subject's attitudes toward money).

\section{Regulatory Focus Theory}

In addition to the limiting influence of the two factors discussed above (i.e., intentions and cognitive focus), a decision maker's motivational orientation, or “regulatory focus" (Higgins, 1997) could impact loss aversion, including the different gain-loss framing effects among medical procedures. Higgins' (1997) regulatory focus theory posits a dualistic motivational network, where one of two possible mechanisms for self-regulation guides people's choices. Individuals have a strategic inclination towards either a promotion focus or a prevention focus, and these self-regulatory tendencies 
influence appraisals of choice outcomes (Higgins, 1997; 2002; Shah \& Higgins, 2001; Shah, Higgins, \& Friedman, 1998).

Promotion focus is the orientation to bring one's actual self into alignment with one's "ideal self." For individuals in a promotion focus, goals are aspirations and accomplishments, so that they are concerned with the absence or presence of desirable end-states. Success reflects the presence of a positive outcome (a gain), and failure reflects the absence of a positive outcome (a non-gain). People in a promotion focus pursue goals via eager approach strategies (Higgins, 1997; 2002; Shah \& Higgins, 2001; Shah, Higgins, \& Friedman, 1998).

In contrast, prevention focus is the orientation to bring one's actual self into alignment with one's “ought self." For individuals in a prevention focus, goals are duties and responsibilities, so that they are concerned with the absence or presence of an undesired end-state. Success reflects the absence of a negative outcome (a non-loss), and failure reflects the presence of a negative outcome (a loss). People in a prevention focus pursue goals via vigilant avoidance strategies (Higgins, 1997; 2002; Shah \& Higgins, 2001; Shah, Higgins, \& Friedman, 1998).

Higgins $(2002 ; 2005)$ proposes that regulatory focus orientations can be both an individual-difference variable and a situational variable (Higgins, 2002; 2005). Individuals have chronic personal dispositions that give rise to either prevention- or promotion-focus orientations. Additionally, situational contexts can induce one regulatory focus dimension or the other.

The current research takes advantage of the fact that an individual's regulatory focus alters the processes underlying judgments and decision-making (Crowe \& Higgins, 
1997; Liberman et al., 2001). For example, researchers have shown that regulatory focus influences whether participants make risky or conservative judgments. In a signal detection task, Crowe and Higgins (1997) experimentally manipulated regulatory focus by telling participants that, depending on their performance on a memory task, they would have an opportunity for performing a liked task (promotion focus) or of not performing a disliked task (prevention focus). They then asked participants to memorize a series of nonsense syllables. Later in a recognition memory task, participants observed the same syllables along with distracter syllables and had to indicate whether they had seen each in the original list. Results indicated that participants in a promotion focus demonstrated a "risky" response bias of saying yes (i.e., high number of hits and false alarms), and those in a prevention focus demonstrated a "conservative" response bias of saying no (i.e., high number of correct rejections and omissions).

Similarly, Liberman and colleagues (2001) employed a series of experiments and found that participants in a promotion focus generate a greater number of hypotheses than do participants in a prevention focus. In two object-naming tasks, participants attempted to guess the name of ambiguous objects. In an attribution task, participants listed potential causes of their past behaviors. For both tasks, participants in a promotion focus generated a greater number of hypotheses (guessed names and listed causes) than did participants in a prevention focus.

Regulatory Fit. Higgins $(2002 ; 2005)$ postulated that when people pursue a goal in a manner that "fits" their regulatory orientation (i.e., a promotion-focused person pursuing a goal in a promotion manner or a prevention-focused person pursuing a goal in a prevention manner), they experience a psychological benefit. The match between 
regulatory orientation and manner of goal pursuit, or regulatory fit (Higgins, 2002; 2005) produces a psychological benefit that can influence later judgments, decisions, and behaviors. Higgins $(2002 ; 2005)$ proposes that experiencing regulatory fit increases the value derived from the goal pursuit activity, and this "goal pursuit value" influences valuation of decision outcomes. Sometimes a person who experiences a psychological benefit from pursuing a goal in a manner that matches one's regulatory orientation incorrectly attributes the benefit to the outcome of the activity rather than to the manner of goal pursuit. As a byproduct, the decision maker may place higher value on that outcome.

The misattribution is the result of confusion between two separate sources of value: methods-value and outcome-value (Higgins, 2002; 2005). Methods-value refers to an evaluation of the outcome-pursuit process. Outcome-value refers to an evaluation of the final end-state. A person experiencing "regulatory fit" transfers positive value from methods-value to subsequent outcome-value. Therefore, after experiencing regulatory fit, the value of a given outcome will be higher than if a process devoid of regulatory fit produced that same outcome. This confusion regarding the source of outcome-value is typically unintended, and people are generally unaware it has occurred. Researchers have shown that experiencing "regulatory fit" intensifies both people's feelings about a decision activity and their motivation to pursue a goal (Forster, Higgins, \& Idson, 1998; Higgins et al., 2003; Shah, Higgins, \& Friedman, 1998).

The increased methods-value resulting from regulatory fit can transfer to subsequent evaluation objects (Forster \& Higgins, 2005; Higgins, 2002; 2005; Higgins et al., 2003; Idson, Liberman, \& Higgins, 2004). In one demonstration involving decisions 
to purchase, Higgins and colleagues (2003) investigated whether individuals place a higher monetary value on objects chosen through a process producing regulatory fit. The researchers expected that decision makers would transfer the value gleaned from experiencing regulatory fit to the evaluation of the purchased object. After measuring participants' chronic regulatory focus, the experimenters asked participants to choose either a mug or a pen. Some participants received promotion-framed instructions (i.e., think about what you could gain by choosing the mug or pen), and other participants received prevention-framed instructions (i.e., think about what you would lose by not choosing the pen or not choosing the mug). The mug was clearly the more valued object, and most of the participants chose it. When asked to estimate the price of the mug, participants assigned it a significantly higher price when their chronic regulatory focus matched the instructions as compared to when their focus did not match the instructions.

A number of additional studies have further demonstrated the value-from-fit effect (Avnet \& Higgins, 2003; Camacho, Higgins, \& Lugar, 2003; Cesario, Grant \& Higgins, 2004; Idson, Liberman, \& Higgins, 2004). Avnet and Higgins (2003) found that participants who chose a book-light via a strategy that fit their regulatory orientation were willing to pay over $40 \%$ more for the book-light than were participants who chose it without experiencing regulatory fit. Shah, Higgins, and Friedman (1998) reported that, in a set of anagram tasks, participants' performance and motivation were greater when the orientation of task incentives and task means matched individuals' chronic regulatory focus.

In another investigation, Speigel, Grant-Pillow, \& Higgins (2004) expected that regulatory fit would enhance motivational strength, which would improve efforts at goal 
attainment and produce greater behavioral modification. Promotion-focused and prevention-focused participants pursued the goal of writing a report on their leisure time after the researchers assigned them to either eagerness-framed or vigilance-framed conditions. Participants who experienced regulatory fit (promotion/eagerness and prevention/vigilance) were approximately 50\% more likely to turn in their reports than were participants who did not experience fit (Speigel, Grant-Pillow, \& Higgins, 2004). Interestingly, regulatory focus is not the only theory which asserts that value is transferred from decision methods to outcome evaluations. Founded on the precepts of prospect theory, transaction utility theory maintains that the utility of the transaction process contributes to the satisfaction and value of a decision over and above the utility of the outcome (Thaler, 1983; 1985). "Transaction utility" refers to the pleasure or displeasure associated with the terms of a deal. Transaction utility theory states that consumers derive psychological benefits not only through buying or selling (economic gain or loss), but also through the pleasurable aspects of the transaction process itself. Furthermore, the psychological benefits produced by the transaction process enhance consumers' overall evaluations of purchase decisions. Factors independent of the exchange, such as perceived fairness and transaction-framing, cause a separate, qualitatively different source of value (Darke \& Dahl, 2003). Similarly, procedural justice theory (see generally Tyler, $1988 ; 1989$ ) is another theory that incorporates the notion that transaction processes can influence subsequent appraisals of outcomes.

Regulatory fit and healthcare decisions. When the framing of a message fits an individual's regulatory focus, the individual experiences a psychological benefit that can increase perceived persuasiveness of the message (Cesario, Grant, \& Higgins, 2004; 
Florack \& Scarabis, 2006). The benefit can also enhance consumers' evaluations of a product (Werth \& Foerster, 2007) and consumers' likelihood to purchase a product (Herzenstein, Posovac, \& Brakus, 2007).

Generally, consumers prefer products that are advertised in a manner that is compatible with their regulatory orientation (Florack \& Scarabis, 2006; Jain, Agrawal, \& Maheswaran, 2006). They also report positive evaluations of products advertised in a way that is consistent with their regulatory orientation (Werth \& Foerster, 2007). Appeals presented in gain frames are more persuasive when the message is promotion focused, and loss-framed appeals are more persuasive when the message is prevention focused (Lee \& Aaker, 2004). When they experience fit between regulatory orientations and presentation of product attributes (i.e., prevention focus and safety features; promotion focus and comfort features), consumers evaluate those products more positively. However, motivation to process information may moderate these effects, such that regulatory fit may only influence product evaluations when participants are less motivated to process information about the product (Wang \& Lee, 2006).

Cesario, Grant, \& Higgins (2004) demonstrated that regulatory fit can influence the persuasiveness and evaluation of healthcare-specific messages. In one experiment, participants received a persuasive message describing the importance of eating more fruits and vegetables. The researchers manipulated regulatory focus by having the message emphasize either the accomplishment concerns or the safety concerns of eating more fruits and vegetables and they framed the message to reflect either eager means or vigilant means of consumption. Regarding the effectiveness of the messages, participants who experienced regulatory fit (i.e., accomplishment concerns and eager means; safety 
concerns and vigilant means) reported higher ratings of perceived persuasiveness and higher opinion ratings (Cesario, Grant, \& Higgins, 2004).

In another study, the researchers eliminated these effects when, before message exposure, they exposed the source of the psychological benefit by directly manipulating regulatory fit separate from the persuasion context. Then, prior to exposing participants to the message, the researchers did or did not draw participants' attention to the true source of their "feeling right" experience. The results suggested that drawing attention to the true source of the feeling right experience reduced or eliminated the regulatory fit effect (Cesario et al. 2004; Higgins et al., 2003). This inference is similar to findings in the emotion as information literature, where perceivers use their experienced mood as a cue to interpret their reactions about independent events until they learn that their experienced mood is the result of another source (Schwartz \& Clore, 1983).

Speigel, Grant-Pillow, and Higgins (2004) found that regulatory fit influenced the likelihood that participants would follow the advice of a health message. Participants read one of two messages urging them to eat more fruits and vegetables. One of the messages was promotion-framed (i.e., the message emphasized accomplishment concerns such as increased energy, better moods, etc.) while the other message was prevention-framed (i.e., the message emphasized safety concerns such as facilitating the immune system, protecting the body from heart disease, etc.). The messages also encouraged participants to imagine either the benefits of compliance or the costs of non-compliance. Participants' daily $\log$ entries for the following week indicated that those who experienced regulatory fit (promotion/benefits; prevention/costs) ate about 20\% more fruits and vegetables than participants who experienced fit violation (promotion/costs; prevention/benefits). 
Recent research further suggests that regulatory fit can enhance intentions to perform health-related behaviors. In two experiments, Keller (2006) examined the fit between efficacy concerns in a health message (i.e., self-efficacy and response-efficacy) and participants' regulatory focus. The first experiment involved a sorting task where participants categorized features of a health message as either eager or vigilant. Results indicated that self-efficacy focus in health messages (i.e., perceived ease of a behavior) exerted greater influence among individuals in a promotion focus and response-efficacy focus in health messages (i.e., perceived effectiveness of a behavior) exerted greater influence among individuals in a prevention focus.

Extending these findings in the second experiment, Keller (2006) tested whether intentions to use sunscreen were higher when there was fit between participants' regulatory focus and efficacy concerns (promotion/self-efficacy; prevention/responseefficacy). As expected, when the appeal emphasized the self-efficacy features of health behaviors, individuals in a promotion focus demonstrated stronger intentions to perform the advocated health behaviors. Similarly, when the appeal emphasized response-efficacy features of health behaviors, individuals in a prevention focus demonstrated stronger intentions to perform the advocated behaviors.

Regulatory fit and prospect theory. In a review of how regulatory fit affects value in consumer choices, Avnet and Higgins (2006) discuss the possibility that promotion-oriented people are more sensitive to gains while prevention-oriented people are more sensitive to losses. The authors added to the tenets of prospect theory by suggesting that differences in regulatory fit among decision makers can influence risk preferences. They began by discussing Forster's and colleagues' (2001) findings 
regarding the effects of success and failure feedback. Those researchers conducted two experiments in which promotion-focused participants and prevention-focused participants solved two sets of anagrams. After completing the first set of anagrams, participants received either success or failure feedback. The researchers assessed participants' performance expectancies for the second set of anagrams and then asked them to complete the second set of anagrams. The results showed that providing success feedback to participants in a promotion state increased their performance expectancies for the second anagram task, but success feedback had no effect on the performance expectancies of participants in a prevention state. In contrast, providing failure feedback to participants in a prevention state decreased their performance expectancies for the second anagram task, but failure feedback had no effect on the performance expectancies of participants in a promotion state.

Avnet and Higgins (2006) go one step further to propose that promotion-oriented people who experience fit should be more gain-seeking than those who do not experience fit. Similarly, prevention-oriented people who experience fit should be more loss averse than those who do not experience fit. The authors argue that experiencing regulatory fit can impact either gain-seeking behavior or loss-avoiding behavior, depending upon which regulatory concern the fit experience is sustaining. In other words, individuals in a promotion focus who experience regulatory fit should value gains more than equivalent losses. This is because the psychological benefit from regulatory fit transfers to the promotion-oriented outcome (presence/absence of a gain), causing that outcome to have increased value. Correspondingly, individuals in a prevention focus who experience regulatory fit should value losses more than equivalent gains (because the psychological 
benefit from regulatory fit transfers to the prevention-oriented outcome (presence/absence of a loss), causing that outcome to have increased value.

Following this line of reasoning, Uskul, Sherman and Fitzgibbon (2009) examined how culture influenced the persuasive effects of regulatory fit in health message framing. They began with the observation that in Western cultures, individuals favor promotion over prevention strategies, whereas in Eastern cultures, individuals favor prevention over promotion strategies. It follows that health messages should be more persuasive when they are congruent with dominant cultural patterns of either promotion or prevention focus.

Uskul et al. (2009) suggested that individuals' motivational orientations might underlie the observed cultural differences and set out to test a mediated cultural moderation hypothesis. They proposed that the interaction between message frame and individuals' regulatory focus would mediate (i.e., explain) the culturally-dependent effects of message framing noted above. In other words, the researchers examined whether the effects of culture (i.e., Eastern favoring prevention; Western favoring promotion) can be explained by an interaction of individuals' regulatory focus and the message frame. They predicted an East-Asian sample would exhibit a psychological benefit from loss-framed messages, whereas the White British sample should exhibit a psychological benefit from gain-framed messages.

Uskul et al. (2009) tested this hypothesis by administering a dental flossing persuasion task to undergraduate participants from a British University, half of whom identified themselves as White British and the other half as East-Asian. These participants completed a regulatory focus measure, read one of two messages (i.e., a gain- 
framed or loss-framed flossing argument), and completed measures assessing their attitudes toward flossing and their intentions to floss. Results showed that the White British participants had more positive attitudes and stronger intentions to floss when they received the gain-framed message, but East-Asian participants had more positive attitudes and stronger intentions to floss when they received the loss-framed message. Moreover, individuals' regulatory focus did not directly mediate the culture-by-messageframe interaction (i.e., observed culture-by-message-frame effects were not the result of differing regulatory focus among decision makers). Instead, the interaction between individuals' regulatory focus orientations and message frame mediated the interaction of culture and message frame. The authors concluded that (1) health messages framed to be culturally congruent produce more positive attitudes and stronger intentions to perform health behaviors and (2) the interaction between regulatory focus and message frame is the pathway through which the cultural difference arises.

\section{Chapter 4: Research Project \& Hypotheses}

As discussed above, the HSA paradigm presupposes a rational actor model of decision making. As such, the law assumes that individual account holders will make rational decisions concerning the exchange of HSA funds for healthcare services.

However, decades of decision making research show that individual account holders may not make rational expenditure decisions but may instead exhibit loss aversion (i.e., a riskseeking preference when considering loss-framed decisions and a risk-avoiding preference when considering gain-framed decisions), as predicted by prospect theory. However, if HSAs behave as embodiments of decision makers' intentions to exchange, owners of HSAs may not exhibit loss aversion (Koszegi \& Rabin, 2006; Novemsky \& 
Kahneman, 2005a; 2005b). The experiments described below addressed this issue by investigating whether HSAs facilitate systematic loss aversion, as predicted by prospect theory, or whether HSAs, as embodiments of decision makers' intentions to exchange pre-budgeted funds, inhibit loss aversion effects in healthcare acquisition decisions. Furthermore, the investigation explored the suggestions from Avnet and Higgins (2006), as well as Uskul, Sherman and Fitzgibbon (2009), testing whether decision makers' regulatory focus orientations might explain the presence and absence of loss aversion effects. Prospect theory predicts that all decision makers will value gains less than equivalent losses (e.g. "losses loom larger than gains"). In contrast, regulatory fit offers a possible explanation for why losses loom larger than gains in some circumstances, while in other circumstances losses do not loom larger than gains. Specifically, regulatory fit in the context of promotion-orientation should inhibit loss aversion and regulatory fit in the context of prevention-orientation should facilitate loss aversion. The experiments investigated the moderating role of regulatory fit in a loss aversion paradigm in which consumers make healthcare delivery decisions.

The underlying logic of this research relies on prospect theory's loss aversion principle to suggest that decision makers should prefer risky choices in healthcare decisions concerning losses but should prefer certain choices in healthcare decisions concerning gains. As a result, decision makers should exhibit gain-loss framing effects among healthcare choices. Specifically, after receiving loss-framed decision tasks, more decision makers should report intentions to obtain "risky" detection oriented medical services, such as professional skin cancer screening, and report higher willingness to pay for such services (Hypothesis 1). However, the framing effect should be strongest for 
detection-oriented medical services and it ought to reverse for prevention-oriented medical services. After receiving gain framed decision tasks, more decision makers should report intentions to obtain prevention services, such as an immunization injection, and report higher willingness to pay for such services (Hypothesis 2). Moreover, when choosing between two different types of treatment services, more participants should report intentions to undergo treatments, such as surgery, and report higher willingness to pay for such services after receiving gain framed decisions (Hypothesis 3).

Additionally, research demonstrating that the intentions of decision makers can moderate loss aversion (Novemsky \& Kahneman, 2005; Koszegi \& Rabin, 2006) predicts an interaction between decision framing and type of benefit plan. As noted previously, one aspect of decision makers' intentions is to designate items as objects of exchange or objects of consumption. Prior work (Novemsky \& Kahneman, 2005; Koszegi \& Rabin, 2006), has shown that items given up "as intended" do not trigger loss aversion. Accordingly, decision makers who have budgeted money for expenses (reflecting intentions to exchange) should not demonstrate loss aversion for within-budget expenditures. Thus, if HSAs behave as embodiments of decision makers' intentions to exchange pre-budgeted funds, HSAs should diminish or eliminate differences in decision maker preferences produced by gain-loss framing. Among decision makers who own HSAs, gain-loss framing effects ought to be diminished or eliminated (Hypothesis 4). Moreover, Avnet and Higgins' (2006) proposal that risk preferences can be explained by differences in regulatory fit predicts a regulatory orientation-by-message frame interaction. When choosing among healthcare options, decision makers who experience regulatory fit between their chronic orientations and the decision process (i.e., 
promotion-focus and gain-frame; prevention-focus and loss frame) will more often report intentions to obtain medical services and will report higher willingness to pay for the services, as compared to decision makers who do not experience regulatory fit (Hypothesis 5).

\section{Chapter 5: Experiment 1}

\section{Overview}

Participants completed an online experiment in which they first filled out a measure of chronic regulatory orientations and then engaged in a survey experiment concerning healthcare acquisition. After providing informed consent, participants completed the Regulatory Focus Questionnaire (RFQ; Higgins et al., 2001), read general instructions for completing the experiment, read one of two descriptions of a healthcare plan (either an HSA or a defined-benefit plan) and read a description of a hypothetical healthcare decision. The website instructed participants to imagine that they were encountering the healthcare decision and asked them to choose how they wished to proceed. Participants read about the risks of developing skin cancer and decided among detection options. The experiment was a 2 (benefit plan: HSA v. Defined-Benefit) x 2 (framing: gain v. loss) completely crossed between-groups design, with all participants completing a continuous measure of chronic regulatory focus (RFQ).

\section{Methodology \& Research Design}

The research team recruited participants through the Study Response Project, a non-profit organization hosted by the School of Information Studies at Syracuse University designed to connect researchers with willing research participants. The 
Project facilitates online research by distributing participation requests via email to adult research participants who have signed up to receive invitations for research participation.

Individuals who accepted the invitation visited an online website on a computer of their choice to complete the experiment. In exchange for their participation, participants received a stipend of $\$ 20$ via Study Response standard procedures. A specially written computer program randomly assigned participants to them to one of the four experimental conditions.

Participants. 233 participants responded to the recruitment message and accessed the experiment website. Any participants who accessed the experimental materials of any of the three experiments (i.e., any material beyond the informed consent form) more than once were excluded from analysis. Any participants who did not complete the primary dependent variables (appearing at the end of the Experiment) were also excluded from analysis.

After these exclusions, 191 participants (100 male; 87 female; 4 not reporting) aged 27 to 89 years $(M=42.23$, s.d. $=12.05)$ completed Experiment 1 . Table 1 depicts participants' demographic characteristics. The vast majority was Caucasian $(n=161)$, spoke English as their primary language $(n=180)$, and completed High School $(n=187)$. In the previous 12 months, 3 participants worked in the field of insurance or finance, 5 worked in the field of healthcare, and 8 worked in a field involving both insurance/finance and healthcare. $^{3}$

\footnotetext{
${ }^{3}$ Removing these participants from the analyses produced two differences from the reported results, both concerning participants' Likelihood to Obtain a screening. After removing these participants from the analyses, chronic prevention focus was no longer a significant main effect; however decision frame became a significant main effect.
} 
Table 1. Experiment 1 participants' demographic characteristics

\begin{tabular}{|c|c|c|}
\hline Characteristic & Frequency & Percentage \\
\hline \multicolumn{3}{|l|}{ Gender } \\
\hline Male & 100 & 52.4 \\
\hline Female & 87 & 45.5 \\
\hline Not Reporting & 4 & 2.1 \\
\hline \multicolumn{3}{|l|}{$\underline{\text { Age }}$} \\
\hline $27-30$ & 29 & 15.2 \\
\hline $31-40$ & 78 & 40.7 \\
\hline $41-50$ & 33 & 17.3 \\
\hline $51-60$ & 31 & 16.0 \\
\hline $61-70$ & 13 & 6.6 \\
\hline Over 70 & 5 & 2.0 \\
\hline Not Reporting & 3 & 1.6 \\
\hline \multicolumn{3}{|l|}{ Race/Ethnicity } \\
\hline Caucasian American & 161 & 84.3 \\
\hline Hispanic/Latin American & 8 & 4.2 \\
\hline Asian American & 6 & 3.1 \\
\hline African American & 6 & 3.1 \\
\hline Other & 6 & 3.1 \\
\hline Not Reporting & 4 & 2.1 \\
\hline
\end{tabular}




\begin{tabular}{|c|c|c|}
\hline \multicolumn{3}{|l|}{ Highest Level of Education } \\
\hline Less than High School & 1 & .5 \\
\hline High School & 41 & 21.5 \\
\hline Associate's Degree & 14 & 7.3 \\
\hline Bachelor's Degree & 82 & 42.9 \\
\hline Master's Degree & 38 & 19.9 \\
\hline $\begin{array}{l}\text { Professional Degree } \\
\text { (Ph.D., M.D., Law) }\end{array}$ & 12 & 6.3 \\
\hline Not Reporting & 3 & 1.6 \\
\hline \multicolumn{3}{|l|}{ Annual Income } \\
\hline Less than $\$ 20,001$ & 18 & 9.4 \\
\hline$\$ 20,001-\$ 40,000$ & 16 & 8.3 \\
\hline$\$ 40,001-\$ 60,000$ & 28 & 14.6 \\
\hline$\$ 60,001-\$ 80,000$ & 41 & 21.4 \\
\hline$\$ 80,001-\$ 100,000$ & 41 & 21.4 \\
\hline$\$ 100,001$ or more & 43 & 22.5 \\
\hline Not Reporting & 4 & 2.1 \\
\hline \multicolumn{3}{|l|}{ Marital Status } \\
\hline Single/Widowed & 28 & 14.6 \\
\hline Married & 141 & 73.8 \\
\hline Divorced/Separated & 15 & 7.8 \\
\hline Not Reporting & 7 & 3.7 \\
\hline
\end{tabular}




\begin{tabular}{|l|c|c|}
\hline Type of HC coverage & & \\
No Healthcare Plan & 18 & 9.4 \\
Personal DC Plan & 24 & 12.6 \\
Personal DB plan & 41 & 21.5 \\
Employer-based DC plan & 21 & 11.0 \\
Employer-based DB plan & 79 & 41.4 \\
Do not know & 6 & 3.1 \\
Not Reporting & 2 & 1.0 \\
\hline
\end{tabular}

Materials \& Procedure. The materials for the experiment, administered on the website, included an informed consent statement, a measure of chronic regulatory orientation (RFQ), General Instructions, a HSA report, a defined benefit plan report, description of a hypothetical healthcare decision, descriptions of healthcare choices for the decision, a demographics form, and a debriefing statement. The informed consent statement (Appendix A) laid out the general purpose of the experiments, including the tasks and requirements for the research participants. It explained to participants that they were able to withdraw from the experiment at any time.

After providing informed consent, all participants completed the 11-item RFQ (Appendix B), which is a standard measure of chronic regulatory focus that provides trait scores on promotion and prevention focus (Higgins, et al., 2001). The RFQ measures individuals' subjective histories of success and failure in promotion and prevention selfregulation (people's own recollection of their past styles of problem solving). It consists 
of 11 items to which respondents reply on a 1 (never or seldom) to 5 (very often) scale, indicating how frequently certain events occurred in their lives. Examples of items on the promotion scale are "I feel like I have made progress toward being successful in my life" and "Compared to most people, are you typically unable to get what you want out of life?" (reverse scored). Examples of items on the prevention scale are "How often did you obey rules and regulations that were established by your parents?" and "Not being careful enough has gotten me into trouble at times" (reverse scored). The RFQ yields scores on a promotion scale and a prevention scale. Individuals who score high on the promotion scale are more likely to adopt an eagerness or accomplishment motivational style in approaching new tasks, while those scoring high on the prevention scale are more likely to adopt a safety or vigilant motivational style. Convergent validity studies of the RFQ indicate that promotion focus relates to ideal-actual self-discrepancies and prevention focus relates to ought-actual self-discrepancies (Higgins, 1998, cited in Higgins et al., 2001). Harlow and colleagues (1997) found that both scales relate moderately to achievement motivation and that prevention focus related to avoiding mistakes and the absence of impulsivity (cited in Higgins et al., 2001). Higgins and colleagues (2001) demonstrated predictive validity showing that promotion focus predicted eagerness to achieve goals and avoidance of errors of omission, whereas prevention focus predicted vigilance in obtaining desired goal states and avoidance of errors of commission.

The website next presented all participants with General Instructions for the Experiment, which asked each participant to act as a healthcare consumer deciding among healthcare options (Appendix C). The instructions asked participants to approach 
the decision task as if they were making decisions regarding their own healthcare in the real world. The instructions told participants that they should carefully read the descriptions of their hypothetical healthcare plan and hypothetical decision task so that they could select their preferred healthcare service option.

After the General Instructions, the website presented at random to one-half of the participants a status report regarding a hypothetical HSA in their name (Appendix D) and presented to the other half a status report regarding a hypothetical defined benefit plan in their name (Appendix E). The HSA status report informed participants of their account balance, interest rate, HDHP coverage, and generic information regarding HSAs. The generic information described how HSAs are tax-exempt trusts administered by a trustee and highlight the (1) use of HSA funds to pay for qualified medical expenses, (2) the required HDHP coverage, and (3) the tax-free nature of contributions, expenditures, annual rollovers, and interest earned. The Defined Benefit status report informed participants of their health coverage, annual premium payment, maximum deductible, and generic information regarding defined benefit plans. This generic information described the regulatory and fiduciary duties of employers and highlighted the employer's responsibility for funding the employee health insurance plan and for distributing healthcare benefits to employees. Wiener and colleagues $(2006 ; 2007)$ employed a similar technique to present hypothetical credit card statements to participants. To help ensure that participants in both conditions understand the nature and quality of their hypothetical healthcare plans, the information appeared both narrative and chart formats. 
After becoming acquainted with their healthcare plans, all participants completed a manipulation and mediation check, which examined their general understanding of Health Savings Accounts and Defined Benefit Plans. These 10 True-or-False questions were the same for all participants. For participants who receive a status report regarding a hypothetical HSA, there are another 6 True-or-False questions based on the information presented in that status report (Appendix F). Similarly, for participants who received a status report regarding a hypothetical defined benefit plan, there were another 6 True-or-False questions based on the information presented in that status report.

Next, the website asked participants to assume that they were encountering a healthcare decision and presented them with a choice of options. Participants received information concerning skin cancer and recommendations for detecting skin cancer. Employing techniques similar to those of Block and Keller (1995), as well as Rothman and colleagues (1993), the display of skin cancer information resembled a brochure disseminated by the American Cancer Society and other health organizations, though in this experiment it was an electronic brochure. The brochure reported the incidence and etiology of skin cancer, contained facts about the disease, provided information on the consequences and warning signs of skin cancer, and recommended techniques to detect and prevent the disease (e.g., a skin cancer examination to detect the presence of skin cancer on the body).

Using the framing paradigm of Rothman and colleagues (1993), the website displayed a gain-framed brochure to one-half of the participants (Appendix G) and a lossframed brochure to the other half (Appendix H). Both brochures discussed the etiology of the disease, its prevalence, and its progression. The gain-framed brochure discussed 
outcomes, and made recommendations for prevention and treatment by emphasizing benefits and focusing on the positive aspects of being concerned about skin cancer. It included statements like: 1) The earlier skin cancer is detected, the better a person's chances are for full recovery; 2) If detected early, most of these cancers are curable and will not be fatal; 3) People who never had a blistering sunburn in the past are less likely to get skin cancer during their life than those who have had a such a burn; and 4) You can significantly decrease your chance of getting skin cancer by not exposing your skin to the sun without protection. The loss framed brochure emphasized losses and focused on the risks of not taking preventative precautions. It included statements like: 1) The later skin cancer is detected, the poorer the chances are of a person's full recovery; 2) Unless they are detected and treated early, most of these cancers are not curable and will be fatal; 3) People who have had a blistering sunburn in the past are more likely to get skin cancer during their life than those who have never had such a burn; and 4) You can significantly increase your chance of ultimately getting skin cancer by exposing your skin to the sun without protection.

After reviewing these materials, participants reported their intentions, under their respective hypothetical healthcare plans, to obtain a professional skin cancer screening (Appendix I). Participants answered two questions. The first question was: 1) Given what you have just learned about skin cancer risks and detection practices, as well as what you know about your current healthcare plan, how likely will you be to obtain a professional skin cancer screening? (1 very unlikely to 9 very likely). The second question asked: 2) Given what you have just learned about skin cancer risks and detection practices, as well as what you know about your current healthcare plan, what is 
the highest cost that you are willing to pay for the professional skin cancer screening?" Following this second question was a rating scale consisting of eleven prices for the procedure, ranging from $\$ 0$ to $\$ 1000$, in intervals of $\$ 100$. Answers to these two questions (i.e., likelihood to obtain a screening for the first question and the selected dollar amount for the second question) were the dependent variables for the Experiment 1 analyses.

Finally, participants completed a demographics form (Appendix J), which made general inquiries about age, gender, education level, prior healthcare experience, and so on. Afterwards, they read a debriefing statement that described the general purpose of the Experiment (Appendix K). The website then directed them to close out their web browser.

Experiment 1 yielded a measure of participants' intentions to obtain cancer screening and a measure of participants' willingness to pay for cancer screening. Results from this experiment address Hypotheses 1, 4, and 5. Hypothesis 1 stated that after receiving loss framed decision tasks, more decision makers should report intentions to obtain a professional skin cancer screening and report higher willingness to pay for the screening. A significant main effect for the type of frame would confirm the hypothesis. Hypothesis 4 stated that decision makers who own HSAs would not exhibit gain-loss framing effects. A significant interaction between type of frame and type of plan showing greater gain-loss effects in the traditional plan condition, compared to the HSA condition, would confirm this hypothesis. Hypothesis 5 stated that decision makers who experienced regulatory fit between their chronic orientations and the decision frame would more often report intentions to obtain medical services and would report higher 
willingness to pay for the services. Three way interactions between the covariates, framing, and type of plan tested this hypothesis.

\section{Results}

RFQ. Participants' chronic promotion focus consisted of their average scores on RFQ items 1 (reverse scored), 3, 7, 9 (reverse scored), 10, and 11 (reverse scored) (Cronbach's alpha $=.54 ; M=3.47 ;$ s.d. $=.58$ ). Participants' chronic prevention focus consisted of their average scores on RFQ items 2 (reverse scored), 4 (reverse scored), 5, 6 (reverse scored), and 8 (reverse scored) (Cronbach's alpha $=.73 ; M=3.36 ;$ s.d. $=.78$ ).

Healthcare Knowledge. To assess whether participants adequately attended to their assigned healthcare plan, the researcher analyzed participants' responses to the manipulation check (i.e., the six True-or-False questions concerning the information presented in each participant's respective Healthcare Status Report). Using responses to that measure, the researcher created a scale of "healthcare plan knowledge" which consisted of participants' total score across all six items, with correct answers counting for 1, incorrect answers counting for -1 (i.e., penalty for guessing), and blank or "I don't know" answers counting for 0 . Thus, possible scores ranged from -6 (all wrong answers) to 6 (all correct answers).

Although there is a good deal of individual variability among respondents, as a group, participants did not demonstrate a strong understanding of their assigned healthcare plans $(M=2.54, M d n=4.00$, s.d. $=3.31)$. Table 2 depicts the frequency distribution for participants' healthcare plan knowledge. 
Table 2. Experiment 1 participants' healthcare plan knowledge scores

\begin{tabular}{|c|c|c|c|}
\hline Score & Frequency & Percentage & Cumulative Percentage \\
\hline-6 & 1 & .5 & .5 \\
\hline-5 & 0 & 0 & .5 \\
\hline-4 & 12 & 6.3 & 6.8 \\
\hline-3 & 5 & 2.6 & 9.4 \\
\hline-2 & 15 & 5.8 & 15.2 \\
\hline-1 & 7 & 3.7 & 18.8 \\
\hline 0 & 27 & 14.1 & 33.0 \\
\hline 1 & 4 & 2.1 & 35.1 \\
\hline 2 & 21 & 11.0 & 46.1 \\
\hline 3 & 3 & 1.6 & 47.6 \\
\hline 4 & 31 & 16.2 & 63.9 \\
\hline 5 & 9 & 4.7 & 68.6 \\
\hline 6 & 60 & 31.4 & 100.0 \\
\hline
\end{tabular}

To probe whether differences in participants' healthcare plan knowledge impacted their healthcare decisions, the researcher performed a median split to dichotomize participants' knowledge scores. Those who scored above the median were in the higher knowledge comparison group and those who scored below the median were in the lower knowledge group. Next, independent t-tests compared the two groups on their ratings of the likelihood that they would obtain a screening $(1=$ very unlikely, $9=$ very likely $)$ and 
their ratings of how much money they would be willing to spend on a screening ( $\$ 0$ to $\$ 1000$-or-more). Participants who scored below the median were more likely to choose the healthcare treatment $(M=.32, S . D .=1.94)$ as compared to those who scored above the median $(M=-.29$, S.D. $=2.37)(t(184.08)=1.94, p=.05) .{ }^{4}$ Similarly, participants who scored below the median were willing to spend more money $(M=1.20$, S.D. $=3.08)$ as compared to those who scored above the median $(M=-1.10, S . D .=2.65)(t(188)=$ $5.53, p<.01)$. To control for these differences, the researcher used healthcare plan knowledge with a median split as a blocking variable in the subsequent analyses.

Healthcare Decisions. The hypothetical healthcare decision yielded two measures of healthcare preferences, a measure of participants' likelihood to obtain a professional skin cancer screening and a measure of the amount of money participants would be willing to spend on a screening. Following Cohen and Cohen's (1983) recommendation for conducting regression analyses with mediation and to facilitate data analysis and interpretation, both dependent variables were centered around their respective means (simply by subtracting the mean of each measure from participants' scores on that measure).

Likelihood to obtain screening. A linear regression analysis including decision frame (Gain vs. Loss), plan type (HSA vs. Defined Benefit), healthcare plan knowledge (Above Median vs. Below Median), and chronic regulatory focus (Promotion and Prevention) tested the effects of the manipulated and measured factors on participants'

\footnotetext{
${ }^{4}$ Because the data failed the test for assuming equal variances, $F=8.58, p<.01$, the reported t-test does not assume equal variances.
} 
likelihood to obtain a skin cancer screening (LO). ${ }^{5}$ To assess the hypotheses for Experiment 1, the regression model included the main effects and two-way interactions among the manipulated factors, as well as the main effects of chronic promotion focus and chronic prevention focus, and the two-way interactions of those two covariates with the manipulated factors. The full model was significant, $F(14,163)=2.20, p=.01, R=$ $.40, R s q r=.16$, showing a satisfactory fit to the data. Table 3 displays the results of the regression analysis, and Table 4 displays the Means and Standard Deviations of the significant interaction.

The regression produced significant main effects for participants' chronic promotion focus, $\beta=.42, p<.05$, such that promotion focus contributed positively to participants' likelihood to obtain a screening. There was also a main effect for participants' chronic prevention focus, $\beta=-.35, p=.05$, such that prevention focus contributed negatively to participants' likelihood to obtain a screening. The main effect for decision frame (Gain vs. Loss) approached significance, $\beta=-.23, p=.08$.

The regression also produced a significant two-way interaction on LO for decision frame $\mathrm{x}$ plan type, $\beta=.34, p<.01$. As seen in Table 4 , applying the LSD posthoc test procedure to compare means revealed that among participants who received hypothetical HSAs, those who received gain-framed information $(M=-.67)$ were significantly less likely to obtain a screening than those who received loss-framed information $(M=.54)$. These results showed a framing effect among participants with HSAs but not with HIPs.

\footnotetext{
${ }^{5}$ Decision frame, plan type and healthcare plan knowledge were dummy-coded as follows: $0=$ Loss Frame, 1 = Gain Frame; 0 = HSA, 1 = Defined Benefit Plan; 0 = Low Knowledge, 1 = High Knowledge.
} 
Table 3. Results of regression analyses on likelihood to obtain a cancer screening

\begin{tabular}{|c|c|c|c|}
\hline Source & $d f$ & $t$ & $B$ \\
\hline Error & 163 & ----- & ----- \\
\hline Decision Frame & 1 & -1.76 & -.23 \\
\hline Plan Type & 1 & -.72 & -.10 \\
\hline Healthcare Plan Knowledge & 1 & -.73 & -.09 \\
\hline Promotion Focus & 1 & $2.23 *$ & .42 \\
\hline Prevention Focus & 1 & -1.97 & -.35 \\
\hline Decision Frame x Plan Type & 1 & $2.69 * *$ & .34 \\
\hline $\begin{array}{l}\text { Decision Frame } \mathrm{x} \\
\text { Healthcare Plan Knowledge }\end{array}$ & 1 & -.58 & -.08 \\
\hline $\begin{array}{l}\text { Decision Frame } \mathrm{x} \\
\text { Promotion }\end{array}$ & 1 & -.52 & -.06 \\
\hline $\begin{array}{l}\text { Decision Frame } \mathrm{x} \\
\text { Prevention }\end{array}$ & 1 & -.05 & -.01 \\
\hline $\begin{array}{l}\text { Plan Type } x \text { Healthcare } \\
\text { Knowledge }\end{array}$ & 1 & -.67 & -.09 \\
\hline Plan Type x Promotion & 1 & .18 & .02 \\
\hline Plan Type x Prevention & 1 & .39 & .05 \\
\hline $\begin{array}{l}\text { Healthcare Plan Knowledge } \\
\text { x Promotion }\end{array}$ & 1 & $-2.13 *$ & -.27 \\
\hline $\begin{array}{l}\text { Healthcare Plan Knowledge } \\
\text { x Prevention }\end{array}$ & 1 & $3.33 * *$ & .35 \\
\hline
\end{tabular}


Table 4. Means and standard error for significant effects on likelihood to obtain a skin cancer screening

\begin{tabular}{|c|c|c|}
\hline Source & $M$ & Std. Error \\
\hline Decision Frame x Plan Type: & & \\
\hline Gain & & \\
HSA & $-.67_{\mathrm{a}}$ & .32 \\
HIP & .43 & .32 \\
Loss & $.54_{\mathrm{b}}$ & .32 \\
HSA & -.09 & .32 \\
HIP & & \\
\hline
\end{tabular}

Means with different subscripts are significantly different from each other $(\mathrm{p} \leq .01)$.

There were also significant two-way interactions of healthcare plan knowledge $\mathrm{x}$ promotion, $\beta=-.27, p<.05$, and healthcare plan knowledge $\mathrm{x}$ prevention, $\beta=.35, p<$ .01. Among participants with lower healthcare knowledge, promotion focus contributed positively to participants' likelihood to obtain a screening $(\beta=.46, p<.05)$, whereas prevention focus did not significantly impact participants' likelihood to obtain a screening $(\beta=-.31, p=.18)$. Among participants with higher healthcare knowledge, neither promotion focus $(\beta=.06, p=.73)$ nor prevention focus $(\beta=.04, p=.86)$ significantly impact participants' likelihood to obtain a screening.

Money spent on screening. Turning to the second measure of participants' healthcare preferences, the amount of money participants would be willing to spend on a screening (MS) (\$0 to \$1000-or-more), an identical linear regression analysis including 
decision frame (Gain vs. Loss), plan type (HSA vs. Defined Benefit), healthcare plan knowledge (Above Median vs. Below Median), and chronic regulatory focus (Promotion and Prevention) tested the effects of the two manipulated and three measured factors on the amount of money people were willing to spend for a screening. ${ }^{6}$ The full model was significant, $F(14,164)=4.15, p<.01, R=.51, R s q r=.26$, showing a satisfactory fit to the data. Table 5 displays the results. Table 6 displays the means and standard deviations of the significant main effects and interactions.

The regression produced a significant main effect for participants' healthcare plan knowledge, $\beta=-.32, p<.01$, such that participants with a high degree of knowledge $(M=$ -.96) would spend less money on a screening than participants with a low degree of knowledge $(M=1.06)$. The regression also produced a significant main effect for participants' chronic prevention focus, $\beta=-.51, p<.01$, such that prevention focus contributed negatively to participants' willingness to spend money on a screening.

There was also a significant two-way interaction of decision frame $\mathrm{x}$ plan type, $\beta$ $=.27, p<.05$. As seen in Table 6 , applying the LSD post-hoc test procedure to compare means revealed that among participants who received hypothetical HSAs, those receiving gain-framed skin cancer brochures $(M=-.49)$ would spend less money to obtain a screening than those receiving loss-framed skin cancer brochures $(M=.43)$. In contrast, among participants who received hypothetical insurance plans, those receiving gainframed skin cancer brochures $(M=.63)$ would spend more money to obtain a screening than those receiving loss-framed skin cancer brochures $(M=-.41)$. Thus, the analyses

\footnotetext{
${ }^{6}$ Decision frame, plan type and healthcare plan knowledge were dummy-coded as follows: $0=$ Loss Frame, $1=$ Gain Frame; $0=$ HSA, $1=$ Defined Benefit Plan; $0=$ Low Knowledge, $1=$ High Knowledge.
} 
showed framing effects in both the HSA and the HIP conditions, but supported a loss aversion effect in the HSA condition and a gain value effect in the HIP condition.

Table 5. Results of regression analyses on amount of money willing to spend

\begin{tabular}{|c|c|c|c|}
\hline Source & $d f$ & $t$ & $B$ \\
\hline Error & 164 & ----- & $---\cdot$ \\
\hline Decision Frame & 1 & -1.10 & -.14 \\
\hline Plan Type & 1 & -1.05 & -.13 \\
\hline Healthcare Plan Knowledge & 1 & $-2.65 * *$ & -.32 \\
\hline Promotion Focus & 1 & -.57 & -.10 \\
\hline Prevention Focus & 1 & $-3.06 * *$ & -.51 \\
\hline Decision Frame x Plan Type & 1 & $2.24^{*}$ & .27 \\
\hline $\begin{array}{l}\text { Decision Frame x Healthcare Plan } \\
\text { Knowledge }\end{array}$ & 1 & -.10 & -.01 \\
\hline Decision Frame $\mathrm{x}$ Promotion & 1 & .25 & .03 \\
\hline Decision Frame $\mathrm{x}$ Prevention & 1 & .77 & .08 \\
\hline Plan Type x Healthcare Plan Knowledge & 1 & -.10 & -.01 \\
\hline Plan Type x Promotion & 1 & .05 & .01 \\
\hline Plan Type x Prevention & 1 & 1.65 & .18 \\
\hline Healthcare Plan Knowledge x Promotion & 1 & .03 & .00 \\
\hline Healthcare Plan Knowledge x Prevention & 1 & 1.35 & .13 \\
\hline
\end{tabular}


Table 6. Means and standard error for significant effects on amount of money willing to spend for skin cancer screening

\begin{tabular}{|c|c|c|}
\hline Source & $M$ & Std. Error \\
Healthcare Plan Knowledge: & -.96 & .30 \\
How & 1.06 & .31 \\
Decision Frame x Plan Type: & \\
Gain & $-.49_{\mathrm{b}}$ & .42 \\
HSA & $.63_{\mathrm{a}}$ & .43 \\
HIP & & \\
Loss & $.43_{\mathrm{a}}$ & .42 \\
HSA & $-.41_{\mathrm{b}}$ & .42 \\
HIP & & \\
\hline
\end{tabular}

Means with different subscripts are significantly different from each other $(\mathrm{p} \leq .05)$.

\section{Discussion}

Experiment 1 predictions were that after receiving loss-framed decision tasks, more decision makers should report intentions to obtain "risky" detection oriented medical services, such as professional skin cancer screening, and report higher willingness to pay for such services (Hypothesis 1 ). While not necessarily supporting that hypothesis, the investigation into individuals' likelihood to obtain a skin cancer screening and the amount of money they would be willing to spend on such a screening produced several interesting results. 
First, knowledge about one's healthcare plan was a significant factor. Individuals with a high degree of knowledge about their plan indicated that they would be less likely to obtain a skin cancer screening and that they would spend less money on a skin cancer screening than would individuals with a low degree of knowledge.

Second, individuals' chronic regulatory focus was a consistently influential factor. Chronic promotion focus increased the likelihood that individuals would obtain a skin cancer screening, particularly among individuals with limited knowledge about their healthcare plans. Conversely, chronic prevention focus decreased the likelihood that individuals would obtain a screening and also decreased the amount of money individuals would be willing to spend money on a screening.

Perhaps most interesting were the results concerning the individuals' type of healthcare plan (HSA or insurance) and the framing of the healthcare decision (Gain or Loss). Among individuals who received hypothetical HSAs, receiving loss-framed skin cancer brochures increased the likelihood they would obtain a screening and increased the amount of money they were willing to pay to obtain a screening, as compared to receiving gain-framed brochures. This is evidence of a loss aversion effect as Prospect Theory would predict. Surprisingly, and in the opposite direction of the predictions, individuals with an HIP showed no framing effects for likelihood to obtain a screening. However, among participants who received HIPs, receiving gain-framed skin cancer brochures increased the amount of money individuals were willing to spend to obtain a screening, as compared to receiving loss-framed skin cancer brochures. 


\section{Chapter 6: Experiment 2}

\section{Overview}

Experiment 2 replicated the procedures in Experiment 1, except participants completed a prevention-oriented decision task. As in Experiment 1, after providing informed consent, participants completed the Regulatory Focus Questionnaire, read General Instructions for completing the experiment and read one of two descriptions of a healthcare plan (either an HSA or a defined-benefit plan). Unlike Experiment 1, the decision task was whether to obtain an immunization injection for a hypothetical disease (i.e., the "Hercytus Virus"). The experiment was a 2 (benefit plan: HSA v. DefinedBenefit) x 2 (framing: gain v. loss) completely crossed between-groups design, with all participants completing the RFQ.

\section{Methodology \& Research Design}

The research team recruited participants through the Study Response Project. As in Experiment 1, participants visited an online website, where the program randomly assigned them to one of four experimental conditions. After reading and agreeing to the informed consent statement, participants completed the RFQ, General Instructions, read one of two Benefit Plan Reports and completed manipulation and mediation check measures.

Participants. 233 participants responded to the recruitment message and accessed the Experiment website. As in Experiment 1, any participants who repeatedly accessed the experimental materials of any of the three experiments (i.e., any material beyond the informed consent form) or who did not complete the primary dependent variables (appearing at the end of the Experiment) were excluded from analysis. 
After these exclusions, 189 participants (110 male; 76 female; 3 not reporting) aged 25 to 77 years $(M=40.64$, s.d. $=10.69)$ completed Experiment 2 . Table 7 depicts participants' demographic characteristics. The vast majority of participants was Caucasian $(n=161)$ and spoke English as their primary language $(n=183)$, and completed High School $(n=181)$. In the previous 12 months, 6 participants worked in the field of insurance or finance, 13 worked in the field of healthcare, and 7 worked in a field involving both insurance/finance and healthcare. ${ }^{7}$

\footnotetext{
${ }^{7}$ Removing these participants from the analyses did not produce any differences concerning participants' Likelihood to Obtain an immunization injection. However, removing the participants caused the full model for participants' willingness to spend money on an injection to become non-significant, $F(9,150)=1.27, p$ $=.23, R=.34, R s q r=.12$, and eliminated most other significant effects, leaving only the chronic promotion main effect and the chronic promotion by healthcare plan knowledge interaction.
} 
Table 7. Experiment 2 participants' demographic characteristics

\begin{tabular}{|c|c|c|}
\hline Characteristic & Frequency & Percentage \\
\hline \multicolumn{3}{|l|}{ Gender } \\
\hline Male & 110 & 58.2 \\
\hline Female & 76 & 40.2 \\
\hline Not Reporting & 3 & 1.6 \\
\hline \multicolumn{3}{|l|}{$\underline{\text { Age }}$} \\
\hline $25-30$ & 34 & 18.0 \\
\hline $31-40$ & 86 & 45.1 \\
\hline $41-50$ & 32 & 16.8 \\
\hline $51-60$ & 25 & 11.2 \\
\hline Over 60 & 11 & 5.7 \\
\hline Not Reporting & 2 & 1.1 \\
\hline \multicolumn{3}{|l|}{$\underline{\text { Race/Ethnicity }}$} \\
\hline Caucasian American & 161 & 85.2 \\
\hline Hispanic/Latin American & 8 & 4.3 \\
\hline Asian American & 6 & 3.2 \\
\hline African American & 9 & 4.8 \\
\hline Other & 4 & 2.2 \\
\hline Not Reporting & 1 & .5 \\
\hline
\end{tabular}




\begin{tabular}{|c|c|c|}
\hline$\underline{\text { Highest Level of Education }}$ & & \\
\hline Less than High School & 3 & 1.6 \\
\hline High School & 32 & 16.9 \\
\hline Associate's Degree & 19 & 10.1 \\
\hline Bachelor's Degree & 87 & 46.0 \\
\hline Master's Degree & 36 & 19.0 \\
\hline Professional Degree & 7 & 3.7 \\
\hline Not Reporting & 5 & 2.6 \\
\hline \multicolumn{3}{|l|}{$\underline{\text { Annual Income }}$} \\
\hline Less than $\$ 20,001$ & 12 & 5.3 \\
\hline$\$ 20,001-\$ 40,000$ & 21 & 11.1 \\
\hline$\$ 40,001-\$ 60,000$ & 34 & 18.0 \\
\hline$\$ 60,001-\$ 80,000$ & 33 & 17.5 \\
\hline$\$ 80,001-\$ 100,000$ & 50 & 26.5 \\
\hline$\$ 100,001$ or more & 36 & 19.0 \\
\hline Not Reporting & 3 & 1.6 \\
\hline \multicolumn{3}{|l|}{$\underline{\text { Marital Status }}$} \\
\hline Single/Widowed & 32 & 17.0 \\
\hline Married & 139 & 73.5 \\
\hline Divorced/Separated & 15 & 8.0 \\
\hline Not Reporting & 3 & 1.6 \\
\hline
\end{tabular}




\begin{tabular}{|l|c|c|}
\hline Type of HC coverage & & \\
No Healthcare Plan & 16 & 8.5 \\
Personal DC Plan & 28 & 14.8 \\
Personal DB plan & 35 & 18.5 \\
Employer-based DC plan & 25 & 13.2 \\
Employer-based DB plan & 77 & 40.7 \\
Do not know & 8 & 4.2 \\
\hline
\end{tabular}

Materials \& Procedure. Experiment 2 examined a prevention-oriented health behavior that is covered by most healthcare plans, an immunization injection for a hypothetical disease (i.e., the "Hercytus Virus") which entailed flu-like symptoms. The symptoms were more serious and lasted longer than the typical flu. Participants received information concerning the "Hercytus Virus" and recommendations for immunization injection. Employing techniques similar to those in Experiment 1, the display of diseaseand immunization-related information resembled a brochure disseminated by the American Medical Association. It reported the incidence, etiology, and facts about the disease, provided information on consequences and warning signs of the disease, and ended with some recommendations for immunization. The website displayed a gainframed brochure to one-half of the participants (Appendix L) and a loss-framed brochure to the other half (Appendix M). The positively framed information emphasized benefits and positive aspects of immunization, whereas the negatively framed information 
described the same information, but emphasized losses and risks of failing to obtain an immunization.

Participants responded to the following questions (also presented in Appendix $\mathrm{N}$ ):

(1) Given what you have just learned about the Hercytus Virus and immunization, as well as what you know about your current healthcare plan, how likely are you to obtain an immunization injection? (1 very unlikely to 9 very likely) and (2) Given what you have just learned about the Hercytus Virus and immunization options, as well as what you know about your current healthcare plan, what is the highest cost that you are willing to pay for the immunization injection? A rating scale of eleven prices for the procedure, ranging from $\$ 0$ to $\$ 1000$, in intervals of $\$ 100$ followed the second question. Answers to these questions were the dependent variables for the Experiment 2 analyses. Participants completed the same demographics form and debriefing statement as in Experiment 1.

Experiment 2 yielded a measure of participants' intentions to obtain an immunization injection and a measure of participants' willingness to pay for the injection. Results from this experiment helped address Hypotheses 2, 4, and 5. Hypothesis 2 states that after receiving gain framed decision tasks, more decision makers would report intentions to obtain an immunization injection, and report higher willingness to pay for the immunization. Significant main effects for framing condition would confirm this hypothesis. Hypothesis 4 stated that decision makers who own HSAs should not exhibit gain-loss framing effects. A significant interaction between type of frame and type of plan showing stronger gain-loss effects in the traditional plan condition than in the HSA condition would confirm this hypothesis. Hypothesis 5 stated that decision makers who experience regulatory fit between their chronic orientations and the decision 
frame would more often report intentions to obtain medical services and would report higher willingness to pay for the services. Three way interactions between the covariates, framing, and type of plan tested this hypothesis.

\section{Results}

RFQ. Participants' chronic promotion focus consisted of their average scores on RFQ items 1 (reverse scored), 3, 7,9 (reverse scored), 10, and 11 (reverse scored) (Cronbach's alpha $=.56 ; \mathrm{M}=3.40 ;$ s.d. $=.60)$. Participants' chronic prevention focus consisted of their average scores on RFQ items 2 (reverse scored), 4 (reverse scored), 5, 6 (reverse scored), and 8 (reverse scored) (Cronbach's alpha $=.71 ; \mathrm{M}=3.19 ;$ s.d. $=.75$ ).

Healthcare Knowledge. As in Experiment 1, the researcher analyzed participants' responses to the manipulation check (i.e., the six True-or-False questions concerning the information presented in each participant's respective Healthcare Status Report) to assess whether participants adequately attended to their assigned healthcare plan. Using responses to that measure, the researcher created a scale of "healthcare plan knowledge" which consisted of participants' total score across all six items, with correct answers counting for 1 , incorrect answers counting for -1 (i.e., penalty for guessing), and blank or "I don't know" answers counting for 0 . Thus, possible scores ranged from -6 (all wrong answers) to 6 (all correct answers).

Like Experiment 1, there was a good deal of individual variability among respondents, but as a group, participants did not demonstrate a strong understanding of their assigned healthcare plans $(M=2.00, M d n=2.00, s . d .=3.42)$. Table 8 depicts the frequency distribution for participants' healthcare plan knowledge. 
Table 8. Experiment 2 participants' healthcare plan knowledge scores

\begin{tabular}{|c|c|c|c|}
\hline Score & Frequency & Percentage & $\begin{array}{l}\text { Cumulative } \\
\text { Percentage }\end{array}$ \\
\hline-6 & 3 & 1.6 & 1.6 \\
\hline-5 & 0 & 0 & 1.6 \\
\hline-4 & 11 & 5.8 & 7.4 \\
\hline-3 & 6 & 3.2 & 10.6 \\
\hline-2 & 21 & 11.1 & 21.7 \\
\hline-1 & 4 & 2.1 & 23.8 \\
\hline 0 & 29 & 15.3 & 39.2 \\
\hline 1 & 6 & 3.2 & 42.3 \\
\hline 2 & 17 & 9.0 & 51.3 \\
\hline 3 & 9 & 4.8 & 56.1 \\
\hline 4 & 27 & 14.3 & 70.4 \\
\hline 5 & 7 & 3.7 & 74.1 \\
\hline 6 & 49 & 25.9 & 100.0 \\
\hline
\end{tabular}

To probe whether differences in participants' healthcare plan knowledge influenced their healthcare decisions, the researcher performed a median split to dichotomize participants' knowledge scores. Those who scored above the median were in the higher knowledge comparison group and those who scored below the median were in the lower knowledge group. Next, an independent t-test compared the two groups on their 
ratings of the likelihood that they would obtain an immunization injection $(1=$ very unlikely, 9 = very likely). Results indicated that participants who scored below the median $(M=-.05, S . D .=2.04)$ were not significantly different from those who scored above the median $(M=.04$, S.D. $=2.58)(t(185.17)=-.26, p=.80) .{ }^{8}$ Because knowledge of health care plan was unrelated to LO, unlike in experiment 1, it was not included as covariate in the analyses that follow.

Healthcare Decisions. The hypothetical healthcare decision yielded two measures of healthcare preferences, a measure of participants' likelihood to obtain an immunization injection for the Hercytus Virus and a measure of the amount of money participants would be willing to spend on an immunization injection. Following Cohen and Cohen's (1983) recommendation for conducting regression analyses with mediation and to facilitate data analysis and interpretation, both dependent variables were centered around their respective means (simply by subtracting the mean of each measure from participants' scores on that measure).

Likelihood to obtain an injection. A linear regression analysis including decision frame (Gain vs. Loss), plan type (HSA vs. Defined Benefit), and chronic regulatory focus (Promotion and Prevention) tested the effects of the manipulated and measured factors on participants' likelihood to obtain an immunization injection (LO). ${ }^{9}$ To assess the hypotheses for Experiment 2, the regression model included the main effects and twoway interactions among the manipulated factors, as well as the main effects of chronic

\footnotetext{
${ }^{8}$ Because the data failed the test for assuming equal variances, $F=6.06, p<.05$, the reported t-test does not assume equal variances.

${ }^{9}$ Decision frame and plan type were dummy-coded as follows: $0=$ Loss Frame, $1=$ Gain Frame; $0=$ HSA, $1=$ Defined Benefit Plan.
} 
promotion focus and chronic prevention focus, and the two-way interactions of those two covariates with the manipulated factors.

Unfortunately, the full model was not significant, $F(9,167)=.94, p=.49, R=$ $.22, R s q r=.05$, showing a poor fit to the data, and none of the factors or the interactions were statistically significant. Table 9 depicts the results. Several possibilities (discussed further below) might help explain the absence of any significant effects, such as use of a fictional malady, non-use of cancer, nature of a prevention procedure, or non-inclusion of healthcare plan knowledge as a covariate.

Table 9. Results of regression analysis on likelihood to obtain immunization injection

\begin{tabular}{|l|c|c|c|}
\hline \multicolumn{1}{|c|}{ Source } & $d f$ & $t$ & $B$ \\
\hline Error & 167 & ----- & ---- \\
Decision Frame & 1 & -1.15 & -.12 \\
Plan Type & 1 & -.1 .33 & -.15 \\
Promotion Focus & 1 & 1.65 & -.22 \\
Prevention Focus & 1 & -.19 & -.03 \\
Decision Frame x Plan Type & 1 & 1.02 & .14 \\
Decision Frame x Promotion & 1 & -.35 & -.04 \\
Decision Frame x Prevention & 1 & -.76 & -.09 \\
Plan Type x Promotion & 1 & -.62 & -.07 \\
Plan Type x Prevention & 1 & -.49 & -.05 \\
\hline
\end{tabular}


Money spent on injection. Turning to the second measure of participants' healthcare preferences, the amount of money participants would be willing to spend on an immunization injection (MS) (\$0 to $\$ 1000$-or-more), the researcher again probed whether differences in participants' healthcare plan knowledge influenced their healthcare decision by performing a median split to dichotomize participants' knowledge scores. As in the earlier analyses, those who scored above the median were in the higher knowledge comparison group and those who scored below the median were in the lower knowledge group. An independent t-test compared the two groups on their ratings of amount of money they would be willing to spend on an immunization injection $(1=$ very unlikely, 9 $=$ very likely). Participants who scored below the median were willing to spend more money $(M=1.02, S . D .=3.55)$ as compared to those who scored above the median $(M=-$ .75$, S.D. $=2.99)(t(152.48)=3.61, p<.01) .{ }^{10}$ To control for this difference, the researcher used healthcare plan knowledge with a median split as a blocking variable in the subsequent analyses.

A linear regression analysis including decision frame (Gain vs. Loss), plan type (HSA vs. Defined Benefit), healthcare plan knowledge (Above Median vs. Below Median), and chronic regulatory focus (Promotion and Prevention) tested the effects of the manipulated and measured factors on the amount of money people were willing to spend for an immunization injection (LO). ${ }^{11}$ The full model was significant, $F(14,163)=$ $3.34, p<.01, R=.47, R s q r=.22$, showing a satisfactory fit to the data. Table 10 depicts the results.

\footnotetext{
${ }^{10}$ Because the data failed the test for assuming equal variances, $F=7.28, p<.01$, the reported t-test does not assume equal variances.

${ }^{11}$ Decision frame, plan type and healthcare plan knowledge were dummy-coded as follows: $0=$ Loss Frame, 1 = Gain Frame; 0 = HSA, 1 = Defined Benefit Plan; $0=$ Low Knowledge, 1 = High Knowledge.
} 
Table 10. Results of regression analyses on amount of money willing to spend on immunization injection

\begin{tabular}{|c|c|c|c|}
\hline Source & $d f$ & $t$ & $B$ \\
\hline Error & 163 & ----- & ----- \\
\hline Decision Frame & 1 & -.39 & -.05 \\
\hline Plan Type & 1 & -.25 & -.03 \\
\hline Healthcare Plan Knowledge & 1 & $-2.44 *$ & -.30 \\
\hline Promotion Focus & 1 & $2.86 * *$ & .53 \\
\hline Prevention Focus & 1 & $-2.68 * *$ & -.44 \\
\hline Decision Frame x Plan Type & 1 & -.01 & -.00 \\
\hline $\begin{array}{l}\text { Decision Frame x Healthcare } \\
\text { Plan Knowledge }\end{array}$ & 1 & -.47 & -.06 \\
\hline Decision Frame $\mathrm{x}$ Promotion & 1 & -.43 & -.04 \\
\hline Decision Frame $\mathrm{x}$ Prevention & 1 & .28 & .03 \\
\hline $\begin{array}{l}\text { Plan Type x Healthcare Plan } \\
\text { Knowledge }\end{array}$ & 1 & .80 & .11 \\
\hline Plan Type $\mathrm{x}$ Promotion & 1 & -1.24 & -.13 \\
\hline Plan Type $\mathrm{x}$ Prevention & 1 & -1.41 & -.14 \\
\hline $\begin{array}{l}\text { Healthcare Plan Knowledge } \\
\text { x Promotion }\end{array}$ & 1 & $-3.30 * *$ & -.49 \\
\hline $\begin{array}{l}\text { Healthcare Plan Knowledge } \\
\text { x Prevention }\end{array}$ & 1 & $2.52 *$ & .30 \\
\hline
\end{tabular}


The regression produced a significant main effect for participants' healthcare plan knowledge, $\beta(14,163)=-.30, p<.05$, such that participants with a high degree of knowledge $(M=-.62)$ would spend less money than participants with a low degree of knowledge $(M=1.31)$. The regression also produced significant main effects for participants' chronic promotion focus, $\beta(14,163)=.53, p<.01$, such that promotion focus contributed positively to participants' willingness to spend money, as well as for participants' chronic prevention focus, $\beta(14,163)=-.44, p<.01$, such that prevention focus contributed negatively to participants' willingness to spend money.

There were also significant two-way interactions of healthcare plan knowledge $\mathrm{x}$ promotion, $\beta(14,163)=-.49, p<.01$, and healthcare plan knowledge $\mathrm{x}$ prevention, $\beta(14,163)=.30, p<.05$. Among participants with lower healthcare knowledge, promotion focus contributed positively to participants' willingness to spend money $(\beta=$ $.52, p<.05)$, whereas prevention focus did not significantly impact participants' willingness to spend money $(\beta=-.37, p=.12)$. Among participants with higher healthcare knowledge, neither promotion focus $(\beta=-.12, p=.46)$ nor prevention focus $(\beta$ $=-.14, p=.41)$ significantly impact participants' willingness to spend money.

\section{Discussion}

In developing this experiment, the researcher predicted that after receiving gain framed decision tasks, more decision makers should report intentions to obtain prevention services, such as an immunization injection, and report higher willingness to pay for such services (Hypothesis 2). Unfortunately, Experiment 2 yielded no effects for the likelihood to obtain prevention services. None of the hypothesized factors, or their interactions, 
significantly influenced the likelihood that individuals would obtain an immunization injection for the hypothetical Hercytus Virus.

As noted above, the reason for the absence of any significant effects is unclear, but several possibilities might help explain the results. Unlike the other two experiments, Experiment 2 involves a fictional malady (i.e., hypothetical Hercytus virus) rather than a real-world malady (e.g., skin cancer or lung cancer). Also, this is the only experiment which does not involve cancer of some kind. Thirdly, Experiment 2 is the only experiment which involves a prevention procedure (vice detection or treatment procedures). Finally, because the independent t-test did not yield a significant difference, knowledge of health care plan was not included as covariate in the analyses. All of these factors distinguish Experiment 2 from the other Experiments in this project and might contribute to the absence of any significant effects concerning participants likelihood to obtain an immunization injection for the hypothetical Hercytus virus.

However, in terms of the amount of money individuals would spend on an immunization injection, there were some interesting effects. First, individuals with a high degree of knowledge about their healthcare plan would spend less money than participants with a low degree of knowledge were willing to spend. This is a consistent finding across all three experiments in this investigation.

Moreover, there is an interesting pattern of results involving regulatory focus and knowledge of health care plans. First, a chronic promotion focus enhanced the amount of money participants would spend on an injection. However, the interaction between promotion focus and healthcare plan knowledge qualified this effect. Among participants with limited knowledge about their healthcare plan, chronic promotion focus increased 
the amount of money that they were willing to spend. In contrast, chronic prevention focus decreased the amount of money participants would spend on an injection regardless of their level of knowledge.

This pattern of results suggests that little knowledge of healthcare plans increases people's willingness to spend dollars for healthcare services. This tendency is offset with increased knowledge about the workings of healthcare plans. However, the inoculation effect of increased knowledge is limited by regulatory focus. The effect of increased knowledge may only be effective for people chronically high in promotion focus.

\section{Chapter 7: Experiment 3}

\section{Overview}

Experiment 3 was a conceptual replication of Experiments 1 and 2, following the same procedures except participants completed a treatment-oriented decision task. After providing informed consent, participants completed a Regulatory Focus Questionnaire, read General Instructions for completing the experiment and read one of two descriptions of a healthcare plan (either an HSA or a defined-benefit plan). However, in Experiment 3 the decision task was similar to the one in McNeil et al. (1982), who investigated how variations in the presentation of risk can influence patients' choices between treatment options. Participants read a description of a healthcare decision task, which concerned lung cancer and provided two healthcare options (i.e., surgery and radiation). Modeled after McNeil et al (1982), the website instructed participants to imagine that their doctor diagnosed them with lung cancer and that they must decide on a course of treatment. The experiment was a 2 (benefit plan: HSA v. Defined-Benefit) x 2 (framing: gain v. loss) completely crossed between-groups design, with all participants completing the RFQ. 


\section{Methodology \& Research Design}

As in Experiments 1 and 2, the research team recruited participants through the Study Response Project. These participants visited an online website, at which time the program randomly assigned them to one of four experimental conditions. Participants completed the same informed consent statement, RFQ, General Instructions, and then, one of two Benefit Plan Reports, and finally the manipulation check and mediation measures, as in the previous experiments.

Participants. 233 participants responded to the recruitment message and accessed the Experiment website. As in the other two Experiments, any participants who repeatedly accessed the experimental materials of any of the three Experiments (i.e., any material beyond the informed consent form) or who did not complete the primary dependent variables (appearing at the end of the Experiment) were excluded from analysis.

After these exclusions, 184 participants (95 male; 86 female; 3 not reporting) aged 27 to 85 years $(M=43.24$, s.d. $=12.653)$ completed Experiment 3 . The majority of participants was Caucasian $(n=145)$, spoke English as their primary language $(n=170)$, and completed High School. $(n=177)$. Table 11 depicts participants' demographic characteristics. In the previous 12 months, 2 participants worked in the field of insurance or finance, 9 worked in the field of healthcare, and 5 worked in a field involving both insurance/finance and healthcare. ${ }^{12}$

\footnotetext{
${ }^{12}$ Removing these participants did not impact results concerning participants' Choice of Treatment or participants' willingness to spend money on the unselected treatment (though, for the latter variable, both the full model and the decision frame factor approached significance). However, concerning money participants were willing to spend on their selected treatment, after removing participants the t-test comparing high-knowledge and low-knowledge participants only approached significance, $p=.08$, and chronic prevention focus was no longer a significant main effect.
} 
Table 11. Experiment 3 participants' demographic characteristics

\begin{tabular}{|c|c|c|}
\hline Characteristic & Frequency & Percentage \\
\hline \multicolumn{3}{|l|}{ Gender } \\
\hline Male & 95 & 51.6 \\
\hline Female & 86 & 46.7 \\
\hline Not Reporting & 3 & 1.6 \\
\hline \multicolumn{3}{|l|}{$\underline{\text { Age }}$} \\
\hline $27-30$ & 22 & 11.9 \\
\hline $31-40$ & 75 & 40.9 \\
\hline $41-50$ & 37 & 20.2 \\
\hline $51-60$ & 26 & 14.0 \\
\hline $61-70$ & 14 & 7.4 \\
\hline Over 70 & 6 & 3.1 \\
\hline Not Reporting & 4 & 2.2 \\
\hline \multicolumn{3}{|l|}{$\underline{\text { Race/Ethnicity }}$} \\
\hline Caucasian American & 145 & 78.8 \\
\hline Hispanic/Latin American & 8 & 4.3 \\
\hline Asian American & 8 & 4.3 \\
\hline African American & 11 & 6.0 \\
\hline Other & 8 & 4.3 \\
\hline Not Reporting & 4 & 2.2 \\
\hline
\end{tabular}




\begin{tabular}{|c|c|c|}
\hline \multicolumn{3}{|l|}{ Highest Level of Education } \\
\hline Less than High School & 1 & .5 \\
\hline High School & 27 & 14.7 \\
\hline Associate's Degree & 22 & 12.0 \\
\hline Bachelor's Degree & 79 & 42.9 \\
\hline Master's Degree & 41 & 22.3 \\
\hline $\begin{array}{l}\text { Professional Degree } \\
\text { (Ph.D., M.D., Law) }\end{array}$ & 8 & 4.3 \\
\hline Not Reporting & 6 & 3.3 \\
\hline \multicolumn{3}{|l|}{ Annual Income } \\
\hline Less than $\$ 20,001$ & 20 & 10.9 \\
\hline$\$ 20,001-\$ 40,000$ & 23 & 12.5 \\
\hline$\$ 40,001-\$ 60,000$ & 21 & 11.4 \\
\hline$\$ 60,001-\$ 80,000$ & 41 & 22.3 \\
\hline$\$ 80,001-\$ 100,000$ & 39 & 21.2 \\
\hline$\$ 100,001$ or more & 35 & 19.0 \\
\hline Not Reporting & 5 & 2.7 \\
\hline \multicolumn{3}{|l|}{ Marital Status } \\
\hline Single/Widowed & 33 & 17.9 \\
\hline Married & 131 & 71.2 \\
\hline Divorced/Separated & 15 & 8.2 \\
\hline Not Reporting & 5 & 2.7 \\
\hline
\end{tabular}




\begin{tabular}{|l|c|c|}
\hline Type of HC coverage & & \\
\hline No Healthcare Plan & 14 & 7.6 \\
Personal DC Plan & 25 & 13.6 \\
Personal DB plan & 42 & 22.8 \\
Employer-based DC plan & 21 & 11.4 \\
Employer-based DB plan & 72 & 39.1 \\
Do not know & 7 & 3.8 \\
Not Reporting & 3 & 1.6 \\
\hline
\end{tabular}

Materials \& Procedure. Participants in Experiment 3 imagined that their doctors diagnosed them with lung cancer and would have to choose a type of treatment, either surgery or radiation. McNeil and colleagues (1982) presented participants with the short-term and long-term consequences of both treatments, either with a gain-framed presentation (survival rates) or with a loss-framed presentation (mortality rates).

Compared to the radiation treatment, the surgery treatment had better long-term survival rates (i.e., $34 \%$ compared to $22 \%$ for radiation) but also had higher risk of death in the short-term (i.e., $10 \%$ chance of postoperative death compared to $0 \%$ for radiation). The researchers then asked participants to choose a type of treatment. The results indicated that participants more frequently chose the riskier short-term option (surgery) when the researcher presented the treatment consequences as survival rates (gain frame).

The current experiment will replicated McNeil and colleagues' (1982) methods. The website asked participants to assume they had a confirmed diagnosis of lung cancer. 
Participants received either gain-framed data or loss-framed data summarizing the results of surgery and of radiation for treating lung cancer. The website presented participants with short-term and long-term consequences of both treatments. One-half of the participants received a gain-framed presentation (survival rates; Appendix O), and the other half received a loss-framed presentation (mortality rates; (Appendix P).

Participants then responded to three questions (Appendix Q). 1) Given what you have just learned about lung cancer and available treatments, as well as what you know about your current healthcare plan, will you choose surgery or radiation to treat your lung cancer? (surgery or radiation) 2) Given what you have just learned about lung cancer and available treatments, as well as what you know about your current healthcare plan, what is the highest cost that you are willing to pay for the treatment option you chose? 3) Given what you have just learned about lung cancer and available treatments, as well as what you know about your current healthcare plan, what is the highest cost that you are willing to pay for the treatment option you did not choose? These last two questions were followed by rating scales of eleven prices, ranging from $\$ 0$ to $\$ 500,000$, in intervals of $\$ 50,000$. Answers to these questions were the dependent variables for the Experiment 3 analyses. Participants also completed a demographics form and read a debriefing statement.

Experiment 3 produced a measure of participants' preferred treatment option and two measures of participants' willingness to pay (i.e., for surgery and for radiation). Results from this experiment will help address Hypotheses 3, 4, and 5. Hypothesis 3 states that after receiving gain framed decisions, more participants would report intentions to undergo surgery, and report higher willingness to pay for the treatment. 
Significant main effects on type of framing for both measures would confirm this hypothesis. Hypothesis 4 states that decision makers who own HSAs would not exhibit gain-loss framing effects. Significant interactions between type of framing and type of plan would confirm this hypothesis such that individuals in the HSA condition will not show gain-loss framing effects as compared to those in the traditional insurance conditions. Hypothesis 5 states that decision makers who experience regulatory fit between their chronic orientations and the decision frame would more often report intentions to obtain medical services and would report higher willingness to pay for the services. Three way interactions between the covariates, framing, and type of plan tested this hypothesis.

\section{Results}

RFQ. Participants' chronic promotion focus consisted of their average scores on RFQ items 1 (reverse scored), 3, 7, 9 (reverse scored), 10, and 11 (reverse scored) (Cronbach's alpha $=.55 ; \mathrm{M}=3.40 ;$ s.d. $=.60$ ). Participants' chronic prevention focus consisted of their average scores on RFQ items 2 (reverse scored), 4 (reverse scored), 5, 6 (reverse scored), and 8 (reverse scored) (Cronbach's alpha $=.72 ; \mathrm{M}=3.28 ;$ s.d. $=.74$ ).

Healthcare Knowledge. As in the previous two experiments, the researcher analyzed participants' responses to the manipulation check (i.e., the six True-or-False questions concerning the information presented in each participant's respective Healthcare Status Report) to assess whether participants adequately attended to their assigned healthcare plan. Using responses to that measure, the researcher created a scale of "healthcare plan knowledge" which consisted of participants' total score across all six items, with correct answers counting for 1 , incorrect answers counting for -1 (i.e., penalty 
for guessing), and blank or "I don't know" answers counting for 0 . Thus, possible scores ranged from -6 (all wrong answers) to 6 (all correct answers).

Like the earlier experiments, there was great individual variability among respondents, but as a group, participants did not demonstrate a strong understanding of their assigned healthcare plans $(M=2.70, M d n=4.00$, s. $d .=3.20)$. Table 12 depicts the frequency distribution for participants' healthcare plan knowledge.

Table 12. Experiment 3 participants' healthcare plan knowledge scores

\begin{tabular}{|c|c|c|c|}
\hline Score & Frequency & Percentage & Cumulative Percentage \\
\hline-6 & 1 & .5 & .5 \\
\hline-5 & 1 & .5 & 1.1 \\
\hline-4 & 11 & 6.0 & 7.1 \\
\hline-3 & 2 & 1.1 & 8.2 \\
\hline-2 & 10 & 5.4 & 13.7 \\
\hline-1 & 7 & 3.8 & 17.5 \\
\hline 0 & 18 & 9.8 & 27.3 \\
\hline 1 & 6 & 3.3 & 30.6 \\
\hline 2 & 21 & 11.4 & 42.1 \\
\hline 3 & 6 & 3.3 & 45.4 \\
\hline 4 & 36 & 19.6 & 65.0 \\
\hline 5 & 11 & 6.0 & 71.0 \\
\hline 6 & 53 & 28.8 & 100.0 \\
\hline
\end{tabular}


To probe whether differences in participants' healthcare plan knowledge influenced their healthcare decisions, the researcher again performed a median split to dichotomize participants' knowledge scores. Those who scored above the median were in the higher knowledge comparison group and those who scored below the median were in the lower knowledge group. Chi Square and independent t-tests compared the two groups on their ratings of the three dependent variables for Experiment 3 (i.e., choice of treatment: radiation or surgery; amount of money participants were willing to spend on their chosen treatment; and an exploratory measure: amount of money participants were willing to spend on the alternative treatment).

Regarding choice of treatment, results indicated that participants who scored below the median $(M=.01, S . D .=.48)$ were not significantly different from those who scored above the median $(M=-.01, S . D .=.47), \chi^{2}(1, N=178)=.07, p=.79$.

Conversely, for the second dependent variable (amount of money participants were willing to spend on their chosen treatment: $\$ 0$ to $\$ 500,000$-or-more), participants who scored below the median were willing to spend more money on their preferred healthcare treatment $(M=.62, S . D .=2.92)$ as compared to those who scored above the median $(M=-.50$, S.D. $=3.20)(t(179)=2.44, p<.05)$. Likewise, for the third, exploratory dependent variable (amount of money participants were willing to spend on the alternative treatment: $\$ 0$ to $\$ 500,000$-or-more), participants who scored below the median were willing to spend more money on the alternative treatment $(M=.62$, S.D. $=$ 3.16) as compared to those who scored above the median $(M=-.51, S . D .=3.38)(t(179)$ $=2.31, p<.05)$. To control for these differences in the latter two dependent variables, the 
researcher used healthcare plan knowledge with a median split as a blocking variable in the subsequent analyses concerning those variables.

Healthcare Decisions. The hypothetical healthcare decision yielded three measures of healthcare preferences: a measure of participants' preferred lung cancer treatment option (surgery or radiation), a measure of the amount of money participants would be willing to spend on their selected treatment, and an exploratory measure of the amount of money participants would be willing to spend on the treatment they did not choose. Following Cohen and Cohen's (1983) recommendation for conducting regression analyses with mediation and to facilitate data analysis and interpretation, the dependent variables were centered around their respective means (simply by subtracting the mean of each measure from participants' scores on that measure).

Choice of treatment. A logistic regression analysis including decision frame (Gain vs. Loss), plan type (HSA vs. Defined Benefit), and chronic regulatory focus (Promotion and Prevention) tested the effects of the manipulated and measured factors on participants' choice of lung cancer treatment. ${ }^{13}$ To assess the hypotheses for Experiment 3 , the regression model included the main effects and two-way interactions among the manipulated factors, as well as the main effects of chronic promotion focus and chronic prevention focus, and the two-way interactions of those two covariates with the manipulated factors.

Unfortunately, the full model was not significant, $\chi^{2}(9, N=161)=3.48, p=.94$, showing a poor fit to the data. Table 13 shows that none of the effects were significant.

\footnotetext{
${ }^{13}$ Decision frame and plan type were dummy-coded as follows: $0=$ Loss Frame, $1=$ Gain Frame; $0=$ HSA, 1 = Defined Benefit Plan.
} 
Participants' 2-to-1 preference for surgery treatment $(n=119)$ over radiation treatment ( $n$ =59) likely explains the lack of significant results.

Table 13. Results of logistic regression analysis on choice of lung cancer treatment

\begin{tabular}{|l|c|c|c|c|}
\hline \multicolumn{1}{|c|}{ Source } & $d f$ & $\operatorname{Exp}(B)$ & $B$ & S.E. \\
\hline Error & 9 & ----- & ----- & ----- \\
Decision Frame & 1 & .54 & -.62 & .51 \\
Plan Type & 1 & .54 & -.62 & .49 \\
Promotion Focus & 1 & 1.05 & .05 & .61 \\
Prevention Focus & 1 & 1.23 & .21 & .49 \\
Decision Frame x Plan Type & 1 & 2.28 & .82 & .70 \\
Decision Frame x Promotion & 1 & 1.46 & .38 & .65 \\
Decision Frame x Prevention & 1 & 1.03 & .03 & .54 \\
Plan Type x Promotion & 1 & .99 & -.02 & .65 \\
Plan Type x Prevention & 1 & .78 & -.25 & .54 \\
\hline * $p<$.05 & & & & \\
\hline
\end{tabular}


Money spent on the selected treatment. Turning to the second measure of participants' healthcare preferences, the amount of money participants would be willing to spend on their selected treatment (MS) (\$0 to $\$ 500,000$-or-more), a linear regression analysis including decision frame (Gain vs. Loss), plan type (HSA vs. Defined Benefit), healthcare plan knowledge (Above Median vs. Below Median), and chronic regulatory focus (Promotion and Prevention) tested the effects of the two manipulated and three measured factors on the amount of money people were willing to spend. ${ }^{14}$

The full model was significant, $F(14,149)=2.43, p<.01, R=.43, R s q r=.19$, showing a satisfactory fit to the data. Table 14 depicts the results for specific effects.

The regression produced a significant main effect for participants' healthcare plan knowledge, $\beta=-.31, p<.05$, such that participants with a low degree of knowledge $(M=$ .62) would spend more money on their preferred healthcare treatment than participants with a high degree of knowledge $(M=-.50)$. The regression produced a significant main effect for decision frame, $\beta=-.31, p<.05$, such that participants receiving loss-framed information $(M=.87)$ would spend more money on their preferred healthcare treatment than participants receiving gain-framed information $(M=-.27)$. The regression also produced significant main effects for promotion focus, $\beta=.43, p<.05$, such that promotion contributed positively to participants' willingness to spend money, as well as for prevention focus, $\beta=-.36, p<.05$, such that prevention focus contributed negatively to participants' willingness to spend money.

\footnotetext{
${ }^{14}$ Decision frame, plan type and healthcare plan knowledge were dummy-coded as follows: $0=$ Loss Frame, 1 = Gain Frame; 0 = HSA, 1 = Defined Benefit Plan; $0=$ Low Knowledge, $1=$ High Knowledge.
} 
Table 14. Results of regression analyses on amount of money willing to spend on selected lung cancer treatment

\begin{tabular}{|c|c|c|c|}
\hline Source & $d f$ & $t$ & $B$ \\
\hline Error & 149 & ----- & ----- \\
\hline Decision Frame & 1 & $-2.11 *$ & -.31 \\
\hline Plan Type & 1 & -1.08 & -.15 \\
\hline Healthcare Plan Knowledge & 1 & $-2.26 *$ & -.31 \\
\hline Promotion Focus & 1 & $2.05^{*}$ & .43 \\
\hline Prevention Focus & 1 & $-2.02 *$ & -.36 \\
\hline Decision Frame x Plan Type & 1 & .49 & .07 \\
\hline $\begin{array}{l}\text { Decision Frame x Healthcare Plan } \\
\text { Knowledge }\end{array}$ & 1 & 1.06 & .15 \\
\hline Decision Frame $\mathrm{x}$ Promotion & 1 & -1.21 & -.15 \\
\hline Decision Frame $\mathrm{x}$ Prevention & 1 & 1.36 & .16 \\
\hline Plan Type x Healthcare Knowledge & 1 & 1.69 & .23 \\
\hline Plan Type x Promotion & 1 & -1.24 & -.14 \\
\hline Plan Type $\mathrm{x}$ Prevention & 1 & -1.25 & -.15 \\
\hline $\begin{array}{l}\text { Healthcare Plan Knowledge } \mathrm{x} \\
\text { Promotion }\end{array}$ & 1 & -.78 & -.11 \\
\hline $\begin{array}{l}\text { Healthcare Plan Knowledge x } \\
\text { Prevention }\end{array}$ & 1 & .34 & .04 \\
\hline
\end{tabular}


Money spent on unselected treatment. Finally, turning to the third, exploratory measure of participants' healthcare preferences, the amount of money participants would be willing to spend on the treatment they did not select, a linear regression analysis including decision frame (Gain vs. Loss), plan type (HSA vs. Defined Benefit), healthcare plan knowledge (Above Median vs. Below Median), and chronic regulatory focus (Promotion and Prevention) tested the effects of the two manipulated and three measured factors on the amount of money people were willing to spend. ${ }^{15}$ The full model was not significant, $F(14,149)=1.56, p=.10, R=.36, R s q r=.13$, showing a poor fit to the data. Table 15 shows that none of the effects were significant.

\footnotetext{
${ }^{15}$ Decision frame, plan type and healthcare plan knowledge were dummy-coded as follows: $0=$ Loss Frame, 1 = Gain Frame; 0 = HSA, 1 = Defined Benefit Plan; $0=$ Low Knowledge, 1 = High Knowledge .
} 
Table 15. Results of regression analyses on amount of money willing to spend on unselected treatment

\begin{tabular}{|c|c|c|c|}
\hline Source & $d f$ & $t$ & $B$ \\
\hline Error & 149 & ----- & ----- \\
\hline Decision Frame & 1 & -1.24 & -.19 \\
\hline Plan Type & 1 & -.73 & -.11 \\
\hline Healthcare Plan Knowledge & 1 & -1.17 & -.17 \\
\hline Promotion Focus & 1 & 1.33 & .29 \\
\hline Prevention Focus & 1 & -1.26 & -.23 \\
\hline Decision Frame x Plan Type & 1 & .93 & .13 \\
\hline $\begin{array}{l}\text { Decision Frame x Healthcare } \\
\text { Plan Knowledge }\end{array}$ & 1 & -.18 & -.03 \\
\hline Decision Frame $\mathrm{x}$ Promotion & 1 & -.89 & -.12 \\
\hline Decision Frame $\mathrm{x}$ Prevention & 1 & 1.07 & .13 \\
\hline $\begin{array}{l}\text { Plan Type x Healthcare } \\
\text { Knowledge }\end{array}$ & 1 & .62 & .09 \\
\hline Plan Type x Promotion & 1 & -.29 & -.03 \\
\hline Plan Type x Prevention & 1 & -1.05 & -.13 \\
\hline $\begin{array}{l}\text { Healthcare Plan Knowledge } x \\
\text { Promotion }\end{array}$ & 1 & -.60 & -.08 \\
\hline $\begin{array}{l}\text { Healthcare Plan Knowledge } \mathrm{x} \\
\text { Prevention }\end{array}$ & 1 & -.40 & -.05 \\
\hline
\end{tabular}




\section{Discussion}

In developing this experiment, the researcher predicted that, when choosing between two different types of treatment services, more participants should report intentions to undergo treatments, such as surgery, and report higher willingness to pay for such services after receiving gain framed decisions (Hypothesis 3). Similar to Experiment

2, though, neither the hypothesized factors nor their interactions significantly impacted individuals' choices of treatment options (radiation or surgery) for a hypothetical diagnosis of lung cancer. The same lack of impact also held true for the exploratory investigation into the amount of money individuals would spend of the treatment that they did not choose.

However, the hypothesized factors did impact individuals' willingness to spend money on their selected treatment. As observed in the earlier experiments, chronic promotion focus increased individuals' willingness to spend money on their selected treatment, whereas chronic prevention focus decreased individuals' willingness to spend money on their selected treatment. Also, individuals with a low degree of knowledge about their healthcare plan would spend more money on their selected treatment as compared to participants with a high degree of knowledge about their plan.

Perhaps most interestingly, though, is the finding that framing the healthcare information as a loss (i.e., mortality rates), versus framing that information as a gain (survivability rates), enhanced the amount of money individuals would spend on their selected healthcare treatment. This supports the traditional loss aversion framing effect. 


\section{Chapter 8: General Discussion}

This investigation set out to examine whether loss aversion occurs equally for healthcare purchasing under the HSA paradigm and for healthcare purchasing under a defined benefit (insurance) paradigm. It also sought to examine whether consumers' regulatory orientations could help explain the inconsistent manifestation of loss aversion effects in the context of healthcare decisions.

Prospect theory's loss aversion principle suggests that decision makers should prefer risky choices in healthcare decisions concerning losses but should prefer certain choices in healthcare decisions concerning gains. This principle led to a number of hypotheses tested by the three experiments in this investigation.

For each of the three experiments, the researcher predicted that among decision makers who own HSAs, gain-loss framing effects ought to be diminished or eliminated (Hypothesis 4) and that when choosing among healthcare options, decision makers who experience regulatory fit between their chronic orientations and the decision process will more often report intentions to obtain medical services and will report higher willingness to pay for the services, as compared to decision makers who do not experience regulatory fit (Hypothesis 5). In addition, the researcher proffered a specific hypothesis pertaining to particular healthcare decisions in each of three experiments.

\section{HSAs \& Defined Benefit Plans}

The results from Experiment 1 indicate that framing effects probably occur under both HSA and defined benefit plans. Interestingly, the results suggest that they occur more often under HSA plans, which is opposite of Hypothesis 4. Moreover, the results suggest that for detection-procedures such as skin cancer screening, gain-loss framing 
effects reverse depending upon the type of healthcare plan. Among HSA owners, lossframed information increased interest in pursuing a skin cancer screening (supporting Hypothesis 1), whereas among HIP owners, gain-framed information increased interest (contrary to Hypothesis 1).

The presence of this reversing effect in the detection-procedure experiment but not in the prevention or treatment experiments may add credence to Rothman and Salovey's (1997) distinctions between detection, prevention, and treatment services. However, it is not entirely clear why the framing effect would reverse depending upon which type of healthcare plan an individual possesses or why each type of plan produces its respective effect.

The effect for HSA owners seems simplest to explain since that effect is consistent with prospect theory's loss aversion principle. The effect further suggests that HSAs are not a boundary to loss aversion, like those proposed by Novemsky and Kahneman (2005), but instead provides support to Bateman's and colleagues' (1997; 2005) contention that loss aversion applies to any loss from the status quo, including money exchanged during a purchase.

The lack of such a loss aversion effect among HIP owners may suggest that HIPs implicate an as yet unknown boundary to loss aversion. Alternatively, HIP owners may have a different reference point than HSA owners. Recall that loss aversion describes a reversing effect around a reference point. If HIP owners have a different reference point, they should have a different perception of what constitutes a "loss." For example, if somehow the gain-framed skin cancer information (but not loss-framed information) was able to establish current skin health as HIP owners' reference point, then HIP owners' 
increased interest in a cancer screening might constitute Samuelson's and Zeckhauser's (1988) status quo bias, in the form of maintaining current skin health.

The presence of the reversing frame effect in Experiment 1 but not other experiments might result from one or more of the distinctions described by Rothman and colleagues $(1993 ; 1997 ; 1999 ; 2006)$, such as distinctions between "same consequences" and "different consequences" manipulations, distinctions between messages associated with health-promoting behaviors and those with health-damaging behaviors, differences in desirability and likelihood of consequences, how contemporary society portrays detection behaviors (e.g., as illness-detecting or health-affirming), or differential degrees of message processing (e.g., participant involvement or need for cognition). The distinction might also implicate differences in cognitive focus among the two types of consumers (Ariely, Huber, \& Wertenbroch, 2005; Carmon \& Ariely, 2000; Lerner, Small, \& Loewenstein 2004).

Unfortunately, the results from this investigation do not lend themselves to an easily discernible conclusion. In any case, this reversing frame effect should be considered and further examined in future research addressing the individual account paradigm and healthcare decisions.

\section{Prospect Theory \& Loss Aversion}

The results from Experiments 1 and 3 suggest that loss aversion seems to occur for detection (e.g., skin cancer screening) and treatment (e.g., surgery or radiation) procedures. In terms of the detection procedure, loss aversion occurred only for those healthcare consumers who owned HSAs. Among those individuals, loss-framed 
information increased the likelihood they would obtain a screening and the amount of money they would be willing to spend on a screening (supporting Hypothesis 1).

In terms of the treatment procedure, framing lung cancer treatment information as a loss (i.e., mortality rates), versus a gain (survivability rates), enhanced the amount of money individuals would spend on their selected healthcare treatment. While contrary to Hypothesis 3 (which predicts a preference for "certain" choices in healthcare decisions concerning gains), this finding is consistent with the classic loss aversion effect. Individuals would spend more money to avoid a loss (mortality) than they would to acquire an objectively equivalent gain (survivability).

These findings further support the conclusion that framing healthcare information can impact the choice-behaviors of healthcare consumers (see Hastie \& Dawes, 2001; Rothman \& Salovey, 1997; Rothman et al., 1993). Healthcare providers would do well to remain aware of and consider the potential impacts resulting from their presentation of information to their clients.

Unfortunately, the experimental results do not support Hypothesis 4. None of the experiments indicated a gain-loss framing effect present under the defined-benefit (insurance) paradigm and absent under the HSA paradigm. This lack of evidence limits extension of the research by Novemsky and Kahneman (2005) and Koszegi and Rabin (2006) showing that items given up "as intended" do not trigger loss aversion. Hypothetical HSAs apparently do not behave as embodiments of decision makers' intentions to exchange pre-budgeted funds and therefore do not diminish or eliminate differences in decision maker preferences produced by gain-loss framing (i.e., hypothetical HSAs do not serve as a per se boundary to loss aversion effects). 


\section{Regulatory Focus Theory}

In all three experiments, chronic prevention focus decreased individuals' willingness to spend money on healthcare services. Conversely, chronic promotion focus tended to increase individuals' willingness to spend money on healthcare services, as well as to increase their likelihood to obtain services. These findings align well with expectations from regulatory focus theory, which predicts that promotion-focused individuals pursue positive outcomes via eager approach strategies whereas preventionfocused individuals evade negative outcomes via vigilant avoidance strategies. The presence of these effects suggests that healthcare providers, consumers, and policymakers should attend to the influence that individual difference factors, such as motivational orientation, exert in the healthcare marketplace.

Moreover, as described earlier, there is an interesting pattern of results concerning regulatory focus and knowledge of health care plans. While chronic promotion focus tends to increase individuals' interest in healthcare services (i.e., likelihood to obtain care or willingness to spend money), that effect only seems true for individuals with limited knowledge about their healthcare plan. Regulatory focus effects seem to be nonexistent among decision-makers who have a high degree of knowledge about their healthcare plans.

This finding is significant given the existing research on financial and healthcare literacy and the suggestion that consumer disparities in understanding healthcare information can impede provision of healthcare services. Prior research has shown that the American public is largely financially illiterate, there is a general lack of knowledge and understanding about fundamental economic concepts (Lusardi \& Mitchell, 2005; 
National Council on Economic Education, 2005), and many healthcare consumers are not able to read and comprehend basic health-related materials (Williams et al., 1995) or understand how traditional or market-driven healthcare plans operate (Edgman-Levitan \& Cleary, 1996; Hibbard \& Jewett, 1997; Hibbard et al., 1998; Isaacs, 1996; Lubalin \& Harris-Kojetin, 1999).

This body of research suggests that regulatory focus effects could be quite pervasive in real world healthcare acquisition decisions. Thankfully, though, researchers have discovered methods to improve communication of technical information (see Kools, Ruiter, Weil, \& Kok, 2004; Wogalter, Howe, Sifuentes, \& Luginbuhl, 1999) and to positively influence individual account holders' knowledge and behavior (Clark et al., 2003; Lusardi, 2004; McCormack, Garfinkel, Hibbard, Norton, \& Bayen, 2001). Perhaps these and other methods might help ameliorate regulatory focus effects through increased understanding of healthcare plans.

Sadly, the results fail to support Hypothesis 5. None of the experiments produced any regulatory fit effects, making impossible any conclusions concerning Avnet and Higgins' (2006) proposal that risk preferences can be explained by differences in regulatory fit.

\section{Limitations}

While the results from this research project should contribute to our growing understanding of prospect theory and regulatory focus in the individual account paradigm, the research is limited. Perhaps most notably, people likely respond differently to simulated trials than to real world decisions. In all three of the current experiments, participants engaged in an entirely hypothetical decision task. While 
instructed to behave as though their decisions reflected real-life concerns, participants were fully aware that their healthcare plans were hypothetical, and thus they were not actually responsible for any costs incurred. Likewise the potential harm to one's health and the healthcare service options were also hypothetical, such that participants did not have any real-world concerns for their physical well-being. Future investigations will hopefully be able to employ real-world research methods (e.g., real healthcare decisions made in consideration of real health threats and healthcare financing). This investigation provides a starting point for such future research, but it cannot be taken as conclusive evidence given this limitation.

In addition, all three experiments suffered from low reliability of the RFQ regarding chronic promotion. Even though the experiments produced regulatory focus effects, including the effects of chronic promotion described above (i.e., tendency to increase interest in healthcare services among individuals with limited knowledge about their healthcare plan), the low RFQ reliability may have impacted the results, possibly impeding the consistency and/or magnitude of chronic promotion effects across the three experiments. Notably, since the initiation of this research project, other investigators have developed alternative measures for assessing chronic regulatory focus (Haws, Dholakia, \& Bearden, 2010), and future research in this area should consider employing those measures rather than the RFQ.

Finally, this research was also limited by individuals' lack of understanding about their healthcare plans. Consistently across all three experiments, people did not understand their health care plans, and individuals with a low degree of knowledge about their healthcare plan would spend more money on healthcare services. In contrast, 
individuals with a high degree of knowledge about their healthcare plan would spend less money than those with a low degree of knowledge. Since some of the primary hypotheses relied on individuals' understanding of their healthcare plans (i.e., predicted differences between individuals owning HSAs and those owning HIPs), individuals lack of knowledge about their healthcare plans likely impeded an accurate evaluation of those hypotheses.

Obviously, these findings that people do not understand their health care plans, and that individuals with little knowledge about their plans tend to spend more money on healthcare services, has importance for lawmakers and policymakers concerned with healthcare policy. Individuals with greater knowledge about their healthcare plans may very well be more cost-conscious in selecting healthcare treatments. They may also become more knowledgeable about potential healthcare services if, for example, they use knowledge of their plan as a foundation for understanding the availability, cost, appropriateness of services. Moreover, differences in plan-knowledge could impact other healthcare-related behavior.

It is possible that people may understand their healthcare plans better in the real world, but there is probably a great need for education among healthcare consumers. Healthcare providers (and their regulators) should take note of the research mentioned above (and in Chapter 2) concerning improved communication and positive influences on account holder knowledge and behavior. The practices described in that literature likely can also help increase consumers' understanding of healthcare plans.

While this investigation took notice of research pertaining to financial and health literacy, those concerns were not the focus of this project. The focus was healthcare 
consumers' decision making. The results concerning limited healthcare plan knowledge, however, suggest that the two components (i.e., literacy and decision making) are interrelated and inter-dependent. Future research should examine both factors concurrently.

\section{Conclusion}

As a whole, this project helps advance our understanding of how the individual account paradigm, embodied by HSAs, interfaces with decision making errors and how loss aversion effects may impact healthcare choices. The results have implications for both psychological theories of decision making and healthcare policy. The results add to the growing evidence which questions the assumptions underlying the rational actor model of decision making, particularly the evidence that suggests the rational actor model is, at best, an incomplete account of decision processes (see Hastie \& Dawes, 2001; Kahneman \& Tversky, 1979; Loewenstein et al., 2001; Thaler, 1983). The results also contribute to the lines of research aimed at understanding the role of loss aversion in the context of healthcare acquisition (Rothman et al., 1993; 1997; 1999; 2006) as well as the role of regulatory focus in that same context (Cesario, Grant, \& Higgins, 2004; Keller, 2006; Speigel, Grant-Pillow, \& Higgins, 2004).

The results directly address assumptions of rational consumer behavior inherent in the HSA paradigm and help reveal deviations from rational decision making. In contrast to predictions premised on the work of Novemsky and Kahneman (2005) as well as Koszegi and Rabin (2006), hypothetical HSAs do not appear to behave as embodiments of decision makers' intentions and do not reduce or eliminate gain-loss framing effects. The results indicate that HSAs may permit common decision making errors, suggesting that lawmakers might want to reconsider some expectations concerning individual 
healthcare accounts. At the very least, the evidence regarding loss aversion, regulatory focus, and low healthcare plan knowledge should trigger new research directed towards finding or developing decision aids that might reduce decision errors in the individual account paradigm.

Finally, although these experiments only aim to understand how people act in their capacities as healthcare consumers, the outcome should further encourage and enable legislators to consider socio-psychological factors when developing or implementing other individualized benefit options, such as retirement accounts and educational accounts. Hopefully, this investigation will promote psychological study of individual difference factors, such as regulatory orientation, when researchers test theoretical models in decision tasks and will also encourage the development of legal and policy structures that incorporate a sophisticated understanding of human decision making and behavior. 


\section{References}

Aaker, J. \& Lee, A. (2006). Understanding regulatory fit. Journal of Marketing Research, 43, 15-19. doi: 10.1509/jmkr.43.1.15

Apanovitch, A., McCarthy, D., \& Salovey (2003). Using message framing to motivate HIV testing among low-income, ethnic minority women. Health Psychology, 22 (1), 60-67. doi: 10.1037/0278-6133.22.1.60

Ariely, D., Huber, J., \& Wertenbroch, K. (2005). When do losses loom larger than gains? Journal of Marketing Research, 42, 134-138. doi: 10.1509/jmkr.42.2.134.62283

Ariely, D. \& Simonson, I. (2003). Buying, bidding, playing, or competing? Value assessment and decision dynamics in online auctions. Journal of Consumer Psychology, 13 (1-2), 113-123. doi: 10.1207/S15327663JCP13-1\&2_10

Avnet, T. \& Higgins, E.T. (2003). Locomotion, assessment, and regulatory fit: value transfer from "how" to "what." Journal of Experimental Social Psychology, 39, 525-530. doi:10.1016/j.jesp.2003.09.001

Avnet, T. \& Higgins, E.T. (2006). How regulatory fit affects value in consumer choices and opinions. Journal of Marketing Research, 43, 1-10. doi: 10.1509/jmkr.43.1.1

Baker, D. W., Gazmararian, J. A., Williams, M. V., Scott, T., Parker, R. M., Green, D. R., et al. (2002). Functional health literacy and the risk of hospital admission among Medicare managed care enrollees. American Journal of Public Health, 92, 1278-1283. doi: 10.2105/AJPH.92.8.1278

Baker, D. W., Parker, R. M., Williams, M. V., Clark, W. S., \& Nurss, J. (1997). The relationship of patient reading ability to self-reported health and use of health services. American Journal of Public Health, 87 (6), 1027-1030. doi: 10.2105/AJPH.87.6.1027

Banks, S. M., Salovey, P., Greener, S., Rothman, A. J., Moyer, A., Beauvais, J., \& Epel, E. (1995). The effects of message framing on mammography utilization. Health Psychology, 14, 178-184. doi: 10.1037/0278-6133.14.2.178

Bateman, I., Kahneman, D., Munro, A., Starmer, C., \& Sugden, R. (2005). Testing competing models of loss aversion: An adversarial collaboration. Journal of Public Economics, 89 (8), 1561-1580.

Bateman, I., Munro, A., Rhodes, B., Starmer, C., \& Sugden, R. (1997). A test of the theory of reference-dependent preferences. Quarterly Journal of Economics, 112, 479-505. doi: 10.1162/003355397555262 
Bernoulli, D. (1954). Specimen theoriae novae de mensura sortis [Exposition of a new theory on the measurement of risk]. Econometrica, 22, 23-36. (Original work published 1738). doi:10.2307/1909829

Block, L. G., \& Keller, P. A. (1995). When to accentuate the negative: The effects of perceived efficacy and message framing on intentions to perform a health-related behavior. Journal of Marketing Research, 32, 192-204. doi:10.2307/3152047

Brenner, L., Rottenstreich, Y., Sood, S., \& Bilgin, B. (2007). On the psychology of loss aversion: Possession, valence, and reversals of the endowment effect. Journal of Consumer Research, 34, 369-376. doi:10.1086/518545

Camacho, C.J., Higgins, E.T. \& Luger, L. (2003). Moral value transfer from regulatory fit: What feels right is right and what feels wrong is wrong. Journal of Personality and Social Psychology, 84 (3), 498-510. doi:10.1037//0022-3514.84.3.498

Carmon, Z. \& Ariely, D. (2000). Focusing on the forgone: How value can appear so different to buyers and sellers. Journal of Consumer Research, 27, 360-70. doi:10.1086/317590

Carmon, Wertenbroch, K., \& Zeelenberg, M. (2003). Option attachment: When deliberating makes choosing feel like losing. Journal of Consumer Research, 30, $15-29$.

Cesario, J., Grant, H. \& Higgins, E.T. (2004). Regulatory fit and persuasion: Transfer from "feeling right." Journal of Personality and Social Psychology, 86, 388-404. doi: $10.1037 / 0022-3514.86 .3 .388$

Chapman, G. (1998). Similarity and reluctance to trade. Journal of Behavioral Decision Making, 11, 47-58. doi: 10.1002/(SICI)1099-0771(199803)11:1<47::AID$\mathrm{BDM} 278>3.0 . \mathrm{CO} ; 2-\mathrm{B}$

Clark, R., D’Ambrosio, M., McDermed, A., \& Sawant, K. (2004). Sex differences, financial education and retirement goals. In O. Mitchell \& S. Utkus (Eds.), Pension design and structure: New lessons from behavioral finance. Oxford: Oxford University Press.

Cohen, J., \& Cohen, P. (1983). Applied multiple regression/correlation analysis for the behavioral sciences (2nd ed.). Hillsdale, NJ: Erlbaum.

Coursey, D., Hovis, J., \& Schultze, W. (1987). The disparity between willingness to accept and willingness to pay measure of value. The Quarterly Journal of Economics, 679-690. doi:10.2307/1884223 
Crowe, B., \& Higgins, E. T. (1997). Regulatory focus and strategic inclinations: Promotion and prevention in decision making. Organizational Behavior and Human Decision Processes, 69, 117-132. doi:10.1006/obhd.1996.2675

Darke, P. \& Dahl, D. (2003). Fairness and discounts: The subjective value of a bargain. Journal of Consumer Psychology, 13 (3), 328-338. doi:10.1207/S15327663JCP1303_13

Davis, K., Doty, M., \& Ho, A. (2005). How high is too high? Implications of high deductible health plans. The Commonwealth Fund, 816. Retrieved from http://www.commonwealthfund.org/usr_doc/816_Davis_how_high_is_too_high_i mpl_HDHPs.pdf?section=4039

Detweiler, J. B., Bedell, B. T., Salovey, P., Pronin, E., \& Rothman, A. J. (1999). Message framing and sunscreen use: Gain-framed messages motivate beach-goers. Health Psychology, 18, 189-196. doi: 10.1037/0278-6133.18.2.189

Dhar, R. \& Wertenbroch, K. (2000). Consumer choice between hedonic and utilitarian goods. Journal of Marketing Research, 37, 60-71. doi:10.1509/jmkr.37.1.60.18718

Edgman-Levitan, S. \& Cleary, P. (1996). What information do consumers want and need? Health Affairs, 15 (4), 42-56. doi:10.1377/hlthaff.15.4.42

Employee Retirement Income and Security Act of 1974, Pub. L. No. 93-406, 88 Stat. 829 (1974).

Florack A. \& Scarabis, M. (2006). How advertising claims affect brand preferences and category-brand associations: The role of regulatory fit. Psychology \& Marketing, 23 (9), 741-755. doi: 10.1002/mar.20127

Forster, J., Grant, H., Idson, L. C., \& Higgins, E. T. (2001). Success/failure feedback, expectancies, and approach/avoidance motivation: How regulatory focus moderates classic relations. Journal of Experimental Social Psychology, 37, 253260. doi:10.1006/jesp.2000.1455

Forster, J. \& Higgins, E.T. (2005). How global versus local perception fits regulatory focus. Psychological Science, 16 (8), 631-636. doi:10.1111/j.14679280.2005.01586.x

Forster, J., Higgins, E. T., \& Idson, C. L. (1998). Approach and avoidance strength as a function of regulatory focus: Revisiting the "goal looms larger" effect. Journal of Personality and Social Psychology, 75, 1115-1131. doi:10.1037//00223514.75.5.1115 
Fronstin, P. (2004). Issue Brief No. 273: Health savings accounts and other accountbased health plans. Retrieved from Employee Benefit Research Institute, http://www.ebri.org/publications/ib/index.cfm?fa=ibDisp\&content_id=3504

Gilbert, D., Morewedge, C., Risen, J., \& Wilson, T. (2004). Looking forward to looking backward: The misprediction of regret. Psychological Science, 15 (5), 346-350. doi:10.1111/j.0956-7976.2004.00681.x

Gilbert, D.T., Brown, R.A., Pinel, E.C., \& Wilson, T.D. (2000). The illusion of external agency. Journal of Personality and Social Psychology, 79, 690-700. doi:10.1037//0022-3514.79.5.690

Gilbert, D.T., Pinel, E.C.,Wilson, T.D., Blumberg, S.J.,\&Wheatley, T.P. (1998). Immune neglect: A source of durability bias in affective forecasting. Journal of Personality and Social Psychology, 75, 617-638. doi:10.1037//00223514.75.3.617

Government Accountability Office. (2006). Consumer-Directed Health Plans: Early Enrollee Experiences with Health Savings Accounts and Eligible Health Plans: Report to the Ranking Minority Member, Committee on Finance, U.S. Senate. Washington, DC.

Hartman, R., Doane, M., \& Woo, C. (1991). Consumer rationality and the status quo. The Quarterly Journal of Economics, February, 141-162. doi:10.2307/2937910

Hastie, R. \& Dawes, R.M. (2001). Rational choice in an uncertain world: The psychology of judgment and decision making. Thousand Oaks, CA: Sage.

Haws, K., Dholakia, U., \& Bearden, W. (2010). An assessment of chronic regulatory focus measures. Journal of Marketing Research, Vol. XLVII, 967-982. doi:10.1509/jmkr.47.5.967

Herzenstein, M., Posovac, S., \& Brakus, J. (2007). Adoption of new and really new products: The effects of self-regulation systems and risk salience. Journal of Marketing Research, 44, 251-260. doi: 10.1509/jmkr.44.2.251

Hibbard, J. \& Jewett, J. (1997). Will quality report cards help consumers? Health Affairs, 16 (3), 218-228. doi:10.1377/hlthaff.16.3.218

Hibbard, J., Jewett, J., Engelmann,S., \& Tusler, M. (1998). Can Medicare beneficiaries make informed choices? Health Affairs, 17 (6), 181-193. doi:10.1377/hlthaff.17.6.181

Higgins, E. T. (1997). Beyond pleasure and pain. American Psychologist, 52, 1280-1300. doi: 10.1037/0003-066X.52.12.1280 
Higgins, E.T. (1998). Promotion and prevention: Regulatory focus as a motivational principle. In M.P. Zanna (Ed.), Advances in Experimental Social Psychology (Vol. 30). Academic Press: New York; 1-46.

Higgins, E.T. (2002). How self-regulation creates distinct values: The case of promotion and prevention decision making. Journal of Consumer Psychology, 12 (3), 17791. doi: 10.1207/S15327663JCP1203_01

Higgins, E.T. (2005). Value from regulatory fit. Current directions in Psychological Science 14 (4), 209-213. doi: 10.1111/j.0963-7214.2005.00366.x

Higgins, E. Idson, L., Freitas, A., Spiegel, S., \& Molden, D. (2003). Transfer of value from fit. Journal of Personality and Social Psychology, 84, 1140-53. doi: 10.1037/0022-3514.84.6.1140

Higgins, E.T., Friedman, R., Harlow, R., Idson, L., Ayduk, O., \& Taylor, A. (2001). Achievement orientations from subjective histories of success: promotion pride versus prevention pride. European Journal of Social Psychology, 31, 3-23. doi: 10.1002/ejsp. 27

Idson, L., Liberman, N., \& Higgins, E. (2000). Distinguishing gains from nonlosses and losses from nongains: A regulatory focus perspective on hedonic intensity. Journal of Experimental Social Psychology, 36, 252-74. doi:10.1006/jesp.1999.1402

Internal Revenue Code, 26 U.S.C. $\S \S 105,106 ; 125 ; 220 ; 223 ; 408 ; 408$ A; 529; 530.

Internal Revenue Service. (2011). Revenue Procedure 2011-32. Washington, DC.

Isaacs, S. (1996). Consumers' information needs: Results of a national survey. Health Affairs, 15 (4), 31-41. doi:10.1377/hlthaff.15.4.31

Jain, S., Agrawal, N., \& Maheswaran, D. (2006). When more may be less: The effects of regulatory focus on responses to different comparative frames. Journal of Consumer Research, 33, 91-98. doi: 10.1086/504139

Kahneman, D., Knetsch, J.K., \& Thaler, R.H. (1991). Anomalies: The endowment effect, loss aversion, and status quo bias. Journal of Economic Perspectives, 5 (1), 193206.

Kahneman, D., Knetsch, J., \& Thaler, R. (1990). Experimental tests of the endowment effect and the Coase Theorem. Journal of Political Economy, 98, 1325-48. doi:10.1086/261737

Kahneman, D. \& Tversky, A. (1979). Prospect theory: An analysis of decision under risk. Econometrica, 47, 263-91. doi: 10.2307/1914185 
Kalichman, S. C., \& Coley, B. (1995). Context framing to enhance HIV antibody- testing messages targeted to African American women. Health Psychology, 14, 247-254. doi: 10.1037/0278-6133.14.3.247

Keller, P. (2006). Regulatory focus and efficacy of health messages. Journal of Consumer Research, 33, 109-114. doi: 10.1086/504141

Knetsch, J. (1989). The endowment effect and evidence of nonreversible indifference curves. American Economic Review, 79, 1277-84.

Knetsch, J. \& Sinden, J. (1984). Willingness to pay and compensation demanded: Experimental evidence of an unexpected disparity in measures of value. Quarterly Journal of Economics, 99, 507-521. doi:10.2307/1885962

Knez, P., Smith, V., \& Williams, A. (1985). Individual rationality, market rationality, and value estimation. American Economic Review, 75, 397-402.

Kools, M., Ruiter, R., Weil, M., \& Kok, G. (2004). Increasing readers' comprehension of health education brochures: A qualitative study into how professional writers make texts coherent. Health Education \& Behavior, 31 (6), 720-740. doi:10.1177/1090198104263340

Koszegi, B. \& Rabin, M. (2006). A model of reference-dependent preferences. The Quarterly Journal of Economics, 121 (4), 1133-1165.

doi:10.1162/qjec.121.4.1133

Lee, A. \& Aaker, J. (2004). Bringing the frame into focus: The influence of regulatory fit on processing fluency and persuasion. Journal of Personality and Social Psychology, 86, 205-218. doi: 10.1037/0022-3514.86.2.205

Lerner, J., Small, D., \& Loewenstein, G. (2004). Heart strings and purse strings: Carryover effects of emotions on economic transactions. Psychological Science, 15 (5), 337-41. doi:10.1111/j.0956-7976.2004.00679.x

Liberman, A., Molden, D.C., Idson, L.C., \& Higgins, E.T. (2001). Promotion and prevention focus on alternative hypotheses: Implications for attributional functions. Journal of Personality and Social Psychology, 80 (1), 5-18. doi:10.1037//0022-3514.80.1.5

Linville, P. W., Fischer, G. W., \& Fischhoff, B. (1993). AIDS risk perceptions and decision biases. In J. B. Pryor \& G. D. Reeder (Eds.), The social psychology of HIV infection (pp. 5-38). Hillsdale, NJ: Erlbaum.

List, J. (2003). Does market experience eliminate market anomalies. The Quarterly Journal of Economics, 118 (1), 41-71. doi:10.1162/00335530360535144 
List, J. (2004). Neoclassical theory versus prospect theory: Evidence from the marketplace. Econometrica, 72 (2), 615-25. doi:10.1111/j.1468-

0262.2004.00502.x

Lo Sasso, A., Rice, T., Gabel, J., \& Whitmore, H (2004). Tales from the new frontier: Pioneers' experiences with consumer-driven health care. Health Services Research, 39 (4), 1071-1090.

Loewenstein, G. \& Haisely E. (2008). The economist as therapist: Methodological ramifications of "light" paternalism. In Caplin \& Schotter (Eds), Perspectives on the future of economics: Positive and normative foundations. In Handbook of Economic Methodologies (Vol. 1), Oxford, England: Oxford University Press.

Loewenstein, G. F., Weber, E. U., Hsee, C. K., \& Welch, N. (2001). Risk as feelings. Psychological Bulletin, 127, 267-286. doi: 10.1037//0033-2909.127.2.267

Lubalin, J. \& Harris-Kojetin, L. (1999). What do consumers want and need to know in making health care choices? Medical Care Research and Review, 56 (1), 67-102. doi:10.1162/00335530360535144

Lusardi, A. (2004). Saving and the effectiveness of financial education. In O. Mitchell \& S. Utkus (Eds), Pension design and structure: New lessons from behavioral finance. Oxford University press.

Lusardi, A. \& Mitchell, O. (2006). Working Paper 2006-114: Baby boomer retirement security: The roles of planning, financial literacy, and housing wealth. Retrieved from Michigan Retirement Research Center, http://www.mrrc.isr.umich.edu/publications/papers/

Lusardi, A. \& Mitchell, O. (2005). Working Paper 2005-108: Financial literacy and planning: Implications for retirement wellbeing. Retrieved from Michigan Retirement Research Center, http://www.mrrc.isr.umich.edu/publications/papers/

Maheswaran, D., \& Meyers-Levy, J. (1990). The influence of message framing and issue involvement. Journal of Marketing Research, 27, 361-367. doi:10.2307/3172593

Mango, P. \& Riefberg, V. (2005). Health savings accounts: Making patients better consumers. The McKinsey Quarterly, 1-7. Retrieved from http://www.mckinseyquarterly.com/Health_savings_accounts_Making_patients_b etter_consumers_1567.

Mann, T. L., Sherman, D. K., \& Updegraff, J. A. (2004). Dispositional motivations and message framing: A test of the congruency hypothesis in college students. Health Psychology, 23, 330-334. doi: 10.1037/0278-6133.23.3.330 
Marteau, T M. (1989). Framing of information: Its influence upon decisions of doctors and patients. British Journal of Social Psychology, 28, 89-94. doi:10.1111/j.20448309.1989.tb00849.x

McCormack, L., Garfinkel, S., Hibbard, J., Norton, E. \& Bayen, U. (2001). Health plan decision making with new medicare information materials. Health Services Research 36 (3), 531-554.

McNeil, B. J., Pauker, S. G., Sox, H. C., \& Tversky, A. (1982). On the elicitation of preferences for alternative therapies. New England Journal of Medicine, 306, 1259-1262. doi:10.1056/NEJM198205273062103

Medicare Prescription Drug Improvement and Modernization Act of 2003, Pub. L. No. 108-173, 117 Stat. 2066 (2003).

Medill, C. (2004). Introduction to employee benefits law: Policy and practice. Thompson-West.

Medill, C. (2006). Transforming the role of the Social Security Administration. Cornell Law Review, 92, 323-361.

Mellers, B.A. (2000). Choice and the relative pleasure of consequences. Psychological Bulletin, 126, 910-924. doi:10.1037//0033-2909.126.6.910

Meyerowitz, B. E., \& Chaiken, S. (1987). The effect of message framing on breast selfexamination attitudes, intentions, and behavior. Journal of Personality and Social Psychology, 52, 500-510. doi:10.1037//0022-3514.52.3.500

National Council on Economic Education. (2005). What American Teens and Adults Know About Economics. Washington, D.C.

Novemsky, N. \& Kahneman, D. (2005a). The boundaries of loss aversion. Journal of Marketing Research, 42, 119-28. doi: 10.1509/jmkr.42.2.119.62292

Novemsky, N. \& Kahneman, D. (2005b). How do intentions affect loss aversion? Journal of Marketing Research, 42, 139-140. doi:10.1509/jmkr.42.2.139.62295

Parker, R. (2000). Health literacy: a challenge for American patients and their health care providers. Health Promotion International, 15 (4), 277-283. doi:10.1093/heapro/15.4.277

Parente, S., Feldman, R., \& Christianson, J. (2004). Employee choice of consumer-driven health insurance in a multiplan, multiproduct setting. Health Services Research, 39 (4), 1091-1112. doi:10.1111/j.1475-6773.2004.00275.x 
Rothman, A. J., Bartels, R. D., Wlaschin, J., \& Salovey, P. (2006). The strategic use of gain- and loss-framed messages to promote healthy behavior: How theory can inform practice. Journal of Communication, 56, S202-S221. doi:10.1111/j.14602466.2006.00290.x

Rothman, A., Martino, S., Bedell, B., Detweiler, J., \& Salovey, P. (1999). The systematic influence of gain- and loss-framed messages on interest in and use of different types of health behavior. Personality and Social Psychology Bulletin, 25 (11), 1355-1369. doi: 10.1177/0146167299259003

Rothman, A. \& Salovey, P. (1997). Shaping perceptions to motivate healthy behavior: The role of message framing. Psychological Bulletin, 121 (1), 3-19. doi: 10.1037/0033-2909.121.1.3

Rothman, A. J., Salovey, P., Antone, C., Keough, K., \& Martin, C. D. (1993). The influence of message framing on intentions to perform health behaviors. Journal of Experimental Social Psychology, 29, 408-433. doi:10.1006/jesp.1993.1019

Samuelson, W. \& Zeckhauser, R. (1988). Status quo bias in decision making. Journal of Risk and Uncertainty, 1, 7-59. doi:10.1007/BF00055564

Savage, L. J. (1954). The foundations of statistics. New York: Wiley.

Schwartz, N. \& Clore, G. (1983). Mood, misattribution, and judgments of well-being: Informative and directive functions of affective states. Journal of Personality and Social Psychology, 45, 513-523.

Schwartz, A., Goldberg, \& Hazen (2008). Prospect theory, reference points, and health decisions. Judgment and Decision Making, 3 (2), 174-180.

Scott T. L., Gazmararian, J., Williams, M. V., \& Baker, D. W. (2002). Health literacy and preventive health care use among Medicare enrollees in a managed care organization. Medical Care, 40, 395-404. doi:10.1097/00005650-20020500000005

Shah, J. Y.,\& Higgins, E. T. (2001). Regulatory concerns and appraisal efficiency: The general impact of promotion and prevention. Journal of Personality and Social Psychology, 80, 693-705. doi: 10.1037//0022-3514.80.5.693

Shah, J., Higgins, E. \& Friedman, R. (1998). Performance incentives and means: How regulatory focus influences goal attainment. Journal of Personality and Social Psychology, 74 (2), 285-93. doi: 10.1037/0022-3514.74.2.285

Sherman, D. K., Mann, T. L., \& Updegraff, J. A. (2006). Approach/avoidance orientation, message framing, and health behavior: Understanding the congruency effect. Motivation and Emotion, 30, 165-169. doi: 10.1007/s11031-006-9001-5 
Speigel, S., Grant-Pillow, H., \& Higgins, E.T. (2004). How regulatory fit enhances motivational strength during goal pursuit. European Journal of Social Psychology, 34, 39-54. doi: 10.1002/ejsp.180

Strahilevitz, M. \& Loewenstein, G. (1998). The effect of ownership history on the valuation of objects. Journal of Consumer Research, 25, 276-89. doi:10.1086/209539

Thaler, R. (1980). Toward a positive theory of consumer choice. Journal of Economic Behaviour and Organization, 1 (1), 39-60. doi:10.1016/0167-2681(80)90051-7

Thaler, R. (1983). Transaction utility theory. Advances in Consumer Research, 10 (1), 229-232.

Thaler, R. (1985). Mental accounting and consumer choice. Marketing Science 4 (3), 199-214. doi:10.1287/mksc.4.3.199

Tyler, T.R. (1989). The psychology of procedural justice: A test of the group value model. Journal of Personality and Social Psychology, 57, 830 - 838. doi:10.1037//0022-3514.57.5.830

Tyler, T.R. (1988). What is procedural justice?: Criteria used by citizens to assess the fairness of legal procedures. Law and Society Review, 22, 103-135. doi:10.2307/3053563

Updegraff, J. A., Sherman, D. K., Luyster, F. S., \& Mann, T. L. (2007). Understanding how tailored communications work: The effects of message quality and congruency on perceptions of health messages. Journal of Experimental Social Psychology, 43, 249-257. doi:10.1016/j.jesp.2006.01.007

U.S. Department of Health and Human Services, Center for Medicare and Medicaid Services. (2009). National Health Expenditures 2009 Highlights. Washington, DC.

U.S. Department of Labor. (2004). Field Assistance Bulletin 2004-1. Washington, DC.

Uskul, A., Sherman, D., \& Fitzgibbon, J. (2009). The cultural congruency effect: Culture, regulatory focus, and the effectiveness of gain- vs. loss-framed health messages. Journal of Experimental Social Psychology, 45, 535-541. doi:10.1016/j.jesp.2008.12.005

Van Dijk, E. \& Van Knippenberg, D. (1996). Buying and selling exchange goods: Loss aversion and the endowment effect. Journal of Economic Psychology, 17, 517-24. doi:10.1016/0167-4870(96)00017-7 
Von Neumann, J., \& Morgenstem, O. (1947). Theory of games and economic behavior. Princeton, NJ: Princeton University Press.

Wang, J. \& Lee, A. (2006). The role of regulatory focus in preference construction. Journal of Marketing Research, 43, 28-38. doi: 10.1509/jmkr.43.1.28

Werth, L. \& Foerster, J. (2007). How regulatory focus influences consumer behavior. European Journal of Social Psychology, 37, 33-51. doi: 10.1002/ejsp.343

Wicker, F., Hamman, D., Hagen, A., Reed, J., \& Wiehe, J. (2001). Studies of loss aversion and perceived necessity. The Journal of Psychology, 129 (1), 75-89. doi:10.1080/00223980.1995.9914949

Wiener, R., Holtje, M., Winter, R., Cantone, J., Block-Lieb, S., \& Gross, K. (2006). Psychology and the BAPCPA Act of 2005: Enhanced disclosure and emotion. Missouri Law Review 71 (4), 1003 - 1033.

Weiner, R., Holtje, M., Winter, R., Cantone, J., Block-lieb, S., \& Gross, K. (2007). Consumer credit card use: The roles of creditor disclosure and anticipated emotion. Journal of Experimental Psychology: Applied, 13, 32-46. doi: 10.1037/1076-898X.13.1.32

Williams, M. V., Baker, D. W., Parker, R. M., \& Nurss, J. R. (1998). Relationship of functional health literacy to patients' knowledge of their chronic disease: A study of patients with hypertension or diabetes. Archives of Internal Medicine, 158, 166-172. doi:10.1001/archinte.158.2.166

Williams, M. V., Parker, R. M., Baker, D. W., Parikh, N. S., Pitkin, K., \& Coates, W. C. (1995). Inadequate functional health literacy among patients at two public hospitals. Journal of the American Medical Association, 274 (21), 1677-1682. doi:10.1001/jama.1995.03530210031026

Wogalter, M., Howe, J., Sifuentes, A., \& Luginbuhl, J. (1999). On the adequacy of legal documents: factors that influence informed consent. Ergonomics, 42, 593-613. doi:10.1080/001401399185504

Zelinsky, E. (2004). The defined contribution paradigm. Yale Law Journal, 114, 451-534. doi:10.2307/4135691 


\title{
Appendix A
}

\author{
$\underline{\text { Informed Consent Form }}$
}

IRB \# 20110411007EP

Michael Holtje, a doctoral student in the Psychology Department at the University of Nebraska-Lincoln (UNL), is conducting the present research study. The title of the study is "Healthcare Decisions." The purpose of the study is to examine how healthcare consumers select medical services. During the time that you participate in this study, you will encounter information regarding hypothetical health insurance as well as a hypothetical decision among healthcare options.

Although your decisions are not real, we ask that you make these decisions based on how you would make choices in your own healthcare decisions. You will also provide information about your motivations and some demographic information. The entire experiment will take place online and should last approximately 30 minutes.

You must be aged 25 years or older to participate in this study. The healthcare decisions you will make in this study are similar to those you might make at some point in your life. However, if any aspect of this experiment makes you nervous, remember that you are free to quit at any time. Indeed, you will be able to leave the study at any time for any reason without penalty.

The results of this study may be published, but your name and identity will not be revealed, and all of the experimental data and demographic information collected from you will remain confidential. All experimental data will be identified with numbers that have no links to you as a research participant and will be kept in an electronic format (database, etc.) on a secure computer server for a period of 5 years, after which it will be destroyed. Nonetheless, some of the questions in the demographics section ask about, among other things, your gender, ethnicity, and age. Please feel free to leave any of those items unanswered if you feel the answers may reveal your identity.

You have been invited to participate in this research because you are at least 25 years of age. Participation in this study may benefit you by allowing you to become better informed about how you make healthcare decisions. This study will also benefit society by contributing to the understanding of healthcare consumer decisions.

There are no known risks to participating in this experiment unless you have anxieties about healthcare decisions.

The alternative to participating in this study is non-participation. Your participation is voluntary. You are free to decide not to participate in this study or to withdraw at any time without adversely affecting your relationship with the investigators or the University of Nebraska-Lincoln. Your refusal to participate will involve no penalty to you or loss of 
any benefits to which you are otherwise entitled. Your non-participation or withdrawal from this study will not harm your relationship with The Study Response Project or with the psychology department at UNL. Your non-participation or withdrawal from this study will not impact the compensation you receive from The Study Response Project.

We will be happy to answer any concerns you may have about the study. You may contact us at (402) 472-9639 or e-mail us at michael.holtje@ huskers.unl.edu. If you have any questions about your rights as a research participant that have not been answered by the investigator or if you wish to report any concerns about the study, you may contact the University of Nebraska-Lincoln Institutional Review Board (IRB), telephone (402) 472-6965.

If you wish to participate in this study, please read the following statement and provide your electronic signature by clicking at the bottom of the webpage. Please note, this information will be stored in a separate database from the experimental data, maintaining your confidentiality associated with the data. It is suggested that you print a copy of this informed consent form for your personal records.

I have read and understood the information presented above. If I have any questions before I begin, I may contact the researchers. Otherwise my concerns have been answered to my satisfaction via this consent form. I consent to take part in this experiment.

\section{You may print a copy of the informed consent form for your records.}




\section{Appendix B}

\section{$\underline{\text { Regulatory Focus Questionnaire }}$}

Event Reaction Questionnaire

This set of questions asks you about specific events in your life. Please indicate your answer to each question by circling the appropriate number below it.

1. Compared to most people, are you typically unable to get what you want out of life?

1

2

3

4

never or seldom

sometimes

very often

2. Growing up, would you ever "cross the line" by doing things that your parents would not tolerate?
1
2
3
4
5

never or seldom

sometimes

very often

3. How often have you accomplished things that got you "psyched" to work even harder?

$\begin{array}{lllll}1 & 2 & 3 & 4\end{array}$

never or seldom

sometimes

very often

4. Did you get on your parents' nerves often when you were growing up?

1

2

3
4

never or seldom sometimes

very often

5. How often did you obey rules and regulations established by your parents?

1

2
3

sometimes
4

never or seldom

very often 
6. Growing up, did you ever act in ways that your parents thought were objectionable?

1

never or seldom

\section{2}

4

5

sometimes very often

7. Do you often do well at different things that you try?

1

2

3
4

5

never or seldom

\section{sometimes}

very often

8. Not being careful enough has gotten me into trouble at times.
1
2
3

4

never or seldom

sometimes

very often

9. When it comes to achieving things that are important to me, I find that I don't perform as well as I ideally would like to do.

1

2

3

sometimes true
4

5

never true

10. I feel like I have made progress toward being successful in my life.

1

2
3

certainly false
4

certainly true

11. I have found very few hobbies or activities in my life that capture my interest or motivate me to put effort into them.

1

2
4

5

certainly false

certainly true 


\section{Appendix C}

\section{$\underline{\text { General Instructions }}$}

Thank you for participating in this experiment. The following questionnaires will ask you to complete a task with which you may already be familiar. It will ask you to act as a healthcare consumer who is deciding among healthcare options.

Although no doctor actually diagnosed you with any ailment and you will not actually purchase any of the healthcare options, you should approach the decision task as if you were making decisions regarding your own healthcare.

Please read the descriptions of your hypothetical health insurance and healthcare options, and determine what course of action you would pursue. You should make this decision assuming that you desire both good health and sound financial footing. In other words, use the same care that you would if making a decision about your own health in the real world. You should respond to decision tasks with the understanding that if this were a real decision, you would receive the medical service selected and you would be responsible for the costs associated with that service.

To make your choice, this website will assign you hypothetical health insurance for your use while you are a participant in this experiment. Please treat the health insurance as if it was your actual means of obtaining healthcare in your life. 


\section{Appendix D}

\section{Hypothetical HSA Status Report}

Below is a description of your hypothetical High Deductible Health Plan (HDHP) and your Health Savings Account (HSA). Please imagine that you are the owner of these accounts, and please make decisions as you would in the real world. For the purposes of this task, assume that these accounts are your only health insurance.

\section{General Information:}

Presently, your health insurance is a High Deductible Health Plan (HDHP). It has a yearly "deductible" of $\mathbf{\$ 1 , 2 0 0}$. The deductible is the amount of money you must pay out of your own pocket for your healthcare expenses before your HDHP begins paying for the costs of healthcare. After you meet the deductible amount, your HDHP will pay for any remaining healthcare costs throughout the year.

The other tool you use to help you pay for your healthcare is your Health Savings Account (HSA), which is a tax-free, personal savings account administered by MidWest Bank. You established this HSA to pay for your medical expenses. Every month you deposit money into your HSA. All these deposits into your HSA are tax-free. That is, your reported taxable income does not include the money you contribute to your HSA. Your HSA is personally owned by you. It is not related to your employer in any way.

You may use the money in your HSA to pay for medical expenses that you owe before you meet your deductible amount. Once you meet your deductible, your HDHP will cover the remaining healthcare costs throughout the year.

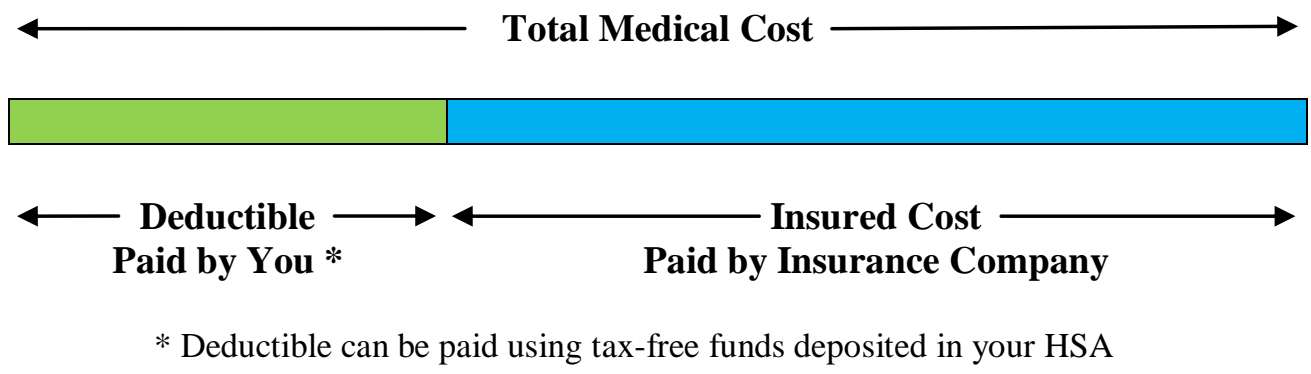

One legal requirement to qualify for the special tax breaks associated with the HSA is that you stay enrolled in a High Deductible Health Plan (HDHP). In other words, you can only own an HSA if you also own a HDHP.

By law, you will not pay taxes on any money you spend from your HSA, up to $\$ 5,800$ per year, so long as you use that money to pay for medical services not covered by your High Deductible Health Plan. In other words, you can use the money in your HSA to pay for medical expenses that are not covered by your HDHP. These expenses 
would include any bills that you must pay for medical services before meeting the $\$ 1,200$ deductible of your HDHP.

If you do not use all of the funds in your HSA by the end of the year, you can carry forward all remaining funds into future years. In other words, the money will stay in your account for you to use in future years. Also, the federal government will not make you pay taxes on any interest you earn on your HSA funds, so long as the money in your HSA is eventually used to pay for medical services.

\section{Most Recent Monthly HSA Statement:}

Your current account balance is $\$ 6,000$.

Your current interest rate is $1 \%$ Annual Percentage Yield (APY), which means that every year, you will earn $1 \%$ interest on the funds in your HSA.

Your annual expenditure limit (i.e., the most you can spend from your HSA in any one year without paying taxes on the money) is $\$ 5800$.

\section{Most Recent Monthly HDHP Statement:}

Your yearly deductible is $\$ 1,200$, and you currently have all $\$ 1,200$ remaining on this deductible. After you pay this deductible amount for any health care bills, your HDHP will pay for any remaining healthcare costs.

The monthly premium payment for your HDHP is $\$ 250$. This means that, every month, you pay $\$ 250$ to maintain your health insurance coverage.

The following charts summarize this important information about the current status of your HDHP and HSA .

\section{HDHP STATUS}

\begin{tabular}{|c|l|l|l|l|}
\hline $\begin{array}{l}\text { Yearly } \\
\text { Deductible }\end{array}$ & $\begin{array}{l}\text { Total Amount That } \\
\text { You Have Paid } \\
\text { Toward Your } \\
\text { Deductible }\end{array}$ & $\begin{array}{l}\text { Monthly } \\
\text { Premium } \\
\text { Payment That } \\
\text { You Pay }\end{array}$ & $\begin{array}{l}\text { Total Amount } \\
\text { That Your } \\
\text { HDHP Has Paid } \\
\text { Out This Year }\end{array}$ & $\begin{array}{l}\text { Number of } \\
\text { Months You } \\
\text { Have Made } \\
\text { Premium } \\
\text { Payments }\end{array}$ \\
\hline$\$ 1,200$ & $\$ 0$ & $\$ 250$ & $\$ 0$ & 24 (2 years) \\
\hline
\end{tabular}

HSA STATUS

\begin{tabular}{|l|l|l|l|l|l|}
\hline $\begin{array}{l}\text { Account } \\
\text { Balance }\end{array}$ & $\begin{array}{l}\text { Your } \\
\text { Monthly } \\
\text { Deposit }\end{array}$ & $\begin{array}{l}\text { Current } \\
\text { Interest } \\
\text { rate }\end{array}$ & $\begin{array}{l}\text { Total Amount } \\
\text { Expended } \\
\text { This Year }\end{array}$ & $\begin{array}{l}\text { Annual } \\
\text { Expenditure } \\
\text { Limit }\end{array}$ & $\begin{array}{l}\text { Number of } \\
\text { Months You } \\
\text { Have Made } \\
\text { Contributions }\end{array}$ \\
\hline$\$ 6,000$ & $\$ 250$ & $1 \%$ & $\$ 0$ & $\$ 5800$ & 24 (2 years) \\
\hline
\end{tabular}




\section{Appendix E}

\section{Hypothetical Health Insurance Plan Status Report}

Below is a description of your hypothetical Health Insurance Plan (Plan). Please imagine that this is your health insurance, and please make decisions as you would in the real world. For the purposes of this task, assume that this is your only health insurance.

\section{General Information:}

MidWest Insurance administers your Health Insurance Plan. Your employer established this Plan to pay for the medical expenses of employees. You joined the Plan two years ago.

Essentially, your Health Insurance Plan pays for your own individual medical expenses that exceed the cost of your deductible and that are covered by the Plan.

The Health Insurance Plan has a yearly "deductible" of \$600. The deductible is the amount of money you must pay out of your own pocket for your healthcare expenses before your health insurance begins paying for the costs of healthcare. After you meet the deductible amount, your Health Insurance Plan will pay for any remaining healthcare costs throughout the year.

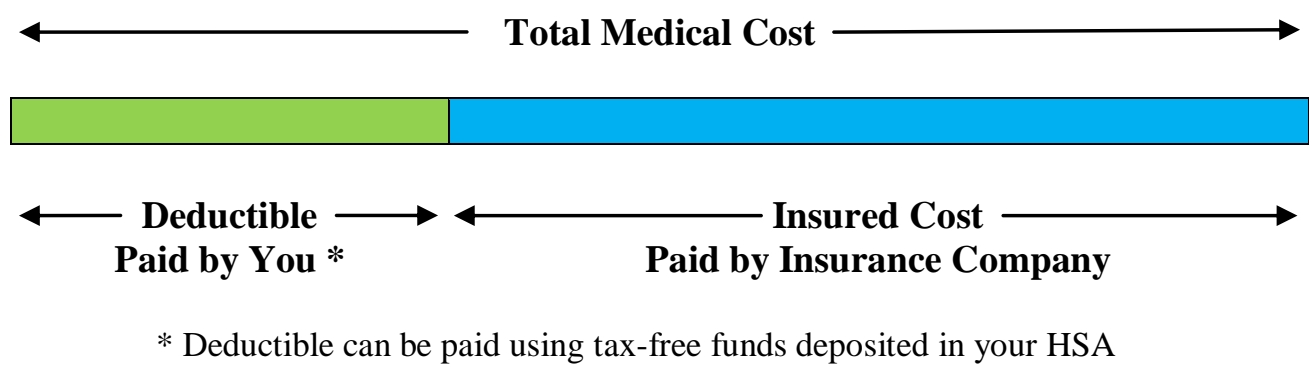

To pay for the Health Insurance Plan, you (like other members of the Plan) make monthly premium payments. This means that, every month, every member of the Health Insurance Plan pays a certain amount of money to maintain his or her health insurance coverage.

Under federal law, your employer has a number of legal duties as the administrator of the Health Insurance Plan of its employees. These duties include partially funding the Plan and ensuring that the plan will have enough money to pay for the healthcare benefits of employees. In other words, your employer also makes payments to fund your health insurance plan.

Most Recent Health Insurance Plan (Plan) Status Report:

MidWest Insurance provides your current health insurance. 
The total yearly premium payment for your Plan is $\$ 12,000$, which is paid in 12 monthly premium payments of $\$ 1,000$. This is the amount of money that you and your employer together must pay into your Plan each year. Each month, your employer pays \$500, and you pay $\$ 500$ to cover the monthly premium payment.

Your yearly deductible is $\$ 600$, and you currently have all $\$ 600$ remaining on this deductible. After you pay this deductible amount for any health care bills, MidWest Insurance will pay for any remaining healthcare costs.

The following chart summarizes the information about your Health Insurance Plan.

\section{PLAN STATUS}

\begin{tabular}{|c|l|l|l|l|l|}
\hline $\begin{array}{c}\text { Yearly } \\
\text { Deductible }\end{array}$ & $\begin{array}{l}\text { Total } \\
\text { Amount That } \\
\text { You Have } \\
\text { Paid Toward } \\
\text { Your } \\
\text { Deductible }\end{array}$ & $\begin{array}{l}\text { Monthly } \\
\text { Premium } \\
\text { Payment } \\
\text { That You } \\
\text { Pay }\end{array}$ & $\begin{array}{l}\text { Monthly } \\
\text { Premium } \\
\text { Payment that } \\
\text { Your } \\
\text { Employer } \\
\text { Pays }\end{array}$ & $\begin{array}{l}\text { Total } \\
\text { Amount That } \\
\text { MidWest } \\
\text { Has Paid Out } \\
\text { This Year }\end{array}$ & $\begin{array}{l}\text { Number of } \\
\text { Months } \\
\text { You Have } \\
\text { Made } \\
\text { Premium } \\
\text { Payments }\end{array}$ \\
\hline$\$ 600$ & $\$ 0$ & $\$ 500$ & $\$ 500$ & $\$ 0$ & $\begin{array}{l}24(2 \\
\text { years })\end{array}$ \\
\hline
\end{tabular}




\section{Appendix F}

\section{Manipulation Check: Understanding of Health Saving Accounts and Health Insurance Plans}

Some people use Health Saving Accounts (HSA) and High Deductible Health Plans (HDHP) to fund their healthcare needs, and others use Health Insurance Plans (HIP). The first set of questions asks about your understanding of these types of accounts, and the second set asks about the insurance plan that we assigned you for this study.

\section{HSA, HDHP, and HIP accounts:}

1. People fund HSAs with personal, tax-free contributions.

True

False

Don't Know

2. People can use the money in their HSAs to pay the costs for medical services before they meet their High Deductible Health Plan (HDHP) deductibles.

True

False

Don't Know

3. When an individual spends money from an HSA to pay for qualified medical services not covered by their High Deductible Health Plan, they pay taxes on the money they spend.

True

False

Don’t Know

4. After an individual meets the deductible amount on their High Deductible Health Plan (HDHP), then the HDHP will only cover routine, non-extraordinary healthcare costs.

True

False

Don't Know

5. If HSA funds are unused and remain in the individual's account at year's end, the government can tax the funds before they roll-over into future years.

True

False

Don’t Know

6. Employers often establish Health Insurance Plans (HIPs) to pay for medical expenses of their employees. 
7. After an employer establishes a Health Insurance Plan, it has no legal obligations to ensure distribution of healthcare benefits to its employees.

True

False

Don’t Know

8. An employer contributes to its employees Health Insurance Plan on a regular basis.

True

False

Don't Know

9. After an employee meets the deductible amount, the Health Insurance Plan will pay for medical expenses that fall within the Plan's coverage.

True

False

Don't Know

10. Most often, private insurance companies fund Health Insurance Plans that companies make available to their employees.

True

False

Don't Know

Questions about the HSA Healthcare Plan that this study assigned to you:

11. Your current HSA balance is $\$ 12,000$.

True

False

Don't Know

12. The most money you can spend tax-free from your HSA in any one year is $\$ 5800$. True False

Don’t Know

13. Every month, you deposit $\$ 300$ into your HSA.

True

False

Don’t Know

14. Your current yearly HDHP deductible is $\$ 1,200$

True

False

Don't Know

15. You currently have $\$ 500$ remaining on your HDHP deductible.

True

False

Don’t Know

16. Your current monthly premium for your HDHP is $\$ 100$.

True

False

Don't Know 


\section{Questions about the Health Insurance Plan that this study assigned to you:}

Manipulation Check: Comprehension of Health Insurance Plan

11. The total monthly premium payment for your Health Insurance Plan is $\$ 600$.

True

False

Don’t Know

12. The Plan has a yearly deductible of $\$ 2000$ for your individual health insurance.

True $\_$False __ Don't Know

13. Your yearly premium is $\$ 12,000$.

True

False

Don't Know

14. You pay $\$ 100$ a month to cover your share of the monthly premium payment. True False Don’t Know

15. You have made premium payments for the past three years.

True

16. Your plan has paid out $\$ 500$ this year.

True

False
False

Don't Know 


\section{Appendix G}

\section{Skin Cancer Brochure (Gain Frame)}

\section{INCIDENCE, ETIOLOGY, \& CONSEQUENCES OF SKIN CANCER}

Overexposure to UV radiation poses the risk of serious health effects for everyone. Skin cancer is the most common type of cancer in the United States. Every year in the United States alone, there are over one million cases of skin cancer.

People who never had a blistering sunburn in the past are less likely to get skin cancer during their life than those who have had such a burn. You can significantly decrease your chance of getting skin cancer by not exposing your skin to the sun without protection.

People get cancer when cells within their bodies divide without control or order. Many types of cells make up the body, and it is normal for them to grow, divide and produce more cells as the body needs them. Cancer occurs when cells keep dividing, even when the body needs no new cells. The mass of extra cells may produce a tumor.

Malignant (cancerous) tumors can harm or destroy the tissue surrounding them, can spread to other parts of the body quickly, and can cause more serious health problems.

\section{SKIN CANCER WARNING SIGNS}

The A,B,C,D's of skin cancer are: Asymmetry, Border irregularity, Color variation within a mole, Diameter increasing in size. If you do not have the following symptoms, this may indicate that you do not have skin cancer:

- A change in color or the appearance of two or more colors.

- A change in shape or an irregularly shaped mole.

- A change in the surface, including scales, nodules or lumps.

- A change in size of a mole.

- A change in the borders or irregular, faded borders.

- A persistent lump or swelling.

- A new or unusual mole.

- A sore that does not heal or begins to bleed. 


\section{DETECTION OF SKIN CANCER}

The earlier skin cancer is detected, the better a person's chances are for full recovery. If detected early, most of these cancers are curable and will not be fatal. You will improve your chances of detecting the presence of skin cancer on the body by obtaining professional skin examinations. 


\section{Appendix H}

\section{Skin Cancer Brochure (Loss Frame)}

\section{INCIDENCE, ETIOLOGY, \& CONSEQUENCES OF SKIN CANCER}

Overexposure to UV radiation poses the risk of serious health effects for everyone. Skin cancer is the most common type of cancer in the United States. Every year in the United States alone, there are over one million cases of skin cancer.

People who have had a blistering sunburn in the past are more likely to get skin cancer during their life than those who have never had such a burn. You can significantly increase your chance of getting skin cancer by exposing your skin to the sun without protection.

People get cancer when cells within their bodies divide without control or order. Many types of cells make up the body, and it is normal for them to grow, divide and produce more cells as the body needs them. Cancer occurs when cells keep dividing, even when the body needs no new cells . The mass of extra cells may produce a tumor.

Malignant (cancerous) tumors can harm or destroy the tissue surrounding them, can spread to other parts of the body quickly, and can cause more serious health problems.

\section{SKIN CANCER WARNING SIGNS}

The A,B,C,D's of skin cancer are: Asymmetry, Border irregularity, Color variation within a mole, Diameter increasing in size. Presence of the following symptoms may indicate that you have skin cancer:

- A change in color or the appearance of two or more colors.

- A change in shape or an irregularly shaped mole.

- A change in the surface, including scales, nodules or lumps.

- A change in size of a mole.

- A change in the borders or irregular, faded borders.

- A persistent lump or swelling.

- A new or unusual mole.

- A sore that does not heal or begins to bleed. 


\section{DETECTION OF SKIN CANCER}

The later skin cancer is detected, the poorer the chances are of a person's full recovery. Unless they are detected and treated early, most of these cancers are not curable and will be fatal. You will decrease your chances of detecting the presence of skin cancer on the body if you do not obtain professional skin examinations. 


\section{Appendix I}

\section{$\underline{\text { Skin Cancer Questionnaire }}$}

1). Given what you have just learned about skin cancer risks and detection practices, as well as what you know about your current healthcare plan, how likely are you to obtain a professional skin cancer screening?

\begin{tabular}{|l|l|l|l|l|l|l|l|l|}
\hline 1 & 2 & 3 & 4 & 5 & 6 & 7 & 8 & 9 \\
\hline $\begin{array}{l}\text { Very } \\
\text { unlikely to } \\
\text { obtain a } \\
\text { screening }\end{array}$ & $\begin{array}{l}\text { Somewhat } \\
\text { unlikely }\end{array}$ & $\begin{array}{l}\text { Neither } \\
\text { likely } \\
\text { nor } \\
\text { unlikely }\end{array}$ & & $\begin{array}{l}\text { Somewhat } \\
\text { likely }\end{array}$ & & $\begin{array}{l}\text { Very } \\
\text { likely to } \\
\text { obtain a } \\
\text { screening }\end{array}$ \\
\hline
\end{tabular}

2). Given what you have just learned about skin cancer risks and detection practices, as well as what you know about your current healthcare plan, what is the highest cost that you are willing to pay for a professional skin cancer screening?

$\$ 0$

$\$ 100$

$\$ 200$

$\$ 300$

$\$ 400$

$\$ 500$

$\$ 600$

$\$ 700$

$\$ 800$

$\$ 900$

$\$ 1000$ 


\section{Appendix J}

\section{Demographic Information}

In the following questionnaire, please provide some real information about yourself. Answer each of the following questions to the best of your ability. All your answers will be held in strict confidence. No answer will be connected to your name or any identifying information. The answers to these questions will only be released as aggregate scores. You may choose to leave any answer blank if you feel it allows you to be identified in any way.

1. What is your age?

2. What is your gender? Check one: Male Female

3. In what state do you currently live?

4. What is your ethnic origin and/or race? (check one):

$\begin{array}{ll}\text { African American } & \text { Asian American } \\ \text { Caucasian } & \text { Hispanic } \\ \text { Latin American } & \text { Native American } \\ \text { Other } & \text { Mixed }\end{array}$

5. Is English your primary language? (circle one): $\quad$ Yes $\quad$ No

a. If no, what is your primary language:

6. What is the highest level of formal education that you completed? (check one):

Less than High School
High School
Associate's Degree

\begin{tabular}{l} 
Bachelor's Degree \\
Master's Degree \\
Professional Degree \\
\hline (E.g., M.D., Law, Ph.D.)
\end{tabular}

7. During the last 12 months, have you been employed in the field of healthcare? (circle one):

Yes $\quad$ No

a. If yes, what was your job title: 
8. During the last 12 months, have you been employed in the field of insurance or finance? (circle one):

$$
\text { Yes } \quad \text { No }
$$

a. If yes, what was your job title:

9. Who is primarily responsible for handling financial matters in your household? (check one):

Self
Spouse
Significant Other
Self with Spouse

Self with Significant Other
Parents
Other

10. Are you (check one):

A full-time student A part-time student Not currently a student

11. Have you been unemployed at any time during the last 12 months? (circle one):

$$
\text { Yes } \quad \text { No }
$$

12. What is your current marital status? (check one):

Widowed

$$
\text { Single }
$$

Separated
Married

Divorced

13. What was your marital status 12 months ago? (circle one):

Widowed

$$
\text { Single }
$$

Separated

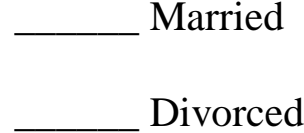

Divorced

14. Have you personally experienced a health crisis or emergency in the past two years? Yes No

15. Has a family member or close friend experienced a health crisis or emergency in the past two years? Yes No 
16. Have you, or a family member, incurred substantial uninsured medical expenses within the past 12 months? (check one):

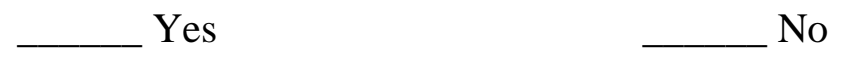

17. What is your current annual household income? (check one):

$\$ 10,000$ or less
$\$ 10,001-\$ 20,000$
$\$ 20,001-\$ 30,000$
$\$ 30,001-\$ 40,000$
$\$ 40,001-\$ 50,000$
$\$ 50,001-\$ 60,000$
$\$ 60,001-\$ 70,000$ $\$ 70,001-\$ 80,000$ $\$ 80,001-\$ 90,000$ $\$ 90,001-\$ 100,000$ $\$ 100,001$ or above

18. What was your annual household income 12 months ago? (check one):

$\$ 10,000$ or less
$\$ 10,001-\$ 20,000$
$\$ 20,001-\$ 30,000$
$\$ 30,001-\$ 40,000$
$\$ 40,001-\$ 50,000$
$\$ 50,001-\$ 60,000$

$\$ 60,001-\$ 70,000$
$\$ 70,001-\$ 80,000$
$\$ 80,001-\$ 90,000$
$\$ 90,001-\$ 100,000$
$\$ 100,001$ or above

19. What type of health insurance do you currently carry? (check all that apply)

a. I have no healthcare plan

b. I have an individual Defined Contribution plan of my own (e.g., HSA)

c. I have an individual Defined Benefit plan of my own (e.g., traditional health insurance)

d. I have an individual Defined Contribution plan through work (e.g., FSA)

e. I have an employer-administered Defined Benefit plan through work (e.g., traditional health insurance)

f. I do not know what kind of health insurance I have 


\section{Appendix K}

\section{$\underline{\text { Debriefing Statement }}$}

The current research studies Health Savings Accounts (HSAs) to determine if those accounts influence healthcare consumers' decisions to acquire health services.

It is possible that HSA's will facilitate rational decisions among healthcare consumers, such that the accounts will help reduce certain types of systemic decision errors, but it is also possible that the accounts will exacerbate systemic decision errors.

The acquisition of healthcare is not the simple result of rational calculations where consumers conduct a straightforward, logical analysis of costs and benefits of each decision. Instead, we hypothesized that the framing of the decision task will influence healthcare choices. For example, framing a decision in terms of mortality rates can lead to different choices than framing a decision in terms of survival rates. Furthermore, people may be more likely to acquire some healthcare services when the framing of the decision matches their motivational predispositions.

We anticipate that the framing of healthcare decisions as losses or gains will impact the number of consumers who choose to pursue various healthcare services. In addition, consumers' motivational predispositions might further influence their choices.

We hope you enjoyed participating in this study. If you have any questions or comments, feel free to contact us at (404) 472-9639. If you were upset by making these healthcare decisions or by the experiment, you may discuss your concerns with the experimenter at (402) 472-9639 or michael.holtje@huskers.unl.edu. 


\title{
Appendix L
}

\author{
Hercytus Virus Brochure (Gain Frame)
}

\section{INCIDENCE, ETIOLOGY, \& CONSEQUENCES OF THE HERCYTUS VIRUS}

Hercytus Virus is a virus that spreads easily from person to person. Most people have little or no immunity against the virus. Estimates are that only $15 \%$ of Americans are immune to the Hercytus Virus. Because the virus is different from typical seasonal viruses, the normal seasonal flu vaccine will not keep one healthy.

The Hercytus Virus spreads from person to person through the coughs and sneezes of people who are sick. When droplets from a cough or sneeze of an infected person are released in the air, they can fall on nearby people. People who do not touch such droplets are less likely to contract the virus. You can significantly decrease your chance of becoming ill from the Hercytus Virus by not exposing yourself to individuals who are sick.

The Virus' symptoms can vary in severity from mild to severe. Most people who have been sick with the virus have recovered without needing serious medical treatment; however, hospitalizations and deaths have occurred. It is possible for otherwise healthy people to develop severe illness. Some people who have become very ill were very healthy just prior to contracting the virus. People of all ages have reported severe illnesses.

\section{WARNING SIGNS OF THE HERCYTUS VIRUS}

The symptoms of the Hercytus Virus are similar to the symptoms of seasonal flu, though generally more severe. Typical symptoms include fever, cough, sore throat, runny or stuffy nose, body aches, headache, chills, fatigue, dizziness, confusion, difficulty breathing, chest pain, and discoloration of the lips. Some people have reported diarrhea and vomiting. Not everyone with the Hercytus Virus will have a fever.

\section{PREVENTION OF THE HERCYTUS VIRUS}

Receiving an immunization injection for the Hercytus Virus is an effective way to stay healthy. After receiving an immunization injection, people are much more likely to be immune to the virus. By receiving an immunization injection, you can improve your chances of boosting your immune system and preventing illness. 


\title{
Appendix M
}

\author{
$\underline{\text { Hercytus Virus Brochure (Negative Frame) }}$
}

\section{INCIDENCE, ETIOLOGY, \& CONSEQUENCES OF THE HERCYTUS VIRUS}

Hercytus Virus is a virus that spreads easily from person to person. Most people have little or no immunity against the virus. Estimates are that $85 \%$ of Americans are susceptible to the Hercytus Virus. Because the virus is different from typical seasonal viruses, the normal seasonal flu vaccine will not prevent the virus.

The Hercytus Virus spreads from person to person through the coughs and sneezes of people who are sick. When droplets from a cough or sneeze of an infected person are released in the air, they can fall on nearby people. People who touch such droplets are more likely to contract the virus. You can significantly increase your chance of becoming ill from the Hercytus Virus by exposing yourself to individuals who are sick.

The Virus' symptoms can vary in severity from mild to severe. Most people who have been sick with the virus have recovered without needing serious medical treatment; however, hospitalizations and deaths have occurred. It is possible for otherwise healthy people to develop severe illness. Some people who have become very ill were very healthy just prior to contracting the virus. People of all ages have reported severe illnesses.

\section{WARNING SIGNS OF THE HERCYTUS VIRUS}

The symptoms of the Hercytus Virus are similar to the symptoms of seasonal flu, though generally more severe. Typical symptoms include fever, cough, sore throat, runny or stuffy nose, body aches, headache, chills, fatigue, dizziness, confusion, difficulty breathing, chest pain, and discoloration of the lips. Some people have reported diarrhea and vomiting. Not everyone with the Hercytus Virus will have a fever.

\section{PREVENTION OF THE HERCYTUS VIRUS}

Failing to receiving an immunization injection for the Hercytus Virus is a strong risk factor for contracting the virus. Individuals who do not receive an immunization injection are much more likely to become ill from the virus. If you do not receive an immunization injection, you significantly increase your chances of contracting the Hercytus virus. 


\section{Appendix N}

\section{$\underline{\text { Immunization Questionnaire }}$}

1). Given what you have just learned about Hercytus Virus and immunization, as well as what you know about your current healthcare plan, how likely are you to obtain an immunization injection?

\begin{tabular}{|l|l|l|l|l|l|l|l|l|}
\hline 1 & 2 & 3 & 4 & 5 & 6 & 7 & 8 & 9 \\
\hline $\begin{array}{l}\text { Very } \\
\text { unlikely } \\
\text { to } \\
\text { obtain } \\
\begin{array}{l}\text { an } \\
\text { injection }\end{array}\end{array}$ & & $\begin{array}{l}\text { Somewhat } \\
\text { unlikely }\end{array}$ & & $\begin{array}{l}\text { Neither } \\
\text { likely } \\
\text { nor } \\
\text { unlikely }\end{array}$ & & $\begin{array}{l}\text { Somewhat } \\
\text { likely }\end{array}$ & & $\begin{array}{l}\text { Very } \\
\text { likely to } \\
\text { obtain } \\
\text { an } \\
\text { injection }\end{array}$ \\
\hline
\end{tabular}

2). Given what you have just learned about the Hercytus Virus and immunization, as well as what you know about your current healthcare plan, what is the highest cost that you are willing to pay for the immunization injection?

$\$ 0$

$\$ 100$

$\$ 200$

$\$ 300$

$\$ 400$

$\$ 500$

$\$ 600$

$\$ 700$

$\$ 800$

$\$ 900$

$\$ 1000$ 


\section{Appendix O}

\section{$\underline{\text { Gain-Framed Survival Rates }}$}

Please imagine you have a confirmed diagnosis of lung cancer and you must choose a type of treatment, either surgery or radiation.

\section{GENERAL INFORMATION}

Surgery for lung cancer involves an operation on the lungs. Most patients are in the hospital for two or three weeks and have some pain around their incisions. They spend a month or so recuperating at home. After that, they generally feel fine.

Radiation therapy for lung cancer involves the use of radiation to kill the tumor and requires coming to the hospital about 4 times a week for six weeks. Each treatment takes a few minutes and during the treatment, patients lie on a table as if they were having an x-ray. During the course of treatment, some patients develop nausea and vomiting, but by the end of the six weeks, they generally feel fine.

After six or so weeks, patients treated with either surgery or radiation therapy feel about the same.

\section{SURVIVAL RATES}

Of 100 people having surgery, 90 will survive the treatment, 68 will be alive after one year, and 34 will be alive after five years. The patients who survive treatment have an average life expectancy (average number years remaining) of 6.8 years.

Of 100 people having radiation therapy, 100 will survive the treatment, 77 will be alive after one year, and 22 will be alive after five years. The life expectancy of patients who undergo radiation is 4.7 years. 


\section{Appendix P}

\section{$\underline{\text { Loss-Framed Presentation of Mortality Rates }}$}

Please assume you have a confirmed diagnosis of lung cancer and you must choose a type of treatment, either surgery or radiation.

\section{GENERAL INFORMATION}

Surgery for lung cancer involves an operation on the lungs. Most patients are in the hospital for two or three weeks and have some pain around their incisions. They spend a month or so recuperating at home. After that they generally feel fine.

Radiation therapy for lung cancer involves the use of radiation to kill the tumor and requires coming to the hospital about 4 times a week for six weeks. Each treatment takes a few minutes and during the treatment, patients lie on a table as if they were having an x-ray. During the course of treatment, some patients develop nausea and vomiting, but by the end of the six weeks, they also generally feel fine.

After six or so weeks, patients treated with either surgery or radiation therapy feel about the same.

\section{MORTALITY RATES}

Of 100 people having surgery, 10 will die during treatment, 32 will die within one year, and 66 will die within five years. The patients who survive treatment have an average life expectancy (average number years remaining) of 6.8 years.

Of 100 people having radiation therapy, 0 will die during treatment, 23 will die within one year, and 78 will die within five years. The life expectancy of patients who undergo radiation is 4.7 years. 


\section{Appendix Q}

\section{Cancer Treatment Questionnaire}

1). Given what you have just learned about lung cancer and available treatments, as well as what you know about your current healthcare plan, will you choose surgery or radiation to treat your lung cancer?

Surgery___ Radiation

2). Given what you have just learned about lung cancer and available treatments, as well as what you know about your current healthcare plan, what is the highest cost that you are willing to pay for the treatment option you chose?

$\$ 0$

$\$ 50,000$

$\$ 100,000$

$\$ 150,000$

$\$ 200,000$

$\$ 250,000$

$\$ 300,000$

$\$ 350,000$

$\$ 400,000$

$\$ 450,000$

$\$ 500,000$ 
3). Given what you have just learned about lung cancer and available treatments, as well as what you know about your current healthcare plan, what is the highest cost that you are willing to pay for the treatment option you did not choose?

$\$ 0$
$\$ 50,000$
$\$ 100,000$
$\$ 150,000$
$\$ 200,000$
$\$ 250,000$
$\$ 300,000$
$\$ 350,000$
$\$ 400,000$
$\$ 450,000$
$\$ 500,000$




\section{Appendix R}

\section{$\underline{\text { Invitation from StudyResponse }}$}

Dear StudyResponse Project Participant:

We are requesting your assistance with a study conducted by a researcher at the University of Nebraska on Healthcare Decisions. You must be at least 25 years of age to participate. The study will take you approximately 20-30 minutes. If you choose not to respond within the first week, we will send you a reminder in one week. Note that instructions on how to discontinue your participation in StudyResponse and stop receiving emails from us appear at the end of this message.

This study is confidential, so please do not enter any identifying information into the research instrument except your StudyResponse ID, which is [ID]. The researcher has pledged to keep your data confidential and only to report aggregated results in any published scientific study.

In appreciation of your choice to participate in the project, you will receive a gift certificate to Amazon.com in the amount of $\$ 20$.

Note that your StudyResponse ID number is [ID] (also shown in the subject line of this message) and that you must enter that number into the survey. Follow this link to participate:

[link to website]

Participation in this study is voluntary and you may withdraw from participation at any time. If you have any questions you may contact the researcher:

Dr. Richard Wiener, Ph.D.

\& Michael Holtje, M.A.

University of Nebraska - Lincoln

(402) 472-9639

michael.holtje@huskers.unl.edu 